Leticia Martins Azeredo

\title{
Avaliação ultrassonográfica e dopplervelocimétrica da esquistossomose mansônica: estudo de campo em áreas de baixa, média e alta endemicidades
}
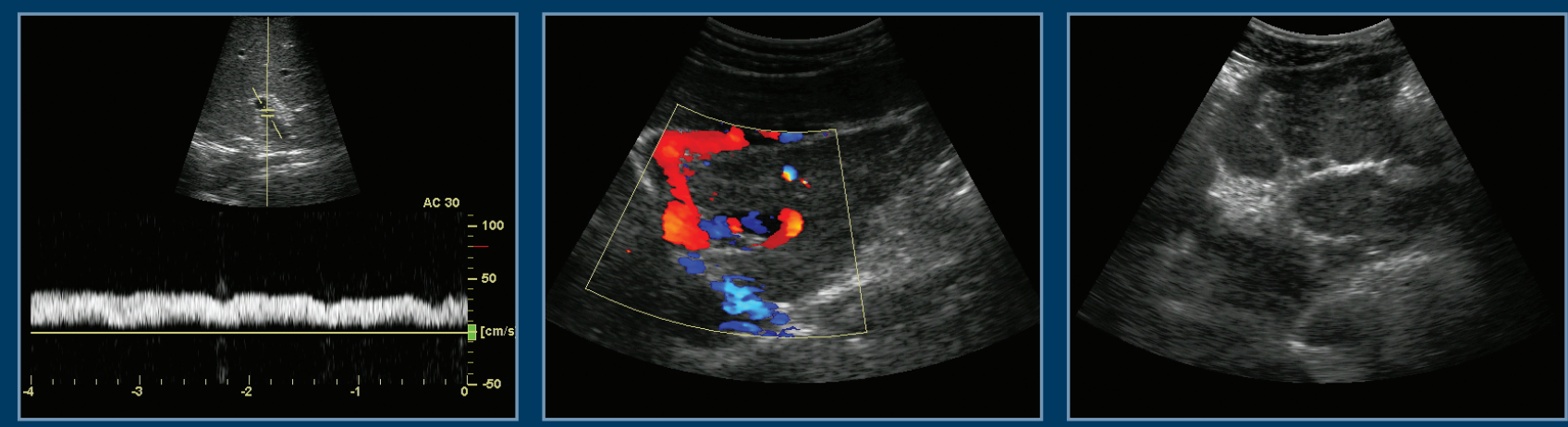

Tese apresentada à Faculdade de Medicina da Universidade de São Paulo para obtenção do título de Doutor em Ciências

Área de concentração: Radiologia

Orientador: Prof. Dr. Giovanni Guido Cerri 


\section{LETICIA MARTINS AZEREDO}

Avaliação ultrassonográfica e dopplervelocimétrica

da esquistossomose mansônica: estudo de campo em áreas de baixa, média e alta endemicidades

Tese apresentada à Faculdade de Medicina da Universidade de São Paulo para obtenção do título de Doutor em Ciências.

Área de concentração: Radiologia.

Orientador: Prof. Dr. Giovanni Guido Cerri.

São Paulo 


\title{
Dados Internacionais de Catalogação na Publicação (CIP)
}

\author{
Preparada pela Biblioteca da
}

Faculdade de Medicina da Universidade de São Paulo

Creprodução autorizada pelo autor

\section{Azeredo, Leticia Martins}

Avaliação ultrassonográfica e dopplervelocimétrica da esquistossomose mansônica : estudo de campo em áreas de baixa, média e alta endemicidades / Leticia Martins Azeredo. -- São Paulo, 2009.

Tese(doutorado)--Faculdade de Medicina da Universidade de São Paulo. Departamento de Radiologia.

Área de concentração: Radiologia.

Orientador: Giovanni Guido Cerri.

Descritores: 1.Esquistossomose mansônica 2.Ultra-sonografia Doppler 3.Estudo de campo 4.Morbidade 
Ao meu marido e companheiro Álvaro, parceiro nesta conquista, e a meus filhos Ana, Álvaro e Marina, pelo carinho, apoio e compreensão.

Ao meu neto João, que mesmo antes de nascer, já tornou nossa vida mais completa. 
Ao meu pai, Amilcar Vianna Martins (in memoriam), meu primeiro mestre, pelo exemplo. Por ter incentivado em mim, desde criança, a curiosidade e a vontade de aprender. Por ter me ensinado que a ciência e a ética devem sempre caminhar juntas.

À minha mãe, Beatriz, pelo exemplo de seus 96 anos de vida. Pelo carinho e apoio incondicionais.

Aos meus irmãos e cunhados, pelo estímulo.

Ao Sérgio e ao Amilcar em especial, pelo apoio fundamental no início da minha carreira acadêmica. 
Ao meu orientador Prof. Dr. Giovanni Guido Cerri, mestre e amigo, pela confiança. Pelos ensinamentos e oportunidades que ampliaram meus horizontes, e, principalmente, por sua generosidade e exemplo ético. 


\section{AGRADECIMENTOS}

Ao Prof. José Roberto Lambertucci, pela generosa acolhida em seu grupo de pesquisa, sem a qual este trabalho não teria sido possível. Pelo exemplo de dedicação ao ensino e à ciência. Por seu apoio, disponibilidade e colaboração em todas as etapas deste projeto.

Ao Prof. Carlos Maurício Antunes, pela contribuição na análise estatística e pela participação fundamental nos trabalhos de campo.

Ao Dr. Leonardo Campos Queiroz, pela parceria neste trabalho e realização competente dos exames ultrassonográficos.

À Dra. Maria Cristina Chammas, pela amizade, confiança e inestimáveis contribuições não apenas na qualificação, mas em todas as etapas deste trabalho.

Ao Prof. José Carlos Serufo, pelo incentivo e participação nos trabalhos de campo.

Ao Prof. Aluisio Prata e às Dras. Raiza Ruiz Guevara e Carolina Coimbra Marinho, pela oportunidade do trabalho em Santa Maria da Vitória.

À Dra. Maria Cristina do Espírito Santo, pela oportunidade do trabalho em Bananal.

Às Dras. Sandra Costa Drummond, Maria Laura Mariano de Matos, Mariana Benevides Santos Paiva e Ahraby Zaryff Morais Kansaon, pela contribuição nos trabalhos de campo em Chonim.

Às Dras. Izabela Voieta, Thais Sanai, Ana Carolina Figueiredo Pereira e Marina Nishi, pela colaboração nos trabalhos de campo em Brejo do Espírito Santo.

Aos Drs. Nestor de Barros e André Scatigno, pelas valiosas contribuições na qualificação desta tese.

Aos Drs. Benito Ceccato, Fátima Ceccato, Regina Moscardini (in memoriam), Francisco Carvalho, Roberto Barroso e Simone Gontijo, companheiros de todas as horas, pelo carinho e dedicação com que me 
iniciaram na ultrassonografia, base fundamental para meu crescimento profissional.

Aos médicos e residentes do IMEDE, do Serviço de Utrassonografia do Hospital Mater Dei e do Serviço de Diagnóstico por Imagem do Hospital das Clínicas-UFMG, pela compreensão e apoio nos vários momentos em que me ausentei durante o programa de pós-graduação.

À Dra. Luciana Mendes de Oliveira Cerri, pela amizade, pela inestimável contribuição para minha formação profissional e pela afetuosa acolhida em São Paulo.

Ao Dr. Wagner Eduardo Ferreira, pela orientação e incentivo que me fizeram trilhar pelo caminho da ultrassonografia.

À Dra. Ana Cláudia Ferreira Rosa, pela amizade, pelos valiosos ensinamentos e prazerosa convivência em São Paulo.

Ao Dr. Rogério Augusto Pinto Silva, pelo estimulo e sugestões apresentadas na elaboração deste projeto.

Ao Dr. Ronaldo Magalhães Lins, pela generosidade e disponibilidade em nos transmitir seus conhecimentos de ultrassonografia.

Ao Dr. Márcio Martins Machado, pelo incentivo nos primeiros passos da minha carreira acadêmica.

À Dra. Ilka Regina Souza de Oliveira, pelo apoio e pelos ensinamentos da técnica Doppler.

Ao Dr. Osmar de Cássio Saito, pela amizade e estímulo.

À Lia de Melo, Elisângela Nivardo Dias e Sandra Pacheco de Barros, pelo carinho e atenção durante o período de pós-graduação.

À Eleonora Fernandes Nascimento, por cuidar da nossa família com carinho e dedicação durante todos estes anos, principalmente nos períodos em que me ausentei.

Aos pacientes, pela confiança depositada nas equipes que realizaram este trabalho. 


\section{NORMATIZAÇÃO ADOTADA}

Esta tese está de acordo com as seguintes normas, em vigor no momento desta publicação:

Referências: adaptado de International Committee of Medical Journals Editors (Vancouver).

Universidade de São Paulo. Faculdade de Medicina. Serviço de Biblioteca e Documentação. Guia de apresentação de dissertações, teses e monografias. Elaborado por Anneliese Carneiro da Cunha, Maria Júlia de A. L. Freddi, Maria F. Crestana, Marinalva de Souza Aragão, Suely Campos Cardoso e Valéria Vilena. $2^{a}$ ed. São Paulo: Serviço de Biblioteca e Documentação; 2005.

Abreviaturas dos títulos dos periódicos de acordo com List of Journals Indexed in Index Medicus. 


\section{SUMÁRIO ${ }^{1}$}

Lista de ilustrações

Lista de tabelas

Lista de símbolos

Resumo

Summary

1 INTRODUÇÃO.

2 OBJETIVOS

5

2.1 Objetivo geral................................................................. 6

2.2 Objetivos específicos............................................................ 6

3 REVISÃO DA LITERATURA.

3.1 A ultrassonografia na avaliação da morbidade relacionada à esquistossomose mansônica.

3.2 A ultrassonografia em trabalhos de campo na esquistossomose mansônica.

3.3 Estudos angiográficos na avaliação da hemodinâmica portal........ 17

3.4 Ultrassonografia Doppler na avaliação da hemodinâmica portal..... 21

3.5 Ultrassonografia Doppler na esquistossomose mansônica............ 26

4 CASUÍSTICA E MÉTODOS

4.1 Desenho do estudo e considerações éticas............................. 35

4.2 Casuística............................................................................. 36

4.2 Áreas estudadas............................................................ 36

4.2.2 Tamanho e composição da amostra.................................... 38

4.3 Métodos......................................................................... 40

4.3.1 Equipamentos e operadores........................................... 40

4.3.2 Sistematização do estudo ultrassonográfico modo B................ 42

4.3.2.1 Avaliação do fígado............................................................ 42

4.3.2.2 Avaliação do espessamento das paredes dos vasos portais.... 44

4.3.2.3 Avaliação dos vasos portais e das artérias hepática e esplênica

4.3.2.4 Avaliação do baço............................................................... 49

4.3.2.5 Avaliação da vesícula biliar.............................................. 49

4.3.2.6 Avaliação da circulação colateral........................................ 50

4.3.2.7 Avaliação da cavidade abdominal.................................... 50

4.3.3 Sistematização do estudo Doppler..................................... 51

4.3.3.1 Análise dopplervelocimétrica dos vasos do sistema portal....... 52

4.3.3.2 Análise dopplervelocimétrica das artérias hepática e esplênica. 54

4.3.3.3 Análise dopplervelocimétrica da circulação colateral............... 55

4.3.3.4 Análise dopplervelocimétrica das veias hepáticas................. 55

\footnotetext{
${ }^{1}$ Este trabalho foi revisado a partir das novas regras ortográficas.
} 
4.3.4 Aquisição e armazenamento das imagens.............................. 57

4.3.5 Análise estatística............................................................ 57

4.3.5.1 Estatísticas descritivas.............................................. 57

4.3.5.2 Comparação por área............................................... 57

4.3.5.3 Associações estatísticas................................................ 58

5 RESULTADOS ................................................................... 59

5.1 Resultados do exame ultrassonográfico modo B........................ 60

5.1.1 Avaliação do fígado............................................................. 60

5.1.2 Avaliação do espessamento das paredes dos vasos portais...... 62

5.1.3 Avaliação dos vasos portais.................................................. 67

5.1.4 Avaliação das artérias hepática e esplênica............................ 70

5.1 .5 Avaliação do baço............................................................. 71

5.1 .6 Avaliação da vesícula biliar............................................. 72

5.1.7 Avaliação da circulação colateral....................................... 73

5.1.8 Avaliação da cavidade abdominal........................................ 74

5.2 Exame ultrassonográfico com Doppler...................................... 74

5.2.1 Análise dopplervelocimétrica dos vasos do sistema portal.......... 74

5.2.2 Análise dopplervelocimétrica das artérias hepática e esplênica... 76

5.2.3 Análise dopplervelocimétrica dos vasos colaterais.................... 77

5.2.4 Análise dopplervelocimétrica das veias hepáticas.................... 81

5.3 Associações estatísticas................................................. 82

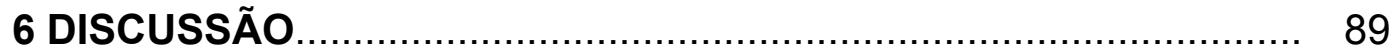

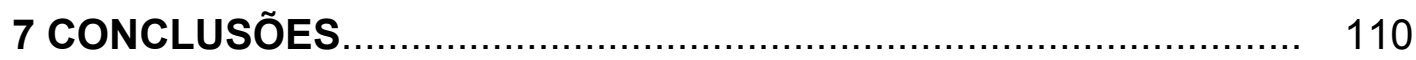

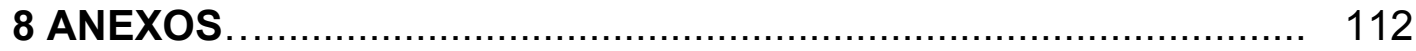

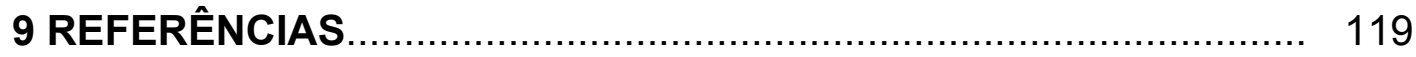

Apêndices 


\section{LISTA DE ILUSTRAÇÕES}

\section{Figuras}

Figura 1. Mapa do Brasil com localização das três áreas estudadas.... 37

Figura 2. Local de realização dos exames (Hospital Municipal) em Brejo do Espírito Santo, Bahia.

Figura 3. Local de realização dos exames em Chonim de Baixo, Minas Gerais

Figura 4. Sala de exame da US-Doppler em Chonim de Baixo, Minas Gerais.

Figura 5. Sala de exame da US-Doppler em Brejo do Espirito Santo, Bahia.

Figura 6. Medidas dos lobos direito e esquerdo do fígado.

Figura 7. Padrões de acometimento não-esquistossomótico do fígado (Niamey Working Group, 2000).

Figura 8. Padrões de acometimento do fígado na esquistossomose mansônica (Niamey Working Group, 2000).

Figura 9. Esquema ilustrativo da medida da espessura da parede do ramo portal de segunda ordem (Niamey Working Group, 2000). 46

Figura 10. Medida do calibre do tronco da veia porta.

Figura 11. (a) Medida do calibre da veia esplênica; (b) Medida do calibre da veia mesentérica superior.

Figura 12. Medida do calibre da artéria hepática.

Figura 13. (a) Medida do diâmetro longitudinal do baço. (b) Medida da espessura da parede da vesícula biliar.

Figura 14. Análise dopplervelocimétrica da veia porta.

Figura 15. Análise dopplervelocimétrica dos ramos portais direito e esquerdo.

Figura 16. Análise dopplervelocimétrica das veias esplênica e mesentérica superior.

Figura 17. Análise dopplervelocimétrica das artérias hepática e esplênica.

Figura 18. Padrão trifásico na veia hepática média. 56

Figura 19. Padrão bifásico na veia hepática direita. 56

Figura 20. Padrão monofásico na veia hepática média. 56

Figura 21. Desenho esquemático e imagem ultrassonográfica do padrão de acometimento "C" - espessamento periportal apenas periférico (Niamey Working Group, 2000). 
Figura 22. Desenho esquemático e imagem ultrassonográfica do padrão de acometimento "D"- espessamento periportal central leve (Niamey Working Group, 2000).

Figura 23. Desenho esquemático e imagem ultrassonográfica do padrão de acometimento "Dc" - central e periférico leve (Niamey Working Group, 2000).

Figura 24. Desenho esquemático e imagem ultrassonográfica do padrão de acometimento "E"- espessamento periportal central moderado (Niamey Working Group, 2000).

Figura 25. Desenho esquemático e imagem ultrassonográfica do padrão de acometimento "Ec"- central e periférico moderado (Niamey Working Group, 2000).

Figura 26. Desenho esquemático e imagem ultrassonográfica do padrão de acometimento "Fc"- central e periférico acentuado (Niamey Working Group, 2000).

Figura 27. Veia porta de calibre aumentado $(15,9 \mathrm{~mm})$.

Figura 28. Esplenomegalia (baço com diâmetro longitudinal de 17,1 $\mathrm{mm})$.

Figura 29. Acentuado espessamento da parede da vesícula biliar ......

Figura 30. Colateral gástrica esquerda. Vaso serpiginoso adjacente ao lobo esquerdo do figado ao modo B (a). Fluxo hepatofugal ao modo colorido (b).

Figura 31. Veia gástrica esquerda calibrosa $(24,2 \mathrm{~mm})(a)$. Veia porta com fluxo hepatofugal de baixa velocidade (b)

Figura 32. Veia paraumbilical dilatada com $7,6 \mathrm{~mm}$ de diâmetro.

Figura 33. Colaterais retroperitoneais. Enovelado de vasos de grosso calibre ao modo B (a) e ao modo colorido (b).

Figura 34. Formação anecoica no lobo direito do fígado,diagnosticada como cisto hepático ao modo B (a). Ao modo colorido, preenchimento de cor demonstrando origem vascular (b).

Figura 35. Anastomose espontânea do ramo portal esquerdo com a veia hepática esquerda.

Figura 36. Padrões espectrais alterados: bifásico na veia hepática direita e monofásico na veia hepática média.

\section{Gráfico}

Gráfico 1. Frequência dos tipos de colaterais 


\section{LISTA DE TABELAS}

Tabela 1. Médias das dimensões, em milímetros, dos lobos direito e esquerdo do fígado, por área de endemicidade

Tabela 2. Avaliação das dimensões do fígado, por área de endemicidade.

Tabela 3. Avaliação qualitativa do espessamento das periportal, por área de endemicidade

Tabela 4. Análise do calibre das veias porta, esplênica e mesentérica superior, por área de endemicidade

Tabela 5. Avaliação do diâmetro longitudinal do baço por área de endemicidade.

Tabela 6. Avaliação da espessura da parede da vesícula biliar por área de endemicidade.

Tabela 7. Médias das velocidades máximas de fluxo na veia porta, ramos portais direito e esquerdo, veias esplênica e mesentérica superior $(\mathrm{cm} / \mathrm{s})$.

Tabela 8. Médias das velocidades de pico sistólico, diástole final e índice de resistividade das artérias hepática e esplênica $(\mathrm{cm} / \mathrm{s})$.....

Tabela 9. Padrão de fluxo nas veias hepáticas, por área de endemicidade.

Tabela 10. Associação entre esplenomegalia e espessamento periportal.

Tabela 11. Classificação das formas da doença, por área de endemicidade.

Tabela 12. Associação entre esplenomegalia e calibre das veias porta e esplênica na área de alta endemicidade

Tabela 13. Associação entre esplenomegalia e: diâmetro, índice de resistividade e velocidade de pico sistólico da artéria esplênica, nas áreas de média e alta endemicidades.

Tabela 14. Associação entre identificação da artéria hepática e: espessamento periportal e seu grau na área de alta endemicidade.....

Tabela 15. Coeficiente de correlação de Spearman entre algumas variáveis da amostra total. 


\section{LISTA DE SÍMBOLOS}

$\begin{array}{ll}\mathrm{Mm} & \text { Milímetro } \\ \mathrm{cm} & \text { Centímetro } \\ \mathrm{mL} / \mathrm{min} & \text { Mililitro por minuto } \\ \mathrm{cm} / \mathrm{s} & \text { Centímetro por segundo } \\ \mathrm{mmHg} & \text { Milímetro de mercúrio } \\ \mathrm{MHz} & \text { MegaHertz } \\ \mathrm{Km} & \text { Quilômetro } \\ = & \text { Igual a } \\ < & \text { Menor que } \\ \leq & \text { Menor ou igual a } \\ > & \text { Maior que } \\ \geq & \text { Maior ou igual a }\end{array}$




\section{RESUMO}

Azeredo LM. Avaliação ultrassonográfica e dopplervelocimétrica da esquistossomose mansônica: estudo de campo em áreas de baixa, média e alta endemicidades. [tese]. São Paulo. Faculdade de Medicina, Universidade de São Paulo; 2009, 128 p.

INTRODUÇÃO: os principais aspectos clínicos da esquistossomose mansônica (EM) são determinados pelas lesões vasculares e suas repercussões na hemodinâmica portal. $O$ acesso não-invasivo a essas alterações tem importância fundamental na avaliação da morbidade da doença e na identificação de pacientes com maior risco de complicações. Este estudo de campo realizado em três áreas com níveis distintos de endemicidade, objetivou: a) verificar a viabilidade da USDoppler em estudos de campo; b) identificar os sinais de morbidade relacionados à EM e correlacioná-los com a endemicidade das áreas estudadas; c) determinar os valores dopplervelocimétricos do sistema vascular esplâncnico na $E M$; e d) determinar as alterações hemodinâmicas na EM. CASUÍSTICA E MÉTODOS: foram examinados por meio da US-Doppler, 554 pacientes esquistossomóticos, divididos em três grupos, de acordo com o local de realização do exame: área de baixa endemicidade $(n=109)$; área de média endemicidade $(n=255)$ e área de alta endemicidade $(n=190)$. Avaliaram-se o fígado, o baço, a vesícula biliar, os vasos portais, as artérias hepática e esplênica, as veias hepáticas e os vasos colaterais. Para análise da morbidade da doença, foi utilizado o protocolo do Niamey Working Group (2000). O protocolo Doppler foi elaborado para fins específicos desta pesquisa. RESULTADOS: houve correlação estatisticamente significante entre as frequências de: espessamento periportal, esplenomegalia, espessamento da parede da vesícula biliar, aumento do calibre dos vasos portais, redução do lobo direito e o nível de endemicidade das áreas. Não houve relação significativa entre a hipertrofia do lobo esquerdo e a endemicidade das áreas. Considerando-se os achados ultrassonográficos de espessamento periportal e/ou esplenomegalia, os pacientes foram alocados em quatro grupos de acordo com a forma de apresentação da doença. As formas hepatointestinal e hepatoesplênica foram mais frequentes na área de alta endemicidade, demonstrando associação significativa entre o nível de endemicidade e a gravidade da doença. A velocidade máxima de fluxo da veia porta apresentou valores normais na maioria dos casos. O fluxo hepatofugal, a trombose portal e a circulação colateral foram pouco frequentes e identificados apenas na área de alta endemicidade. A veia gástrica esquerda foi a colateral prevalente. As veias hepáticas apresentaram padrão de fluxo alterado em $1 / 4$ dos casos, alteração essa relacionada à presença e à intensidade de espessamento periportal. A artéria hepática não apresentou alterações significativas nos parâmetros avaliados. As alterações da artéria esplênica (aumento do calibre, da velocidade de pico sistólico e do índice de resistividade) foram mais frequentes na área de alta endemicidade e na forma hepatoesplênica, com diferença significativa entre os grupos. CONCLUSÃO: a US-Doppler mostrouse viável e adequada para avaliação das alterações hemodinâmicas da EM em estudos de campo. Os sinais de morbidade detectados ultrassonograficamente são parâmetros fidedignos do nivel de endemicidade da EM, e, as informações funcionais do sistema portal obtidas pela US-Doppler, contribuem para o diagnóstico mais preciso das formas clínicas da doença nas áreas endêmicas.

Descritores: Esquistossomose mansônica. Ultrassonografia Doppler. Estudo de campo. Morbidade. 


\section{SUMMARY}

Azeredo LM. Ultrasonographic and dopplervelocimetric evaluation of schistosomiasis mansoni: field-based study in areas of low, medium and high endemicity.[thesis]. São Paulo. Faculdade de Medicina, Universidade de São Paulo; 2009, 128 p.

INTRODUCTION: The main clinical aspects of schistosomiasis mansoni (SM) are determined by vascular lesions and their effects on the portal hemodynamic. The non-invasive access to these alterations has fundamental importance in assessing the morbidity of the disease and in identifying patients at higher risk of complications. This field study, carried out in three areas with different levels of endemicity, aimed to: a) assess the feasibility of Doppler ultrasound (US) in fieldbased studies; b) identify the signs of morbidity related to SM and correlate them with the endemicity of the studied areas; c) determine the dopplervelocimetric values of the splanchnic vascular system in SM; and d) determine the hemodynamic changes in SM. PATIENTS AND METHODS: Doppler US was performed in 554 patients with SM, divided into three groups according to the local of the examination: low endemicity area $(n=109)$, medium endemicity area $(n=255)$, and high endemicity area $(n=190)$. The liver, the spleen, the gallbladder, the portal vessels, the hepatic and splenic arteries, the hepatic veins and collateral vessels were evaluated. The Niamey Working Group (2000) protocol was used for the disease morbidity analysis. The Doppler protocol was developed for the specific purposes of this study. RESULTS: There was a statistically significant correlation between the frequency of: periportal thickening, splenomegaly, gallbladder wall thickening, dilatation of the portal vessels, right lobe atrophy and the endemicity level of the areas. No significant correlation between the left lobe hypertrophy and the endemicity level was observed. Taking into account the US findings of periportal thickening and/or splenomegaly, the patients were allocated in four groups according to the form of the disease. The hepatointestinal and hepatosplenic forms were more frequent in the high endemicity area, showing a significant association between the endemicity level and the disease severity. The maximum flow velocity in portal vein showed normal values in most cases. The hepatofugal flow, portal vein thrombosis and collateral vessels were infrequent and identified only in the area of high endemicity. The left gastric vein was the prevalent collateral. The hepatic veins flow pattern was abnormal in 1/4 of the cases, with significant relation to the presence and intensity of periportal thickening. The hepatic artery had no significant alterations in the evaluated parameters. The splenic artery changes (increase of its diameter, peak systolic velocity and resistive index) were more frequent in the high endemicity area and in the hepatosplenic form, with significant difference between the analysed groups. CONCLUSION: Doppler US proved to be feasible and appropriate for the evaluation of the SM hemodynamic changes in field-based studies. The morbidity signs detected by ultrasound are reliable parameters of the endemicity level of SM, and the functional information of the portal system obtained by Doppler US, contributes to a more accurate diagnosis of clinical forms of the disease in endemic areas.

Keywords: Schistosomiasis mansoni. Doppler ultrasonography. Field-based study. Morbidity. 
1. INTRODUÇÃO 
A esquistossomose é uma endemia parasitária milenar, com alta prevalência em várias regiões tropicais do mundo, principalmente na África, Ásia e América do Sul. Segundo a Organização Mundial de Saúde (OMS), a doença acomete cerca de 200 milhões de pessoas em 76 países, e expõe mais de 600 milhões ao risco de infecção (WHO, 1993; Katz \& Almeida, 2003; Coura \& Amaral, 2004).

A parasitose chegou ao Brasil com os escravos africanos, que, embora infectados por duas espécies, S. mansoni e S. haematobium, somente a primeira se desenvolveu no país. Dados do Programa de Controle da Esquistossomose do Ministério da Saúde mostram prevalência global de 6,1\% em 2004, com aproximadamente 4 a 6 milhões de brasileiros infectados e mais de 30 milhões vivendo em áreas de risco.

As áreas de média e alta endemicidades ocorrem em dezenove estados, numa faixa contínua desde o Rio Grande do Norte até Minas Gerais. No restante do país, a transmissão é de baixa intensidade e se verifica em áreas focais, com alguns poucos focos de transmissão mais intensa (Silveira, 1989; Dias, 1994).

A fase aguda da doença é geralmente assintomática ou apresenta-se sob forma leve. Excepcionalmente os pacientes desenvolvem a forma aguda toxêmica, caracterizada por manifestações clínicas graves. Esta forma é rara nas áreas endêmicas, onde a maior parte dos casos é diagnosticada já na fase crônica (Bina \& Prata, 1984).

Na fase crônica, a maioria dos indivíduos apresenta forma branda, sem sintomas ou sinais da doença, exceto pela possível presença de ovos de $S$. 
mansoni nas fezes. Clinicamente, essa fase pode ser classificada em forma intestinal, hepatointestinal e hepatoesplênica. A forma hepatoesplênica, a mais grave, é caracterizada pelo envolvimento do fígado e do baço, podendo evoluir com hipertensão portal e circulação colateral.

Aproximadamente 5 a $10 \%$ dos infectados desenvolvem a forma hepatoesplênica (Coutinho, 1968), sendo a principal causa de hipertensão portal em nosso meio (Cleva et al., 1998). A hemorragia digestiva alta decorrente da ruptura de varizes esofagogástricas, é a responsável pela morbimortalidade relacionada à doença (El-Rooby, 1985).

A fibrose periportal, lesão hepática característica da esquistossomose mansônica (Symmers, 1904), respeita os limites da cápsula de Glisson e não invade o interior dos lóbulos hepáticos, preservando sua arquitetura (Bogliolo, 1954).

Portanto, são as lesões vasculares e suas repercussões hemodinâmicas que determinam os aspectos clínicos principais da doença. A compreensão dessas alterações é de fundamental importância para o planejamento terapêutico/cirúrgico relacionado ao alívio da sobrecarga sobre o sistema venoso portal (Mies et al., 1980a; 1980b).

Vários autores, utilizando diferentes métodos angiográficos, dedicaramse ao estudo hemodinâmico da hipertensão portal esquistossomótica (Bogliolo,1957a, 1957b, 1958; Andrade \& Cheever, 1971; Mies et al., 1980a; 1980b; 1997; Cleva et al., 1998). No entanto, por serem invasivos, dispendiosos e pouco acessíveis, têm sua aplicação limitada (Abdel-Latif et al., 1981). 
A ultrassonografia (USG), por sua capacidade em revelar o estágio de gravidade da doença, tem sido amplamente utilizada na avaliação da morbidade relacionada à EM (Homeida et al., 1988b; Abdel-Wahab et al., 1990; Lambertucci et al., 1996; Gerspacher-Lara et al., 1998; Martins et al., 1998; King et al., 2003). É atualmente considerada o método de escolha para identificar as alterações características da EM em estudos populacionais (Richter et al., 2001) e sua aplicação nas áreas endêmicas é recomendada pela OMS (WHO, 1985). Nesses estudos, tem sido demonstrado que o exame físico isolado não é suficiente para a definição do grau de acometimento da doença (Lambertucci et al., 2001).

A introdução da ultrassonografia Doppler (US-Doppler) representou um marco no estudo da circulação portal, possibilitando o acesso não-invasivo aos seus aspectos morfológicos e funcionais (Taylor et al., 1985).

Os estudos prévios sobre a hemodinâmica portal na EM por meio da US-Doppler, todos realizados em ambiente hospitalar, voltaram-se para a investigação da circulação portal nas formas graves da doença.

Assim, torna-se importante uma investigação dopplervelocimétrica mais abrangente, que contemple as diversas formas de apresentação da doença, principalmente as oligo ou assintomáticas, maioria nas áreas endêmicas.

Este trabalho, o primeiro a utilizar a US-Doppler em estudos de campo na EM e a avaliar três áreas com níveis distintos de endemicidade, buscou identificar as alterações ecográficas e hemodinâmicas nos vários estágios da doença. 
2. OBJETIVOS 


\subsection{Objetivo geral}

Avaliar, por meio da US-Doppler, as alterações ultrassonográficas e dopplervelocimétricas de pacientes com histórico de infecção esquistossomótica, em áreas de baixa, média e alta endemicidades.

\subsection{Objetivos específicos}

- Verificar a viabilidade e aplicabilidade da US-Doppler em estudos de campo.

- Identificar os sinais ecográficos da morbidade relacionada à esquistossomose mansônica e correlacioná-los com a endemicidade das áreas estudadas.

- Determinar os valores dopplervelocimétricos do sistema vascular esplâncnico na esquistossomose mansônica.

- Determinar as alterações hemodinâmicas na esquistossomose mansônica. 
3. REVISÃO DA LITERATURA 


\subsection{A ultrassonografia na avaliação da morbidade relacionada à esquistossomose mansônica}

Até o final da década de 70, as informações diagnósticas e a avaliação da morbidade relacionada à EM eram obtidas por métodos invasivos, pelo exame clínico e pelas evidências de complicações. A introdução da USG modificou completamente esse quadro, tornando possível uma visão direta, de forma não-invasiva e com minúcias de detalhes do fígado, vias biliares e de todo o sistema portal. Além disso, seu baixo custo e sua mobilidade, possibilitam a realização de grandes estudos populacionais.

Atualmente, além da USG, outros métodos de imagem como a tomografia computadorizada e a ressonância magnética têm sido utilizados na avaliação da morbidade relacionada à EM (Lambertucci et al., 2002; 2004; Bezerra et al., 2007). No entanto, o custo elevado e a limitada disponibilidade impossibilitam o uso desses métodos em grande escala.

Os primeiros relatos do uso da USG na EM foram apresentados por Abdel-Wahab et al. (1978) e Abdel-Latif et al. (1978). Esses autores descreveram áreas de hiperecogenicidade ao longo dos ramos portais de pacientes infectados, as quais não eram vistas nos pacientes do grupocontrole portadores de hepatopatia alcoólica ou hepatite crônica. Esses achados correspondiam à fibrose periportal, confirmados por estudos anatomopatológicos de biópsias hepáticas. 
Em 1981, Abdel-Latif et al. demonstraram a relação entre a presença de varizes esofagianas e o aumento do diâmetro das veias porta e esplênica na EM.

A primeira contribuição brasileira neste campo surge com a tese de doutoramento de Cerri (1984a), resumida em dois artigos publicados no mesmo ano (Cerri, 1984b; Cerri; Alves \& Magalhães, 1984c). Estudando 103 pacientes com esquistossomose mansônica hepatoesplênica $(E M H)$, o autor detalhou as alterações ecográficas relacionadas à doença, comparando com os achados histológicos e com indivíduos normais. Foram descritos como sinais ultrassonográficos da EMH a fibrose periportal, a hipertrofia do lobo esquerdo, o espessamento perivesicular, o aumento do calibre dos vasos portais e a esplenomegalia. Além destes, outros sinais encontrados foram a atrofia do lobo direito, os vasos colaterais, os granulomas hepáticos e os nódulos sideróticos esplênicos.

Faatar et al. (1984), por meio de exames ultrassonográficos de 22 pacientes provenientes do Egito, descreveram o padrão ecográfico de fibrose periportal tipo bird's claw, caracterizado por prolongamentos de feixes de fibrose grosseira, emergindo da porta hepatis e bifurcando ao longo dos ramos portais. Os autores chamaram a atenção para a similaridade entre esses achados e o quadro anatomopatológico macroscópico descrito por Bogliolo (1954; 1957b), dado confirmado por Hussain et al. (1984) em número idêntico de pacientes, também submetidos à biópsia hepática confirmatória. 
Em estudo cego da acurácia diagnóstica da USG quando comparada à biópsia hepática peroperatória, Homeida et al. (1988a) avaliaram 41 pacientes do Sudão, com diversos diagnósticos clínicos. Todos os 28 pacientes com fibrose de Symmers confirmada histologicamente foram corretamente diagnosticados pela USG. Consideraram-se $100 \%$ a sensibilidade e especificidade do método no diagnóstico da fibrose periportal.

Em 1991, Homeida et al. constataram, pela primeira vez, por meio da USG, a redução da intensidade da fibrose de Symmers em 28 pacientes sudaneses após tratamento com praziquantel, sendo que em doze houve completo desaparecimento das lesões após intervalo de três anos.

Para sua dissertação de mestrado, Pinto-Silva (1992) examinou 137 pacientes divididos em dois grupos: 66 com EMH e 71 sem infecção (grupocontrole). Em estudo detalhado investigou vários parâmetros relativos ao fígado, baço, vesícula biliar e trato portal. As alterações relacionadas à $\mathrm{EMH}$ foram semelhantes às encontradas em trabalhos anteriores. Algumas foram mensuradas e comparadas entre os dois grupos, estabelecendo-se, assim, níveis de corte para algumas medidas. Foram ainda descritos oito tipos de colaterais porto-sistêmicas, sendo as mais frequentes a veia gástrica esquerda, as veias gástricas curtas e a veia parumbilical.

Abdel-Wahab \& Esmat (1992) avaliaram no Egito, 130 pacientes hospitalizados, 309 escolares e 146 adultos, realizando exame parasitológico, clínico e USG em todos eles e endoscopia e biópsia hepática nos hospitalizados. Com o objetivo de rastrear a existência de varizes e o 
risco de sangramento, correlacionaram as características ecográficas da hipertensão portal e o grau de fibrose usando quatro parâmetros: tamanho do baço, grau da fibrose periportal, presença de colaterais e diâmetro da veia porta. Encontraram boa relação desses parâmetros com os resultados endoscópicos e o histórico de hematêmese.

Comparando os diâmetros dos vasos portais de pacientes hepatoesplênicos obtidos pela USG com a pressão intraesplênica medida pela esplenoportografia, Pinto-Silva et al. (1994) referiram que diâmetros maiores que $14 \mathrm{~mm}$ para a veia porta e $12 \mathrm{~mm}$ para a veia esplênica apresentam 100\% de acurácia no diagnóstico de hipertensão portal. Mencionaram, ainda, que o aumento do diâmetro da veia esplênica mostrouse a alteração mais sensível para o diagnóstico de quadro hipertensivo portal, seguido pelo aumento do diâmetro da veia porta.

Hatz et al. (1992), entre eles Cerri, em trabalho de revisão afirmaram ser a USG importante ferramenta para a avaliação da morbidade da doença e para o acompanhamento da regressão das lesões pós-tratamento. Ressaltaram, no entanto, a dificuldade do método em identificar as formas brandas da doença, muito prevalentes nas áreas endêmicas. Salientaram, também, a necessidade de padronização metodológica, para que os resultados obtidos em épocas e regiões diferentes pudessem ser comparados.

A padronização metodológica em escala mundial já havia sido objeto de estudo da OMS, quando em 1991 reuniu no Cairo-Egito um grupo de especialistas no International Expert Meeting. O encontro resultou em um 
protocolo de exame ultrassonográfico, publicado em 1992 (Cairo Working Group, 1992). Esse trabalho foi revisado no Second International Workshop em Niamey-Nigéria, em 1996, e no Satellite Symposium: Ultra-sonography in methodology in Schistosoma mansoni infection em 1997, em Belo HorizonteBrasil, resultando no protocolo Niamey-Belo Horizonte (Niamey Working Group, 2000).

No Second Satellite Symposium on Ultrasound in Schistosomiasis, Richter et al. (2001), avaliando a experiência e os resultados da aplicação do protocolo de Niamey-Belo Horizonte (Niamey Working Group, 2000) em diversos trabalhos no Brasil e na África, concluíram que pesquisas mais abrangentes deveriam ser conduzidas para a determinação da reprodutibilidade do método.

\subsection{A ultrassonografia em trabalhos de campo na esquistossomose mansônica}

Como já visto anteriormente, a USG, por sua acurácia em detectar as alterações características da EM, agrega informações importantes ao exame clínico. O significativo progresso tecnológico ocorrido nos últimos anos possibilitou o desenvolvimento de equipamentos cada vez menores e dotados de tecnologias cada vez mais avançadas. Aliado a isto, o seu baixo custo, a sua mobilidade e a ausência de efeitos deletérios ao ser humano 
tornaram o método ferramenta fundamental e perfeitamente adaptada a estudos de campo, mesmo em condições adversas.

O primeiro trabalho de campo usando equipamento ultrassonográfico portátil foi realizado no Sudão, por Homeida et al. (1988b). Os autores pesquisaram a prevalência da fibrose de Symmers em seiscentos pacientes e realçaram que muitos pacientes sem esplenomegalia ao exame físico apresentavam fibrose periportal ao ultrassom. Perceberam, ainda, grau leve de fibrose periportal, não observado em pacientes hospitalizados.

Abdel-Wahab et al. (1990) estudaram 309 escolares em área endêmica no Egito, a partir de exames parasitológico, clínico e ultrassonográfico. A hepatomegalia comum ao exame físico e ecográfico não mostrou relação com os dados parasitológicos. Já a fibrose periportal e a esplenomegalia mostraram correlação significativa com a intensidade da infecção determinada pela carga parasitária no exame de fezes.

Com o intuito de verificar a acurácia da palpação esplênica na identificação da esplenomegalia, Gerspacher-Lara et al. (1998) examinaram 285 pacientes em área de alta prevalência de EM. Comparando com o padrão ouro da medida do eixo longitudinal do baço à USG (> $120 \mathrm{~mm}$ ), concluíram que a palpação abdominal é um método falho e insuficiente para o diagnóstico da esplenomegalia.

A partir de exames clínico, laboratorial e USG, Martins et al. (1998) analisaram a morbidade relacionada à EM em 138 pacientes em uma área endêmica no nordeste de Minas Gerais. Encontraram 12,2\% dos indivíduos com baço palpável e $18,2 \%$ com fibrose periportal à USG. Apenas quatro 
dos dezesseis pacientes com baço palpável apresentaram fibrose à USG. Atribuíram a esplenomegalia nos demais doze pacientes a outras doenças ou a um grupo de hepatoesplênicos que ainda não havia desenvolvido fibrose periportal. Sugeriram que a regressão da esplenomegalia, se observada no acompanhamento após o tratamento, confirmaria a infecção pelo S. mansoni como a causa mais provável do baço palpável, demonstrando ser a USG ferramenta útil na identificação dos pacientes que respondem rapidamente ao tratamento.

Lambertucci et al. (2001), examinando 741 indivíduos por meio da palpação abdominal e USG em área endêmica em Minas Gerais, verificaram quatro grupos distintos de pacientes: com fibrose periportal intensa e baço palpável; com fibrose periportal leve/moderada e baço palpável; com fibrose periportal intensa sem esplenomegalia; e sem fibrose com esplenomegalia. Com esses resultados enfatizaram que a fibrose periportal intensa pode ocorrer em pacientes sem esplenomegalia e que indivíduos com a forma grave da doença podem não ter sido corretamente identificados em estudos prévios de morbidade. Propuseram, então, a associação de aspectos clínicos e ultrassonográficos para classificação da forma hepatoesplênica da doença.

Para verificar a validade do protocolo de Niamey-Belo Horizonte, King et al. (2003) examinaram 3.954 pacientes no Egito e no Quênia. Nesse estudo de larga escala, os parâmetros quantitativos, como as medidas do calibre da veia porta e do espessamento da parede dos ramos portais, apresentaram discordância significativa interobservador; e os parâmetros 
qualitativos, como as pranchas dos padrões de acometimento hepático, mostraram ser úteis na detecção e comparação da morbidade da doença em estudos com esse perfil.

Magalhães et al. (2005) avaliaram 223 pacientes em uma área de baixa morbidade para EM e nove pacientes hospitalizados com a forma hepatesplênica. Todos foram submetidos aos exames de fezes, USG e clínico. Alterações leves no fígado não detectadas pelo exame clínico foram evidenciadas pela USG. Os pacientes infectados foram tratados com oxamniquine e alguns reavaliados um ano após o tratamento. Constatou-se redução da fibrose em $57,9 \%$ dos pacientes que apresentavam espessamento periportal leve, além de significativa diminuição dos diâmetros das veias porta e esplênica. Os autores concluíram que os sinais mais fidedignos para determinar o estágio da doença foram a fibrose periportal e o tamanho do baço.

Após quatro anos de tratamento com oxamniquine, pacientes hepatoesplênicos foram acompanhados por Cota et al. (2006) em área endêmica no nordeste de Minas Gerais. Observaram redução da esplenomegalia em $59 \%$ dos pacientes e da fibrose periportal em $32 \%$. Apontaram o espessamento da parede da vesícula biliar como bom marcador para a não-regressão da fibrose periportal após tratamento.

No mesmo ano, Marinho et al. (2006), examinando 411 pacientes esquistossomóticos em área endêmica no interior da Bahia, compararam a palpação abdominal e a USG na avaliação do tamanho do fígado e do baço. 
Concluíram que os exames físico e ultrassonográfico são complementares e devem ser usados associados na avaliação da EMH.

Também nas áreas de baixa endemicidade a USG tem sido utilizada na avaliação da EM. Ruiz et al. (2002), com a finalidade de avaliar a morbidade da doença em áreas de baixa prevalência na Venezuela, realizaram estudo clínico e ultrassonográfico a partir do protocolo de Cairo (Cairo Working Group, 1992) em 175 portadores de esquistossomose e 87 não infectados. Os resultados revelaram que a morbidade hepática relacionada à EM é branda e pouco frequente nessas áreas. Informaram que o protocolo superestima a prevalência da fibrose periportal, havendo a necessidade de alguns ajustes no método, no sentido de melhorar sua acurácia.

Com o mesmo objetivo, Espírito-Santo et al. (2008) empregaram a USG em 109 pacientes em área de baixa endemicidade no interior de São Paulo. Todos os participantes haviam sido tratados previamente durante programa de controle da parasitose e não apresentavam manifestações clínicas da doença. Foi utilizado o protocolo de Niamey para o exame ultrassonográfico, que identificou cinco pacientes com fibrose periportal leve. Os autores concluíram que a USG é método sensível na identificação de casos com comprometimento hepático leve em área de baixa endemicidade.

Os exames ultrassonográficos utilizando o protocolo de Niamey feitos por Malenganisho et al. (2008) em duas áreas endêmicas na Tanzânia identificaram fibrose periportal em 41,5 e 16,7\%, estando a diferença relacionada à prevalência e à intensidade da infecção. Relataram, ainda, correlação significativa entre o grau de fibrose determinado pelas pranchas 
da OMS e a espessura das paredes dos ramos portais e a dilatação da veia porta. Não encontraram relação significativa entre a classificação de fibrose das pranchas e a frequência de hipertrofia do lobo esquerdo e de esplenomegalia.

\subsection{Estudos angiográficos na avaliação da hemodinâmica portal}

Dada a natureza primordialmente vascular das alterações hepáticas na EM, os estudos angiográficos foram de muita importância na compreensão da hemodinâmica portal nessa doença.

A esplenoportografia foi introduzida na década de 50 e a primeira portografia obtida peroperatoriamente foi realizada por Souza Pereira (1950², apud Pinto-Silva, 1992). Em seguida, Abeatici \& Campi (1951³ , apud Pinto-Silva, 1992) e Leger (19514 ${ }^{4}$ apud Pinto-Silva, 1992) desenvolveram e relataram a esplenoportografia a partir da punção transparietal do baço, tendo tido o trabalho ampla divulgação em face das excelentes informações fornecidas no tocante às alterações estruturais da árvore portal.

A primeira esplenoportografia na esquistossomose foi realizada por Dantas et al. (19535 ${ }^{5}$, apud Cerri, 1984a), que demonstraram aumento da

\footnotetext{
${ }^{2}$ Souza Pereira A. La method plébographique dnas l'étude dês troubles de la circulation du système porte. In: Compte Rendu du Congrés de Cardiologie, 1950: Tome III.

${ }^{3}$ Abeatici S. \& Campi L. La visibilizzazione radiológica della porta per via splenica (nota preventiva). Minerva Méd. 1951; 42: 593-4.

${ }^{4}$ Leger L, Albot G. \& Arvay N. La phlébographie portale dans l'exploration des affections hépatospléniques. Presse Méd. 1951; 59: 1230-2.

${ }^{5}$ Dantas O, Rocha P. \& Barros $F^{\circ}$ NM. Esplenoportografia. Sua aplicação na síndrome da hipertensão porta. Rev Paulista Méd. 1953; 42: 272-84.
} 
pressão venosa portal pelo bloqueio pré-sinusoidal, dilatação das veias esplênica e porta, bem como a existência de veias colaterais.

Almeida et al. $\left(1956^{6}\right.$, apud Pinto-Silva, 1992) verificaram, à esplenoportografia, que o aumento do calibre médio das veias porta e veia esplênica era maior nos esquistossomóticos do que nos cirróticos.

Em 1956, Bogliolo (1956a) observou na EM, redução do leito vascular intra-hepático com amputação dos ramos portais e aumento do calibre das veias porta e esplênica. O mesmo autor (1958), em estudo esplenoportográfico pioneiro, destacou a tortuosidade da veia esplênica e a trama angiomatoide periportal característica da esquistossomose. A seguir, Barros \& Borrotchin (1960), em estudo in vivo, relataram essa trama como sombra acessória, de menor densidade, paralela aos ramos portais de segunda e terceira ordem, dando a impressão de duplo contorno vascular. Posteriormente, essa mesma imagem foi percebida por Shiroma et al. (1963) em $61 \%$ dos seus casos e por Ferreira (1976) em 55\%.

De cem esplenoportografias transcutâneas, Abdalla \& Queiroz (1959) encontraram alterações de origem esquistossomótica em 57. Reportaram acentuada dilatação dos vasos do sistema porta em mais alto grau que na cirrose, ausência de opacificação da árvore vascular intra-hepática e repleção ampla de colaterais. Em vários casos notaram tortuosidade da veia esplênica e irregularidades em suas paredes.

\footnotetext{
${ }^{6}$ Almeida AL, Rapoport I, Leite AM, Cintra ABU. Esplenoportografia e manometria por via percutânea. Rev Hosp Clin Fac Med São Paulo. 1956; 11: 135-46.
} 
O primeiro trabalho acerca das pressões supra-hepáticas na EM foi publicado por Coutinho (1960). Em 60\% dos pacientes a pressão suprahepática ocluída estava normal (nitidamente inferior à pressão portal) e, no restante, apresentava-se moderadamente aumentada, porém com valores ainda significativamente mais baixos que os da pressão portal. Identificou, assim, que nos esquistossomóticos a pressão supra-hepática ocluída não acompanha a elevação da pressão portal, como observado nos cirróticos. Com esses elementos confirmou dados morfológicos que sugeriam a existência de um bloqueio pré-sinusoidal na EM.

Toledo (1963 ${ }^{7}$, apud Cerri, 1984a), em estudo radiográfico seriado do sistema esplenoportal na EM, constatou que a dilatação da veia esplênica é frequente e que no tronco da veia porta o sangue contrastado proveniente da veia esplênica não se mistura imediatamente com o sangue da veia mesentérica superior. Salientou, também, refluxo para as veias mesentérica superior, coronária esquerda, plexo gastroesofágico e circulação colateral, com formação de anastomoses simultâneas.

Em relação às alterações arteriais da EM, vários autores são unânimes em referir aumento do calibre da artéria esplênica, como Coutinho (1964), Andrade \& Ferraz (1971), Speranzini $\left(1971^{8}\right.$, apud Cerri, 1984a), Yamauchi et al. (1973 ${ }^{9}$, Cerri, 1984a) e Alves et al. (1977).

\footnotetext{
${ }^{7}$ Toledo PA. Estudo-crítico e sugestões sobre a fisiopatologia e a cirurgia da hipertensão porta. Rev Ass Med Bras. 1963; 9: 147.

${ }^{8}$ Speranzini MB. Vascularização arterial do figado na fibrose hepatica esquistossomótica após anastomose espleno-renal: estudo angiográfico [tese]. São Paulo: Faculdade de Medicina, Universidade de São Paulo; 1971.

${ }^{9}$ Yamauchi H, Yamamoto K, Koyama K, Matsuo Y, Kashimura S, Sato. Interaction between the splenic and hepatic arteries in portal hypertension. Tohoku J Exp Med. 1973; 109: 175.
} 
No entanto, as referências quanto ao diâmetro da artéria hepática são contraditórias. Alguns autores referem valores normais, outros citam valores reduzidos e há ainda um terceiro grupo que sugere valores acima do normal.

Bogliolo (1956b), em trabalho realizado com moldes plásticos, acentua que a artéria hepática não participa do processo patogênico esquistossomótico, acompanhando-o passivamente. Relatou ainda que a neoformação vascular é de origem exclusivamente portal e que os ramos arteriais intra-hepáticos permanecem uniformes. Esses resultados foram corroborados por Coutinho et al. (1964) que, com base em manometria hepática transparietal, detectaram sistema arterial hepático normal na EM.

Speranzini (1971, apud Cerri, 1984a), que descreveu pela primeira vez de forma sistemática o aspecto arteriográfico do fígado na esquistossomose, acrescenta que em doentes não operados a arteriografia confirma esses resultados. O autor demonstra a pouca participação do sistema arterial na EM, afirmando que a artéria hepática apresenta-se com calibre aparentemente normal, com dimensões menores que as da artéria esplênica e com ramificações intra-hepáticas finas, retilíneas, alongadas e com distribuição habitual.

Todavia, Magalhães et al. (1960), em análise das alterações vasculares portais em modelos plásticos, ressaltam que os ramos arteriais seguem os ramos portais e que nos locais onde a circulação portal está apagada pela fibrose existe uma rede arterial hiperdesenvolvida para suprir a falta de sangue portal. Em concordância com esses resultados, Andrade \& Cheever (1971), trabalhando também com moldes plásticos dos vasos intra-hepáticos 
de cadáveres com EM e comparando-os com moldes de cadáveres com fígado normal, informam, nos esquistossomóticos, aumento em número e calibre de ramos arteriais intra-hepáticos. Esclarecem, também, que o aumento do suprimento arterial explicaria a manutenção do fluxo sanguíneo hepático normal, compensando a redução do fluxo portal.

Em contrapartida, Mies et al. (1980a), em pesquisa angiográfica em cinquenta portadores de EM com hipertensão portal, sugerem um sistema arterial intra-hepático diminuído, provavelmente em consequência ao aumento do fluxo portal. Nessa série, as artérias hepáticas comum e própria apresentaram redução de diâmetro em relação à artéria esplênica. No conjunto, o aspecto angiográfico mostrou sempre o fígado com irrigação arterial pobre.

\subsection{Ultrassonografia Doppler na avaliação da hemodinâmica portal}

Em geral, os vasos portais são bem identificados pela USG convencional (Richter et al., 2001), porém o acesso às informações hemodinâmicas só era possível mediante o uso de técnicas radiológicas invasivas, como as descritas no tópico anterior (Sugiura et al., 1992).

O efeito Doppler de onda contínua aplicado à USG por Satomura (1957) possibilitou, de maneira não-invasiva, a análise qualitativa e quantitativa do fluxo de praticamente todo o sistema vascular do corpo humano. Por meio dessa técnica, tem sido possível agregar aos dados 
morfológicos obtidos pela USG aspectos funcionais e hemodinâmicos fundamentais na compreensão fisiopatológica de várias doenças.

Em 1985, Taylor et al., usando a técnica de Doppler pulsado, avaliaram os vasos profundos do abdômen e da pelve, possibilitando a investigação da presença, direção e velocidade do fluxo nesses vasos. Salientaram que cada vaso tem características espectrais próprias, o que denominaram de “assinatura” Doppler.

O método Doppler permite a análise quantitativa, hemodinâmica propriamente dita, que consiste na mensuração da velocidade e do volume do fluxo. Vários autores demonstraram a confiabilidade do método para a análise da fluxometria. Ohnish et al. (1985a) obtiveram alta correlação ao compararem a velocidade do fluxo portal obtida por meio da cineangiografia com os resultados do Doppler, concluindo que a técnica permite avaliação hemodinâmica com relativa segurança e reprodutibilidade.

Mouriyasu et al. (1986a) em estudo com Doppler pulsado estabeleceram que o volume de fluxo hepático no humano sadio é de $889 \pm$ $284 \mathrm{~mL} / \mathrm{min}$. Enfatizaram que a possibilidade de acesso ao fluxo portal de maneira não-invasiva e em condições fisiológicas era de fundamental importância para a avaliação da fisiopatologia hepática. O mesmo grupo (Mouriyasu et al., 1986b) calculou, pela correlação entre a área da secção transversa da veia porta e a velocidade do fluxo portal, o que denominaram de "índice de congestão" da veia porta. Nos resultados, encontraram diferença estatisticamente significativa entre esse índice dos indivíduos sadios e dos hepatopatas, sendo mais elevado nos cirróticos, concluindo 
que o índice de congestão da veia porta reflete o estado hemodinâmico do sistema venoso portal.

A análise da velocidade e do volume do fluxo portal em populações de cirróticos e normais revelou que a velocidade média nos cirróticos é significativamente menor, ou seja, $10,5 \mathrm{~cm} / \mathrm{s}$ versus $16 \mathrm{~cm} / \mathrm{s}$ no grupocontrole. Contudo, não houve diferença significativa do volume de fluxo portal (694 $\mathrm{mL} / \mathrm{min}$ versus $736 \mathrm{~mL} / \mathrm{min}$ ) em consequência ao aumento do diâmetro vascular. Esses dados de Zoli et al. (1986) foram corroborados por vários autores, entre eles Gaiani et al. (1989) e Zironi et al. (1992), sendo que estes últimos definiram em $15 \mathrm{~cm} / \mathrm{s}$ o limite inferior da velocidade média da veia porta, abaixo do qual se pode estabelecer o diagnóstico de hipertensão portal com sensibilidade de $88 \%$ e especificidade de $96 \%$.

Outras pesquisas concentraram-se no uso do Doppler para avaliação da direção do fluxo venoso, dado fundamental no entendimento da fisiopatologia da hipertensão portal. Nessa linha, um dos trabalhos pioneiros foi o de Ohnish et al. (1985b), que avaliaram a direção do fluxo na veia esplênica em 21 pacientes com derivação esplenorrenal espontânea diagnosticada por angiografia. O Doppler pulsado realçou inversão do fluxo da veia esplênica em onze pacientes com encefalopatia hepática, enquanto os outros, sem encefalopatia, tinham fluxo hepatopetal.

Em 1986, Nelson et al., avaliando a direção do fluxo em pacientes com hipertensão portal e comparando os achados Doppler com o padrão ouro - a angiografia -, obtiveram índice de correlação de 83\%. 
O estudo da direção do fluxo por meio do Doppler permitiu confirmar, por método não-invasivo, algumas constatações angiográficas, como, por exemplo, que o fluxo hepatofugal na hipertensão portal não é tão frequente como teoricamente se esperaria, uma vez que o sistema é avalvular. Neste sentido, Kawasaki et al. (1989) demonstraram, na cirrose hepática, presença de fluxo hepatofugal em apenas três de 132 pacientes, ou seja, 2,3\%.

As comunicações porto-sistêmicas, importantes indicadores de hipertensão portal, também foram estudadas pelo Doppler. Em 1989, Mostbeck et al. utilizaram o Doppler pulsado em onze pacientes com cirrose e veia umbilical recanalizada. Nos pacientes em que o fluxo portal hepatopetal era menor que o fluxo hepatofugal da veia umbilical, não foram detectadas varizes esofagianas. Em todos os outros, em que a veia umbilical apresentava fluxo menor do que o fluxo portal, foram identificadas varizes com risco de sangramento. A conclusão foi que o fluxo hepatofugal na veia umbilical, quando maior que o fluxo portal, reduz a chance de formação de varizes esofágicas e de sangramento digestivo alto.

Bolondi et al. (1989) relacionaram a velocidade e o volume de fluxo na veia porta com a presença, o calibre e as características das varizes esofágicas, sendo que a velocidade da veia porta foi significativamente menor nos pacientes com sangramento prévio ou com red signal. Verificaram que nos pacientes com hipertensão portal e varizes esofágicas a velocidade diminuída da veia porta pode ser um indicador útil de prognóstico, sugerindo alto risco de sangramento. 
O padrão das curvas espectrais das veias supra-hepáticas em cirróticos também foi investigado por Bolondi et al. (1991). Comparando o espectro de ondas dessas veias em indivíduos sadios com pacientes portadores de hepatopatia crônica fibrosante, encontraram no primeiro grupo um padrão trifásico modulado pelo ciclo cardíaco e no grupo de cirróticos um padrão bem distinto, caracterizado pela perda da fasicidade. Atribuíram essas alterações às distorções da arquitetura hepática secundárias à fibrose.

Utilizando o Doppler pulsado acrescido do modo colorido em 121 pacientes com hipertensão portal, Sugiura et al. (1992) constataram ser essa técnica de grande utilidade não só na rápida demonstração da patência e direção do fluxo, como também na identificação de derivações colaterais não visibilizadas ao modo $B$ ( $55 \%$ nessa série).

Bolognesi et al. (1996) acompanharam 26 indivíduos normais e 207 com quadro de hipertensão portal de diferentes etiologias e em variadas condições hemodinâmicas. Medindo o índice de resistividade e o índice de pulsatilidade da artéria esplênica, referenciaram aumento significativo nesses índices nos pacientes cirróticos. Como resultado, assinalaram que, na cirrose, os índices de impedância da artéria esplênica refletem a resistência do fluxo venoso portal. Corroborando essas informações, Piscaglia et al. (2002) também encontraram significativo aumento do índice de resistividade da artéria esplênica e redução da velocidade do fluxo portal nos cirróticos.

O índice vascular hepático foi estabelecido em 1997 por Iwao et al., calculado a partir da correlação entre a velocidade do fluxo na veia porta e o 
índice de pulsatilidade na artéria hepática. $O$ valor definido como limite foi de $12 \mathrm{~cm} / \mathrm{s}$, abaixo do qual poderia se confirmar o diagnóstico de hipertensão portal com sensibilidade e especificidade de 97 e 93\%, respectivamente.

O comportamento da artéria hepática na hipertensão portal também foi objeto de estudo de vários autores, todos com resultados bastante semelhantes (Sacerdoti et al., 1995; Piscaglia et al., 1997; Colli et al., 1998 e Schneider et al., 1999): o aumento do índice de resistividade da artéria concomitante ao aumento da pressão portal.

Erden et al. (1999), avaliando o índice de resistividade da artéria hepática de pacientes com hipertensão portal em sítios diferentes (présinusoidal e sinusoidal) e de indivíduos sadios, destacaram que a resistência arterial hepática não se altera nos pacientes com quadro hipertensivo présinusoidal, enquanto nos pacientes com hipertensão sinusoidal essa resistência encontra-se significativamente aumentada.

\subsection{Ultrassonografia Doppler na esquistossomose mansônica}

As pesquisas sobre as aplicações do Doppler na investigação da hipertensão portal de origem cirrótica produzem, por ano, inúmeras publicações. No entanto, o mesmo não acontece em relação à hipertensão portal esquistossomótica. Estudos prévios sobre este tema totalizam dezoito publicações, sendo duas referentes à esquistossomose japônica e o restante à EM. 
A primeira avaliação Doppler na EM foi realizada por ParanaguáVezozzo em tese de doutoramento em 1992. Nesse trabalho foram comparados dois grupos: 32 pacientes com a forma hepatoesplênica e dezesseis com a forma hepatointestinal e intestinal. Foram avaliados o fígado, baço, vesícula biliar, a veia porta, seus ramos direito e esquerdo, veia esplênica, veia mesentérica superior e artéria hepática. A autora concluiu: presença de hipertrofia do lobo esquerdo em ambos os grupos, não podendo ser explicada pelo hiperfluxo das veias esplênica e mesentérica superior; aumento significativo do fluxo nas veias porta, esplênica e mesentérica superior no grupo hepatesplênico; taxa mais baixa de visibilização da artéria hepática no grupo hepatoesplênico, sugerindo componente arterial diminuído e padrão alterado de ondas nas veias hepáticas do grupo hepatoesplênico. Essa tese foi resumida em artigo publicado no mesmo ano (Paranaguá-Vezozzo \& Cerri, 1992), no qual os autores atribuem o hiperfluxo portal no grupo hepatoesplênico ao aumento do diâmetro do vaso, já que os valores da velocidade da veia porta não apresentaram diferença significativa entre os grupos $(23,5 \pm 5,8$ versus 26,8 $\pm 9,2 \mathrm{~cm} / \mathrm{s})$.

Após esse estudo pioneiro, alguns autores se dedicaram à avaliação de aspectos específicos que envolvem a hemodinâmica portal nos pacientes com hipertensão portal esquistossomótica, como o risco de sangramento e as alterações decorrentes da presença de colaterais. Martins et al. (2000), em investigação endoscópica, USG convencional e Doppler em quarenta pacientes com EMH compensada, analisaram quais parâmetros poderiam 
indicar risco mais alto de sangramento. Os resultados ressaltaram que os parâmetros dopplervelocimétricos isolados não contribuem nessa tarefa, sendo o Doppler mais útil no diagnóstico da trombose portal. Os parâmetros mais preditivos de sangramento foram endoscópicos (calibre das varizes, red signs, gastropatia congestiva e varizes fúndicas) e ultrassonográficos (diâmetro da veia porta e fibrose periportal).

Com o objetivo de avaliar as características biométricas e hemodinâmicas dos vasos portais relacionadas ao achado de veia paraumbilical recanalizada, Oliveira et al. (2001) avaliaram 75 portadores de hipertensão portal esquistossomótica, por meio da US-Doppler. Os pacientes foram alocados segundo a ausência (grupo A) ou presença (grupo B) de recanalização. Os diâmetros e velocidades de fluxo na veia porta e na veia paraumbilical foram mensurados, evidenciando-se que $17,33 \%$ dos pacientes tinham veia paraumbilical recanalizada e todos eles exibiam aumento do diâmetro e da velocidade de fluxo na veia porta e no seu ramo esquerdo. Concluiram que a presença dessa colateral condiciona alterações biométricas e hemodinâmicas significativas no sistema venoso portal.

Com o mesmo intuito, Widman et al. (2001a) examinaram pela USDoppler, 24 pacientes com hipertensão portal esquistossomótica, histórico de sangramento digestivo alto e veia paraumbilical pérvia com fluxo hepatofugal. Medindo o diâmetro e a velocidade média de fluxo na veia paraumbilical e a velocidade média da veia porta e de seus ramos direito e esquerdo, concluiram que a veia paraumbilical com diâmetro $\geq 0,68 \mathrm{~cm} \mathrm{e}$ velocidade média de fluxo $\geq 18,41 \mathrm{~cm} / \mathrm{s}$ provoca o aumento da velocidade 
média de fluxo na veia porta e seu ramo esquerdo. Descreveram ainda que a velocidade média de fluxo na veia paraumbilical é mais sensível do que seu diâmetro para avaliar a influência desta veia sobre o sistema portal na esquistossomose hepatoesplênica.

Outros autores pesquisaram as alterações hemodinâmicas após tratamento cirúrgico, avaliando seu efeito na circulação esplâncnica e suas complicações, como a trombose da veia porta. Brandt et al. (1995) examinaram 25 crianças com EMH e varizes esofagianas submetidas à esplenectomia e ligadura da veia gástrica esquerda. Mediram, antes e depois da cirurgia, os diâmetros e as velocidades da veia porta e da artéria hepática. Após a cirurgia, o calibre estava reduzido na veia porta e aumentado na artéria hepática. A velocidade do fluxo também se apresentou diminuída na veia porta, porém na artéria hepática não houve diferença significativa. Os autores constataram que o tratamento cirúrgico da hipertensão portal esquistossomótica resulta em redução do fluxo portal e aumento do fluxo arterial.

Ao avaliar o fluxo portal na EMH e o efeito tardio do tratamento cirúrgico na hemodinâmica portal, Alves Jr. et al. (2001) utilizaram o Doppler em 64 pacientes com hipertensão portal esquistossomótica, sendo um grupo de não-operados (G1), outro submetido à desconexão ázigo-portal com esplenectomia (G2) e um terceiro submetido à derivação esplenorrenal distal (G3). Os dados sugeriram que: existe aumento do fluxo portal na hipertensão portal esquistossomótica; o tratamento cirúrgico interferiu na hemodinâmica portal, diminuindo o fluxo sanguíneo da veia porta; essa 
redução do fluxo sanguíneo portal correlacionou-se com o tempo de seguimento pós-operatório no G3, mas não no G2.

Widman et al. (2001b) compararam os resultados da US-Doppler de 58 portadores de hipertensão portal esquistossomótica com histórico de sangramento: um grupo com 29 pacientes com acompanhamento clínicoendoscópico e outro com 29 pacientes submetidos à desvascularização esofagogástrica e esplenectomia. Foram medidos o diâmetro e a velocidade de fluxo na veia porta e nos seus ramos direito e esquerdo. No grupo não operado, o diâmetro da veia porta tinha valores superiores aos de seus ramos, porém com velocidade de fluxo semelhante. No grupo de operados, houve redução significativa tanto no diâmetro quanto na velocidade do fluxo de todos os vasos.

O mesmo grupo, Widman et al. (2002), avaliou pela US-Doppler as alterações morfológicas e hemodinâmicas tardias no território esplênico em portadores de hipertensão portal esquistossomótica submetidos à anastomose esplenorenal distal. Participaram desse estudo quarenta nãooperados e doze com anastomose esplenorrenal distal. A comparação dos resultados entre os dois grupos revelou que: nos pacientes operados houve redução dos índices biométrico e volumétrico do baço; não se verificou modificação dos parâmetros morfológicos e hemodinâmicos nem dos índices velocimétricos da artéria esplênica; detectou-se aumento da velocidade média de fluxo na veia esplênica. Os autores concluíram que a redução do volume do baço e o aumento da velocidade de fluxo na veia esplênica podem ser atribuídos a mais facilidade de escoamento venoso esplênico 
proporcionada pela cirurgia, eliminando, assim, o fator congestão, um dos componentes da esplenomegalia.

Para avaliar a relação entre o fluxo portal e o perfil laboratorial hepático, Alves Jr. et al. (2003) acompanharam 64 pacientes com hipertensão portal esquistossomótica, sendo um grupo de não-operados, outro submetido à desconexão ázigo-portal com esplenectomia e um terceiro submetido à derivação esplenorrenal distal. Avaliou-se o perfil laboratorial pela dosagem de vários indicadores da função hepática e o fluxo portal pelo Doppler. Afirmaram ser a gama-glutamil transferase a variável laboratorial mais representativa da influência do fluxo portal na atividade funcional hepática e que as cirurgias, pela redução do quadro congestivo, são benéficas ao diminuírem o grau de colestase e ao reduzirem a indução microssomal.

Por ser complicação frequente no pós-operatório de pacientes hepatoesplênicos submetidos à descompressão cirúrgica do sistema porta, a trombose da veia porta foi objeto de estudo de vários autores. Buscando definir a prevalência de trombose portal espontânea e no pós-operatório tardio, Widman et al. (2003) realizaram US-Doppler em 168 pacientes divididos em três grupos: a) 92 indivíduos não operados; b) 62 submetidos à desvascularização esofagogástrica e esplenectomia; e c) quatorze submetidos à anastomose esplenorenal distal. Evidenciou-se ocorrência de trombose espontânea em $5,4 \%$ do grupo 1 e de trombose pós-operatória tardia em 19,3 e 50,0\% nos grupos 2 e 3, respectivamente. Comprovou-se que o tratamento cirúrgico na hipertensão portal estimula uma tendência natural à trombose portal na $E M H$ e a diferença de ocorrência dessa 
complicação entre os dois grupos operados sugere a existência de fatores hemodinâmicos determinados pela técnica cirúrgica empregada.

$\mathrm{Na}$ tentativa de definir parâmetros pré-operatórios que pudessem predizer o risco dessa complicação, Ferreira et al. (2005) compararam os dados Doppler da veia porta no pré e pós-operatório de 65 pacientes esquistossomóticos submetidos à desconexão ázigo-portal com esplenectomia com a ocorrência de trombose da veia porta no pósoperatório. O índice de congestão portal pré-operatório, apesar de mais alto nos doentes com trombose no pós-operatório, não foi preditivo desse fenômeno, mas a simples observação dos dados que compõem esse índice (diâmetro, área e volume de fluxo na veia porta) pode auxiliar na identificação dos pacientes nos quais se deve ter mais preocupação com fenômenos trombóticos.

Com o mesmo objetivo, Cleva et al. (2005) avaliaram quarenta pacientes hepatoesplênicos com indicação de desvascularização esofagogástrica e esplenectomia. Os resultados Doppler demonstraram ocorrência de trombose portal após a cirurgia em $22 \%$ dos pacientes, mas essa complicação não mostrou correlação com a redução do volume do fluxo portal, com os testes laboratoriais realizados, com o diâmetro da veia porta ou com o peso do baço.

Paranaguá-Vezozzo et al. (2006), comparando o volume de fluxo portal e esplênico de 48 pacientes portadores das formas hepatoesplênica e hepatointestinal da EM com vinte voluntários sadios, informaram aumento significativo dos valores dos fluxos portal e esplênico nos dois grupos 
esquistossomóticos quando comparados aos dos indivíduos normais. Entre os grupos hepatoesplênico e hepatointestinal não houve diferença significante nos valores dos fluxos. Os resultados indicam haver hiperfluxo portal e esplênico nas duas formas da doença.

Parâmetros ultrassonográficos (modo B e Doppler) de 27 pacientes hepatoesplênicos com (G1) e sem (G2) antecedentes de hemorragia digestiva alta foram pesquisados por Arruda et al. (2008). Constatou-se aumento significativo da média de velocidade de fluxo na veia porta no grupo 1. Embora estatisticamente não significante, quando considerados todos os tipos de colaterais houve prevalência de colateral esplenorrenal no grupo 2. Segundo os autores, os achados dopplerfluxométricos sugerem que a hipertensão portal esquistossomótica é fortemente influenciada pelo hiperfluxo e que a circulação colateral exerce importante papel no equilíbrio hemodinâmico desses pacientes.

No acompanhamento a 21 pacientes com a forma hepatoesplênica da esquistossomose, Leão et al. (2008) analisaram a reprodutibilidade da USDoppler na quantificação do volume de fluxo portal em esquistossomóticos. A mensuração do fluxo portal foi realizada por três observadores de forma independente, sendo calculada a concordância entre eles. Obtiveram concordância interobservador considerada excelente, definindo ser a USDoppler método confiável para quantificar o fluxo portal em pacientes com quadro hipertensivo esquistossomótico. 


\section{CASUÍSTICA E MÉTODOS}




\subsection{Desenho do estudo e considerações éticas}

Este estudo transversal descritivo foi realizado seguindo os princípios da Declaração de Helsinque, elaborados pela Organização Mundial da Saúde em 1982.

A pesquisa de campo foi parte integrante de três projetos relacionados à EM nos quais foram realizados exames ultrassonográficos, tendo sido acrescida a US-Doppler para fins específicos deste trabalho.

Todos os participantes foram informados a respeito do estudo e forneceram consentimento para inclusão na pesquisa, com assinatura do Termo de Consentimento Livre e Esclarecido (Apêndice A). Os voluntários

menores de dezoito anos tiveram o Termo de Consentimento Livre e Esclarecido assinado por seus responsáveis.

O estudo foi aprovado pela Comissão de Ética para Análise de Projetos de Pesquisa do Hospital das Clínicas da Faculdade de Medicina da Universidade de São Paulo (Apêndice B).

O método propedêutico utilizado na investigação - exame de USDoppler - não oferece qualquer risco aos participantes. Aqueles com diagnósticos alternativos foram encaminhados para assistência médica adequada. 


\subsection{Casuística}

\subsection{1 Áreas estudadas}

As áreas estudadas foram selecionadas de acordo com critério de endemicidade para EM definido pela OMS (1985), levando-se em conta a prevalência, a carga parasitária e a manifestação clínica da doença.

São definidas como áreas de alta endemicidade aquelas com prevalência superior a 15\%, carga parasitária acima de 120 ovos/grama/ fezes e adultos com manifestações clínicas graves. As áreas de média endemicidade são definidas pela prevalência acima de $10 \%$, carga parasitária superior a 120 ovos/grama/fezes e indivíduos com manifestações clínicas leves. As áreas de baixa endemicidade têm prevalência inferior a 10\%, carga parasitária de até 96 ovos/grama/fezes e maioria dos infectados assintomáticos (WHO, 1985).

De acordo com esses critérios, as áreas selecionadas foram (Figura 1):

1. Alta endemicidade: Brejo do Espírito Santo, distrito rural do município de Santa Maria da Vitória-Bahia, localizado a 865 Km de Salvador. Área hiperendêmica, com prevalência de $75 \%$ em estudo coproscópico em 1976 e de 19\% em 2004 (Ruiz-Guevara, 2005), apresentando adultos com formas crônicas graves da doença (Figura 2).

2. Média endemicidade: Chonim de Baixo, distrito do município de Governador Valadares-Minas Gerais, localizado a $330 \mathrm{~km}$ de Belo Horizonte. Prevalência de 22,5\%, carga parasitária de 170 ovos/grama/ 
fezes em 2004 e indivíduos com manifestações clínicas leves da doença (Queiroz, 2006) (Figura 3).

3. Baixa endemicidade: município de Bananal-São Paulo, localizado a 331 Km de São Paulo. Prevalência de 1,8\%, carga parasitária de 79 ovos/ grama/ fezes em 2000 e pacientes assintomáticos (Teles et al., 2002).

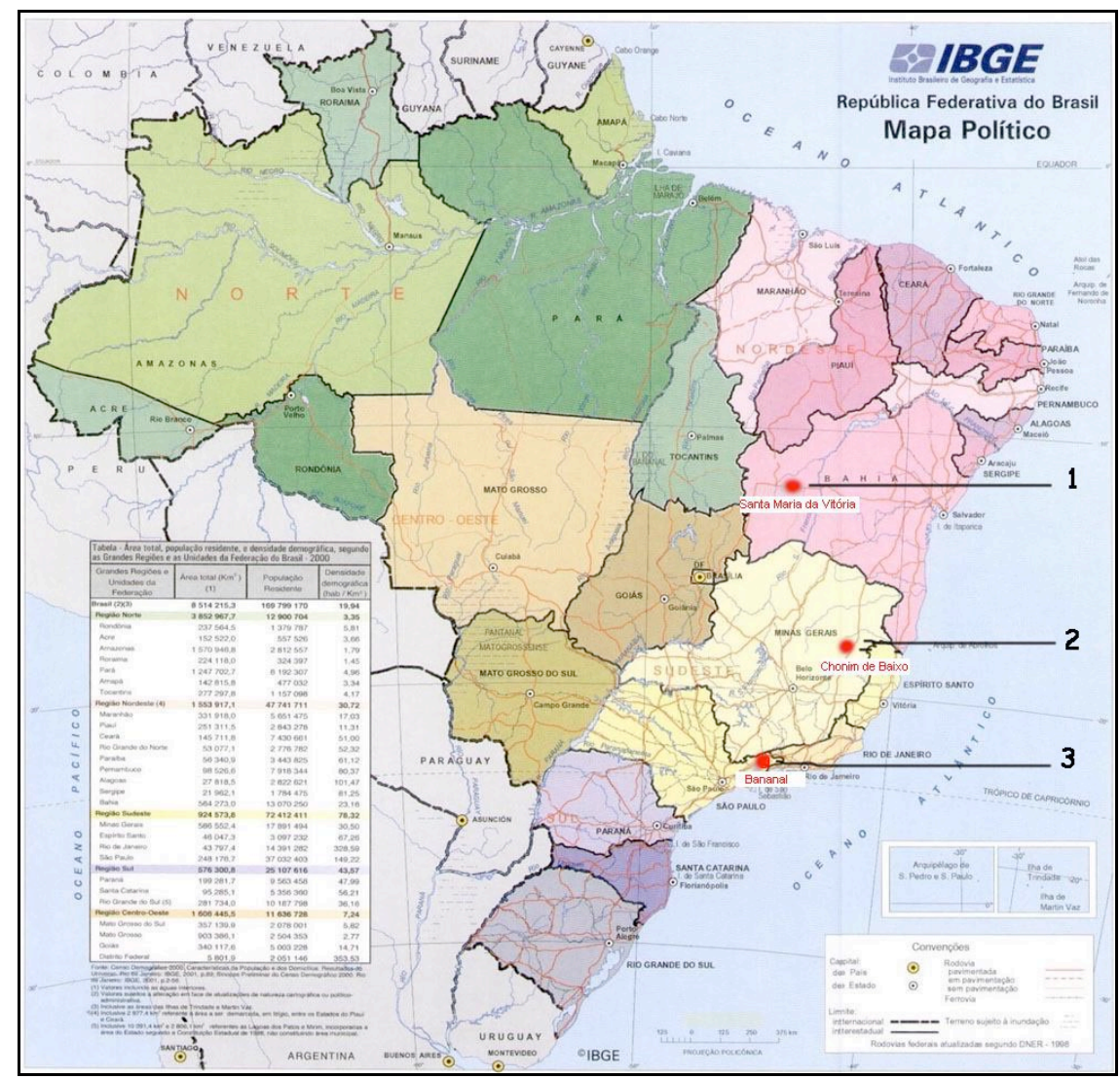

Figura 1. Mapa do Brasil com localização das três áreas estudadas

1. Área de alta endemicidade: Brejo do Espírito Santo (município de Santa Maria da Vitória), Bahia.

2. Área de média endemicidade: Chonim de Baixo (município de Governador Valadares), Minas Gerais.

3. Área de baixa endemicidade: município de Bananal, São Paulo. 


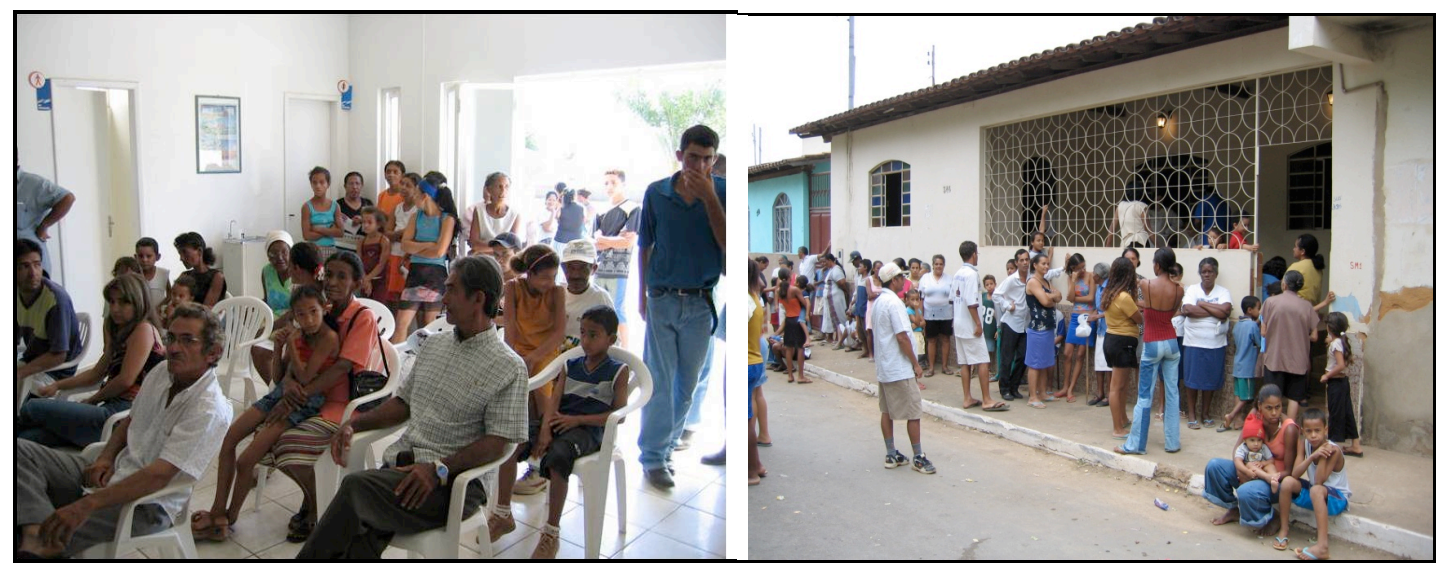

Figura 2. Local de realização dos exames (Hospital Municipal) em Brejo do

Figura 3. Local de realização dos exames Espírito Santo, Bahia em Chonim de Baixo, Minas Gerais

\subsubsection{Tamanho e composição da amostra}

Foram incluídos no estudo pacientes com histórico de infecção atual ou anterior pelo Schistosoma mansoni, comprovado por exame parasitológico de fezes (método Kato-Katz)(Katz et al.,1972), moradores de regiões de baixa, média e alta endemicidades para a doença.

$\mathrm{Na}$ área de baixa endemicidade (Bananal, São Paulo), dos 306 infectados identificados em levantamento coproscópico, a US-Doppler foi realizada em 110 que concordaram em participar do estudo.

$\mathrm{Na}$ área de média endemicidade (Chonim de Baixo, Minas Gerais), foram identificados em inquérito coproscópico 422 infectados, dos quais 306 concordaram em participar da pesquisa. Por razões técnicas do tempo de execução do exame, a US-Doppler foi realizada em 261.

$\mathrm{Na}$ área de alta endemicidade (Brejo do Espírito Santo, Bahia), foi selecionada uma amostra de 411 voluntários, composta por indivíduos com 
dados clínicos sugestivos de formas graves da doença e outros que nunca apresentaram sinais clínicos de formas graves. Por razões técnicas do tempo de execução do exame, a US-Doppler foi realizada em 208 indivíduos.

Desta forma, ingressaram no momento inicial do estudo 579 voluntários.

Foram adotados os seguintes critérios de exclusão: esplenectomia, hepatopatia crônica não-esquistossomótica identificada pelo exame ultrassonográfico e ascite.

Por esses critérios, foram excluídos 25 participantes: dezessete esplenectomizados, cinco com sinais ecográficos sugestivos de hepatopatia crônica cirrótica e três com aumento importante da ecogenicidade do parênquima hepático sugestivo de esteatose acentuada. Os pacientes com aumento leve ou moderado da ecogenicidade do parênquima hepático não foram excluídos do estudo, por se entender não haver comprometimento hepático significativo nesses casos. Assim, permaneceram na pesquisa, 554 voluntários.

Os participantes foram divididos em três grupos, de acordo com o local de realização do exame: área de baixa endemicidade( $\mathrm{n=109);} \mathrm{área} \mathrm{de} \mathrm{média}$ endemicidade( $n=255)$; e área de alta endemicidade( $n=190)$ (Anexo A).

Quanto à distribuição por sexo na amostra total, 325 pacientes $(58,7 \%)$ eram do sexo masculino e $229(41,3 \%)$ do sexo feminino. Na estratificação por local de realização do exame, a área de baixa endemicidade apresentou 
número mais elevado de homens $(75,2 \%)$ e a área de alta endemicidade número superior de mulheres $(50,0 \%)$ (Anexo $A)$.

A idade dos participantes variou de 10 a 92 anos, com média de 36,7 anos, mediana de 36,0 anos e desvio-padrão de 16,8 anos. A média mais alta de idade foi na área de alta endemicidade (45,8 anos) e a mais baixa na área de média endemicidade (31,2 anos) (Anexo A).

\subsection{Métodos}

\subsubsection{Equipamentos e operadores}

Os exames ultrassonográficos modo $\mathrm{B}$ foram realizados utilizando-se equipamento portátil General Eletric modelo Logiq 100 (General Eletric - E Medical Systems, Milwaukee, Winsconsin, Estados Unidos da América) com sonda convexa de $3,5 \mathrm{MHz}$, em tempo real. As imagens foram obtidas por dois operadores (LMA e LCQ), membros titulares do Colégio Brasileiro de Radiologia e Diagnóstico por Imagem, com experiência de quatro anos em USG à época de realização dos exames, treinados para aplicação do protocolo de Niamey-Belo Horizonte (Niamey Working Group, 2000).

Os exames US-Doppler (colorido e pulsado) foram executados em equipamento portátil General Eletric modelo Logiq-Book (General Eletric Medical Systems, Milwaukee, Winsconsin, Estados Unidos da América) com sonda convexa de 3,5 MHz, em tempo real (Figuras 4 e 5). As imagens 
foram obtidas por único operador (LMA), membro titular do Colégio Brasileiro de Radiologia e Diagnóstico por Imagem, com experiência de quatro anos em US-Doppler à época da realização dos exames.

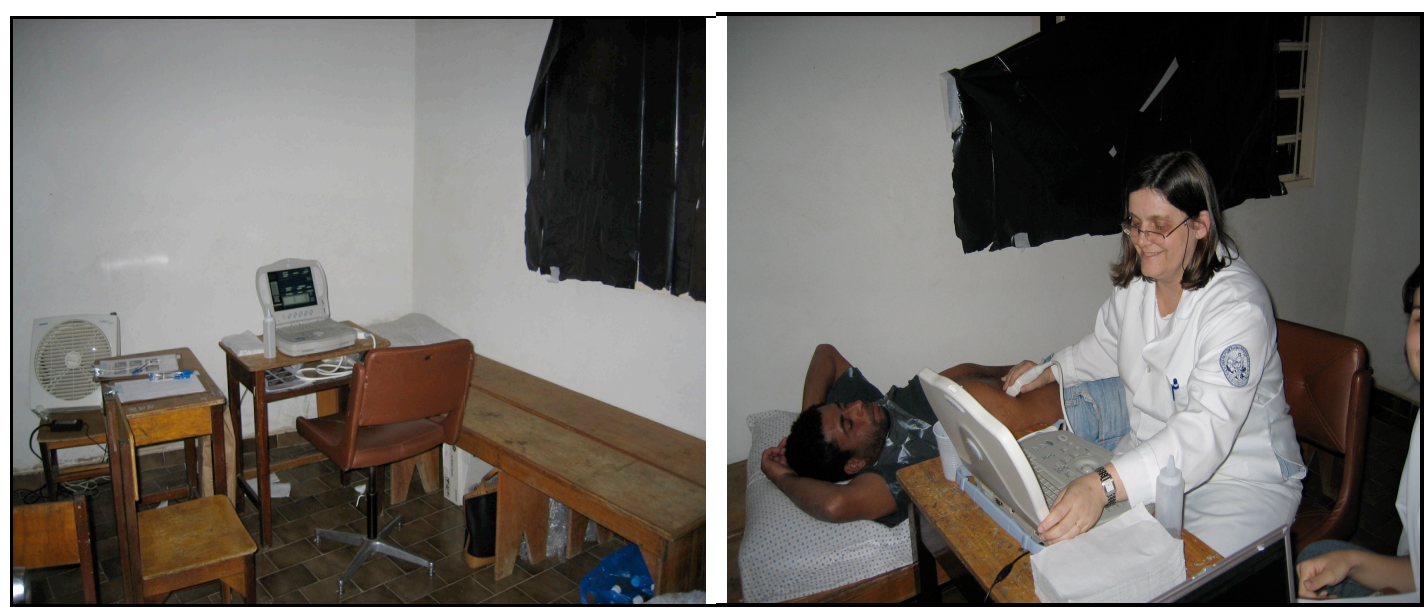

Figura 4. Sala de exame da US-Doppler em Chonim de Baixo, Minas Gerais

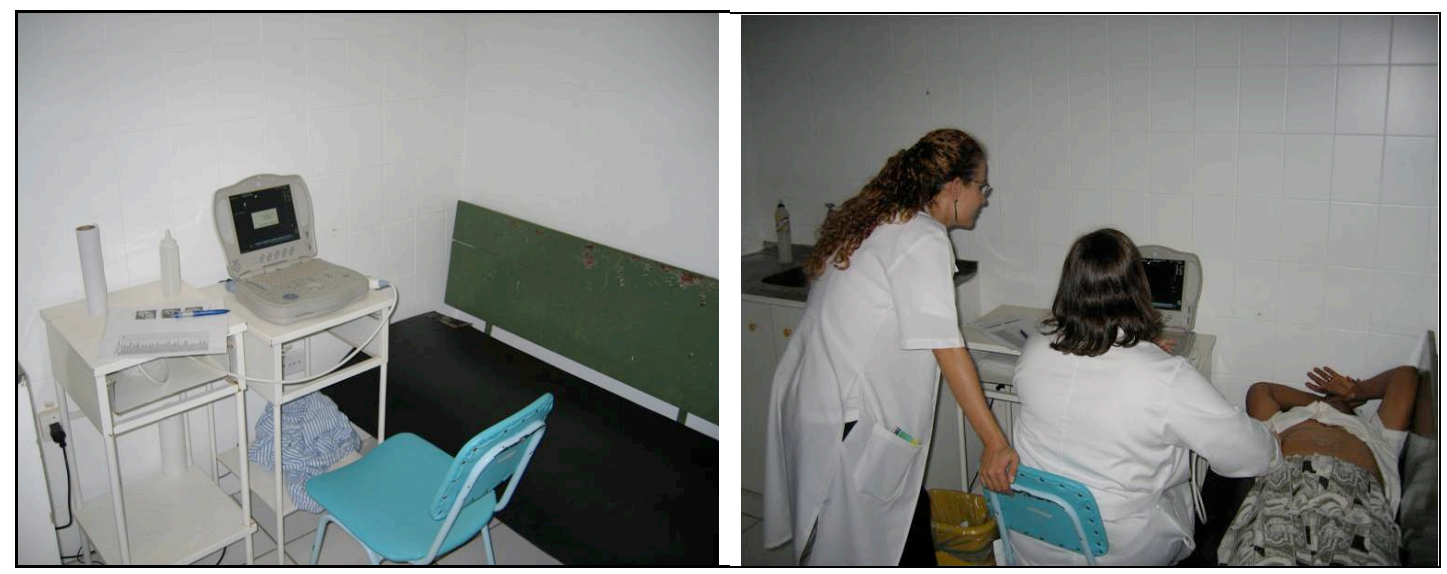

Figura 5. Sala de exame da US-Doppler em Brejo do Espírito Santo, Bahia 


\subsubsection{Sistematização do estudo ultrassonográfico modo B}

Os pacientes foram examinados sem jejum prévio e sem preparo intestinal com laxativos ou antifiséticos, devido à dificuldade de se obter este preparo em estudos de campo.

Ao modo $\mathrm{B}$, foram estudados o fígado, a vesícula biliar, o baço, o trato portal, as artérias hepática e esplênica e a cavidade abdominal, com interesse em linfonodomegalias, vasos colaterais e ascite. A posição padronizada para o exame foi o decúbito dorsal, tendo sido também utilizados os decúbitos laterais direito e esquerdo, quando necessário.

No protocolo dos exames ultrassonográficos modo B (Anexo B), foi adotada a sistematização definida pelo Niamey Working Group (2000) para avaliação da morbidade associada à EM.

\subsubsection{Avaliação do fígado}

$\mathrm{Na}$ análise do fígado, foi medido o eixo longitudinal dos lobos direito e esquerdo, tendo sido considerados como limite superior da normalidade os valores de 155 e $110 \mathrm{~mm}$, respectivamente (Machado et al., 2002). A medida do lobo direito foi obtida em secção longitudinal na linha axilar anterior, tendo como referência a visibilização do rim direito (Figura 6). O lobo esquerdo foi medido em secção longitudinal da linha paraesternal esquerda, tendo como referência a visibilização da aorta (Figura 6). 

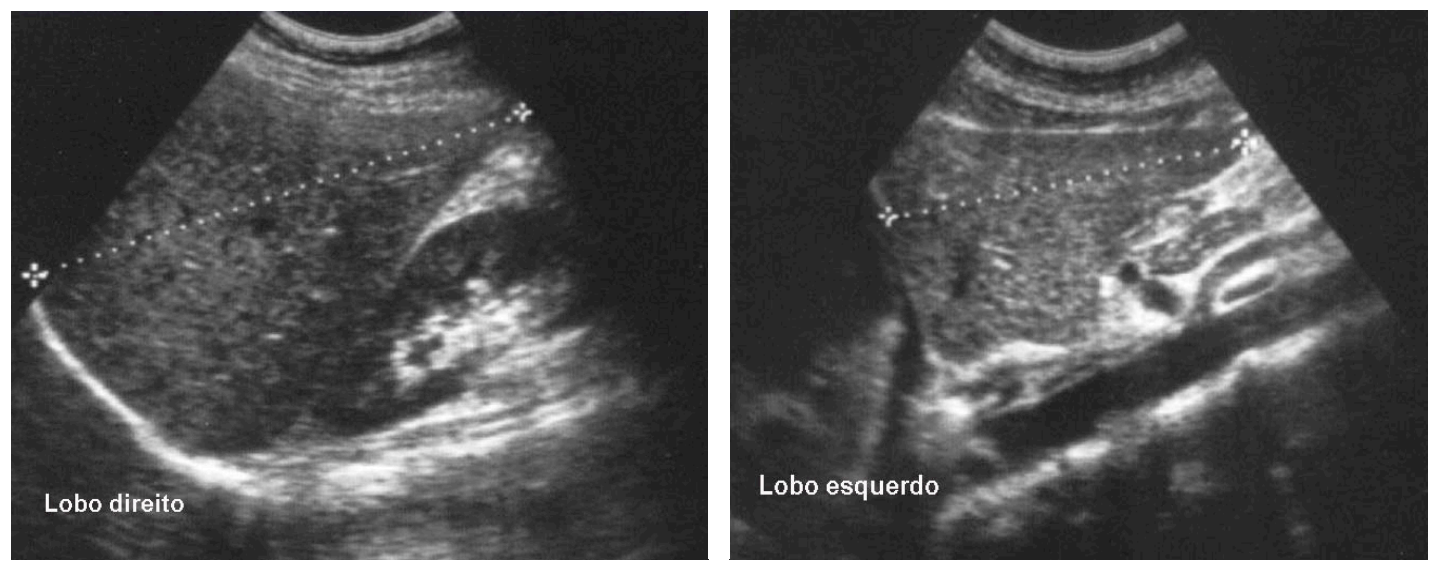

Figura 6. Medidas dos lobos direito e esquerdo do fígado

A textura e ecogenicidade do parênquima hepático foram avaliadas buscando-se identificar sinais ecográficos de alterações não associadas à EM. A classificação dessas alterações foi feita de acordo com as pranchas de referência dos padrões de acometimento não-esquistossomótico estabelecidos pelo Niamey Working Group (2000) (Figura 7).

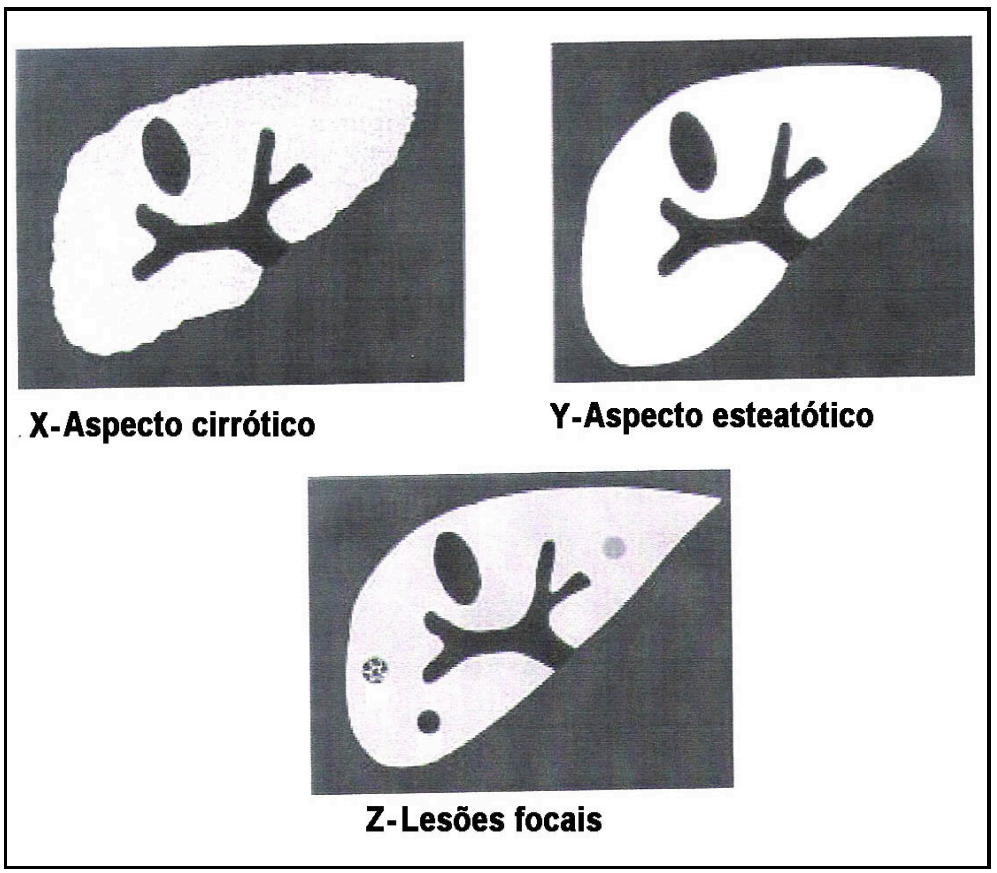

Figura 7. Padrões de acometimento não-esquistossomótico do fígado (Niamey Working Group, 2000) 
Quando presente, o aumento da ecogenicidade do parênquima hepático foi classificado em três graus distintos (Machado et al, 2002): leve (aumento discreto da ecogenicidade, com visibilização preservada do diafragma e dos vasos intra-hepáticos); moderado (aumento moderado da ecogenicidade, com redução da visibilização do diafragma e dos vasos intrahepáticos); acentuado (aumento importante da ecogenicidade, com perda parcial ou completa da visibilização do diafragma e dos vasos intrahepáticos).

Os contornos hepáticos foram classificados como lisos ou rugosos, conforme seu aspecto.

\subsubsection{Avaliação do espessamento das paredes dos vasos portais}

\section{- Avaliação qualitativa}

A avaliação qualitativa subjetiva foi feita pela observação da existência ou não de espessamento ecogênico das paredes dos vasos portais. Nos casos positivos, foi classificado como leve, moderado ou intenso e sua distribuição como central, periférica ou central e periférica.

Também foi feita a classificação em comparação aos modelos propostos pelo Niamey Working Group (2000), baseada em pranchas de referência que possuem os padrões das letras $A$ a $F$, podendo haver composição de padrões com as letras B e C, tais como Dc ou Ec (Figura 8). O padrão A corresponde à ausência de espessamento; B: presença de focos 
ecogênicos dispersos pelo parênquima hepático; C: espessamento nos ramos portais periféricos; D: espessamento leve nos ramos portais principais; E: espessamento moderado nos ramos principais; $F$ : espessamento intenso nos ramos principais. Os padrões Dc, Ec ou Fc correspondem a espessamento central leve, moderado ou acentuado associado a espessamento periférico.
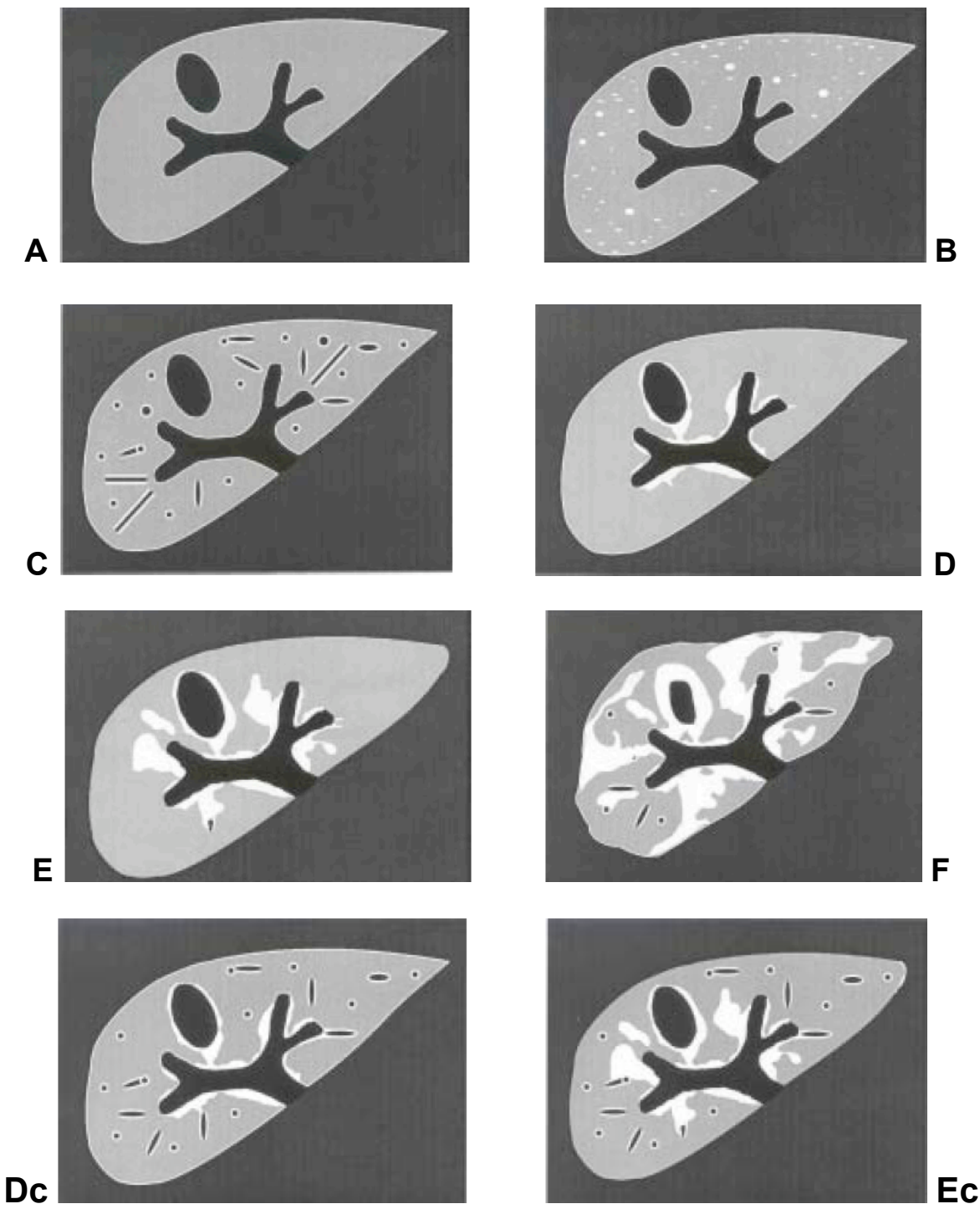

Figura 8. Padrões de acometimento do fígado na esquistossomose mansônica (Niamey Working Group, 2000) 


\section{- Avaliação quantitativa}

$\mathrm{Na}$ avaliação quantitativa do espessamento periportal, foram medidas em milímetros as paredes da veia porta no hilo hepático, na bifurcação e em um ramo portal periférico de segunda ordem, sendo observados os critérios do Niamey Working Group (2000). A espessura da parede foi obtida subtraindo-se o diâmetro do lúmen (medida borda interna - borda interna) do diâmetro medido da borda externa - borda externa do vaso (Figura 9).

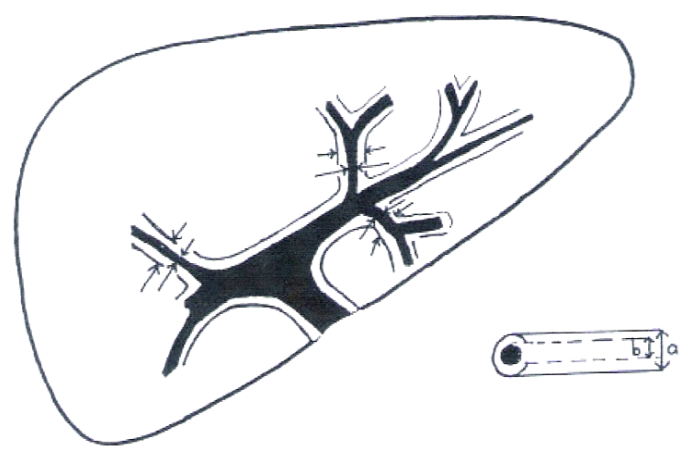

Figura 9. Esquema ilustrativo da medida da espessura da parede do ramo portal de segunda ordem (Niamey Working Group, 2000)

\subsubsection{Avaliação dos vasos portais e das artérias hepática e esplênica}

$\mathrm{Na}$ avaliação do trato portal, foram medidos em milímetros os calibres do tronco da veia porta no hilo hepático, de seus ramos direito e esquerdo e das veias esplênica e mesentérica superior. A mensuração foi feita no sentido ântero-posterior, com o posicionamento dos "cálipers" junto às paredes internas do vaso. 
O tronco da veia porta foi medido na secção subcostal oblíqua direita no local de maior diâmetro, com o paciente em breve apneia, evitando-se a inspiração profunda (Figura 10).

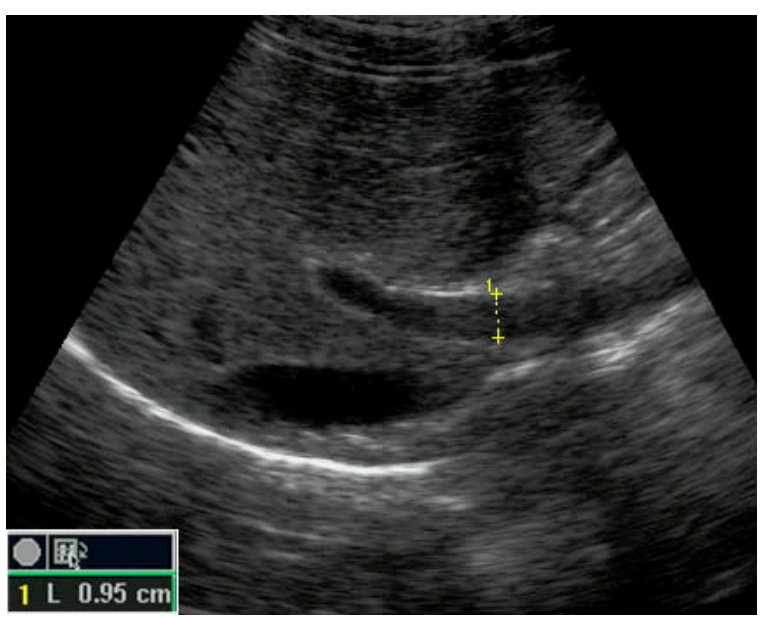

Figura 10. Medida do calibre do tronco da veia porta

Os ramos portais (direito e esquerdo) foram medidos na secção transhepática subcostal, logo após a bifurcação.

A veia esplênica foi medida na secção transversa subesternal, preferencialmente em sua porção posterior ao corpo pancreático (Figura 11a).

A medida do calibre da veia mesentérica superior foi obtida em secção longitudinal paraesternal, cerca de $2 \mathrm{~cm}$ caudalmente à confluência com a veia esplênica (Figura 11b). 


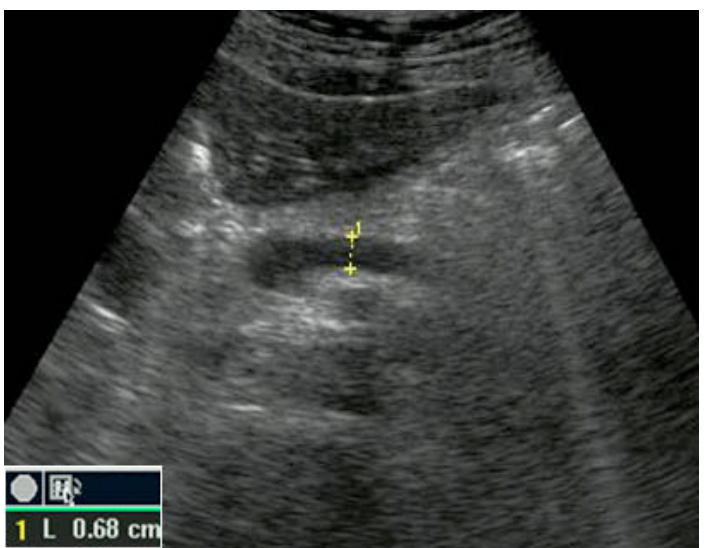

Figura 11. (a) Medida do calibre da veia esplênica

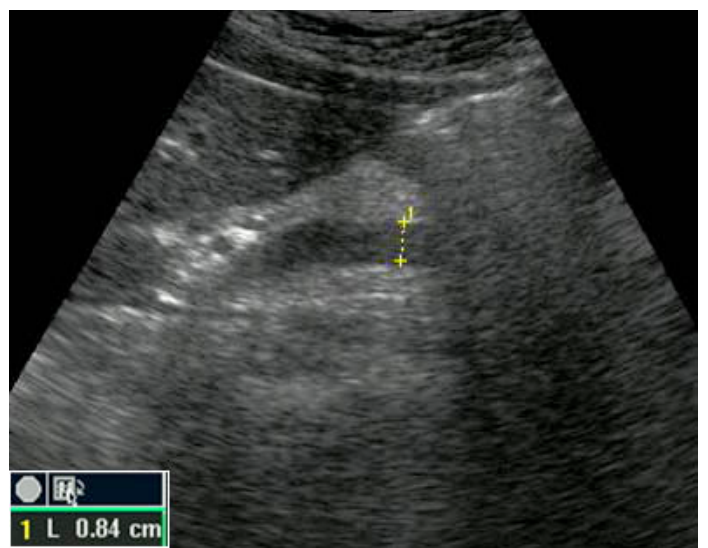

Figura 11. (b) Medida do calibre da veia mesentérica superior

Os diâmetros considerados normais foram de $12 \mathrm{~mm}$ para a veia porta e de $9 \mathrm{~mm}$ para as veias esplênica e mesentérica superior (Cerri, 1984a).

O calibre da artéria hepática foi mensurado em milímetros no hilo hepático, em posição anterior à veia porta (Figura 12); e o da artéria esplênica, cerca de $2 \mathrm{~cm}$ distalmente à sua emergência do tronco celíaco.

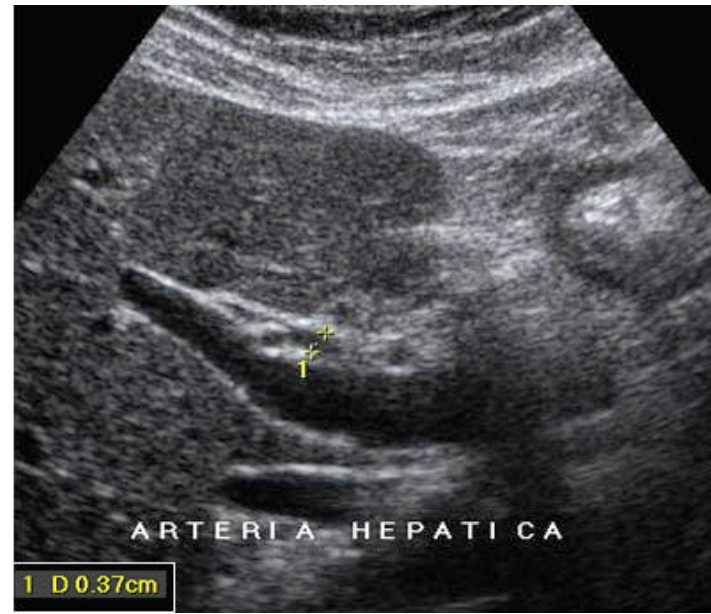

Figura 12. Medida do calibre da artéria hepática

Consideraram-se normais para o diâmetro da artéria hepática os valores de 3,8 $\mathrm{mm} \pm 0,8$ (Tziafalia et al., 2006). Não foram encontrados na literatura valores de referência para o diâmetro da artéria esplênica. 


\subsubsection{Avaliação do baço}

O comprimento longitudinal do baço foi medido em milímetros, através de seção intercostal oblíqua esquerda, sendo considerado normal o diâmetro máximo de 120 mm (Cerri, 1984a; Hatz, et al., 1992) (Figura 13a).

\subsubsection{Avaliação da vesícula biliar}

O estudo da vesícula biliar incluiu a medida da espessura parietal, que foi feita em milímetros no ponto mais espessado da parede anterior (melhor local para se evitarem artefatos). O plano de corte ideal para examinar a vesícula pode variar, devendo ser estudada no seu maior eixo longitudinal. Considerou-se normal a espessura parietal igual ou inferior a $5 \mathrm{~mm}$ (Cerri, 1984a; Pinto-Silva, 1992, Gerspacher-Lara et al., 1998) (Figura 13b). Foi também avaliada a presença de cálculos no interior da vesícula biliar e/ou de pólipos parietais.

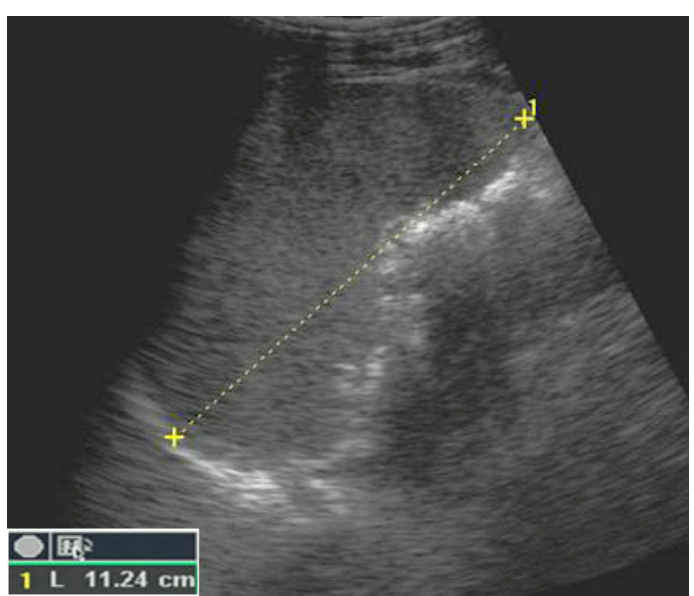

Figura 13. (a) Medida do diâmetro longitudinal do baço

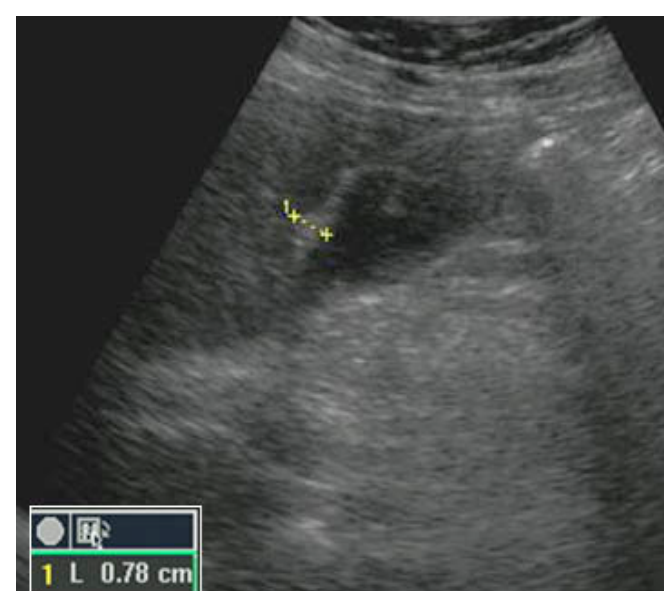

(b) Medida da espessura da parede da da vesícula biliar 


\subsubsection{Avaliação da circulação colateral}

As colaterais foram avaliadas quanto à presença, localização e calibre (medido em milímetros). Foram objeto de busca ativa as veias gástrica esquerda, paraumbilical, gástricas curtas e esplenorrenais espontâneas. $\mathrm{Na}$ iminência de outras colaterais, estas foram classificadas de acordo com sua localização.

O ligamento falciforme e o ramo esquerdo da veia porta foram os pontos anatômicos de referência para investigação da veia paraumbilical. A veia gástrica esquerda foi estudada próximo da confluência esplenomesentérica, em planos de corte transversais ou longitudinais oblíquos. As veias gástricas curtas foram pesquisadas no polo superior do baço, em plano de corte longitudinal na linha axilar média esquerda, com o transdutor angulado em direção cefálica. As veias esplenorrenais espontâneas foram avaliadas na região dos hilos esplênico e renal. Finalmente, toda a cavidade abdominal foi rastreada em busca de outras colaterais menos frequentes.

\subsubsection{Avaliação da cavidade abdominal}

A cavidade abdominal foi analisada à procura de linfonodos maiores que $10 \mathrm{~mm}$ (Downey,1998). Também foi averiguado se havia líquido livre na cavidade abdominal. 


\subsubsection{Sistematização do estudo Doppler}

O exame Doppler foi realizado imediatamente após a USG convencional, de acordo com protocolo elaborado especificamente para este estudo (Anexo C). Nesse protocolo, além da avaliação dopplervelocimétrica, foram novamente investigadas a presença, o grau, a distribuição do espessamento periportal e sua classificação de acordo com as pranchas do Niamey Working Group (2000).

Foram utilizados os mesmos decúbitos do exame modo B. As curvas espectrais foram obtidas em breve apneia, evitando-se a inspiração profunda ou manobra de Valsalva, minimizando-se o efeito da respiração sobre o fluxo portal.

O exame foi feito com transdutor convexo de 3,5 MHz. Como rotina, em primeiro lugar, os vasos eram identificados ao modo $B$, sendo em seguida aplicado o modo colorido para identificação de vasos de pequeno calibre como as artérias e pequenas colaterais, muitas vezes não visibilizadas pelo método convencional. Ainda pelo modo colorido, analisou-se a direção do fluxo. Pelo modo pulsado, com angulação de insonação do feixe Doppler inferior a $60^{\circ}$, posicionou-se a amostra de volume (cerca de $2 / 3$ do calibre) na luz do vaso em seu eixo longitudinal, obtendo-se a curva espectral do fluxo.

Foram padronizados locais fixos para a obtenção de amostra do sinal Doppler pulsado. 


\subsubsection{Análise dopplervelocimétrica dos vasos do sistema portal}

O protocolo do exame incluiu os seguintes itens: patência, direção e velocidade máxima de fluxo da veia porta, seus ramos direito e esquerdo, veias esplênica e mesentérica superior. A perviedade foi definida pelo preenchimento dos vasos ao Doppler colorido e obtenção de traçado espectral ao Doppler pulsado. A trombose total foi determinada pela ausência de fluxo e a parcial pela presença de fluxo ocupando apenas parcialmente a luz do vaso.

A direção do fluxo foi classificada como hepatopetal ou hepatofugal (em direção ao fígado ou afastando-se deste), determinada pelo Doppler colorido (aproximando ou afastando do transdutor) e pelo Doppler pulsado (traçado espectral acima ou abaixo da linha de base).

O fluxo da veia porta foi analisado no hilo hepático no nível da borda do fígado, em secção coronal intercostal, com o transdutor posicionado na linha axilar anterior. Desta forma, obtinha-se a imagem do eixo longitudinal do vaso com angulação inferior a $60^{\circ}$ (Figura 14).

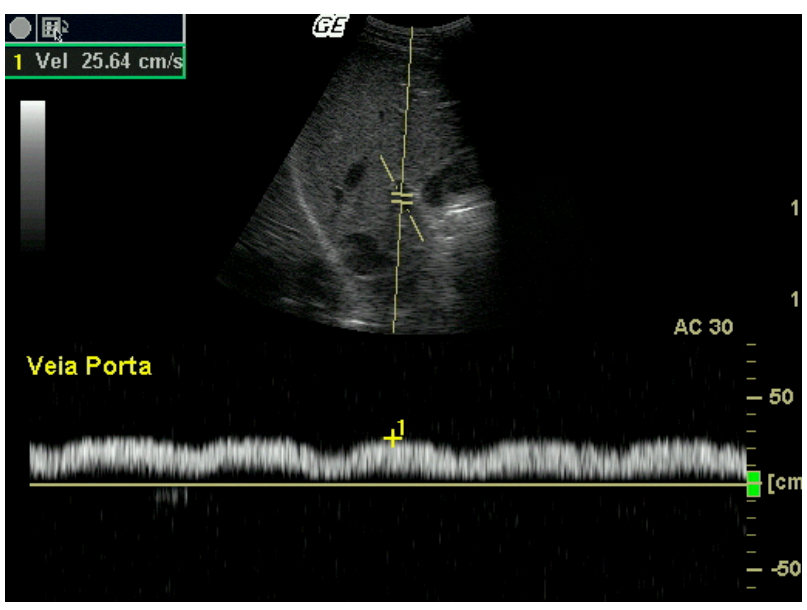

Figura 14. Análise dopplervelocimétrica da veia porta 
Os ramos direito e esquerdo da veia porta foram insonados em corte oblíquo subcostal, onde se identifica o "H" biliar. O volume de amostra foi posicionado a $1 \mathrm{~cm}$ da bifurcação, preservando-se o ângulo < $60^{\circ}$ (Figura 15).
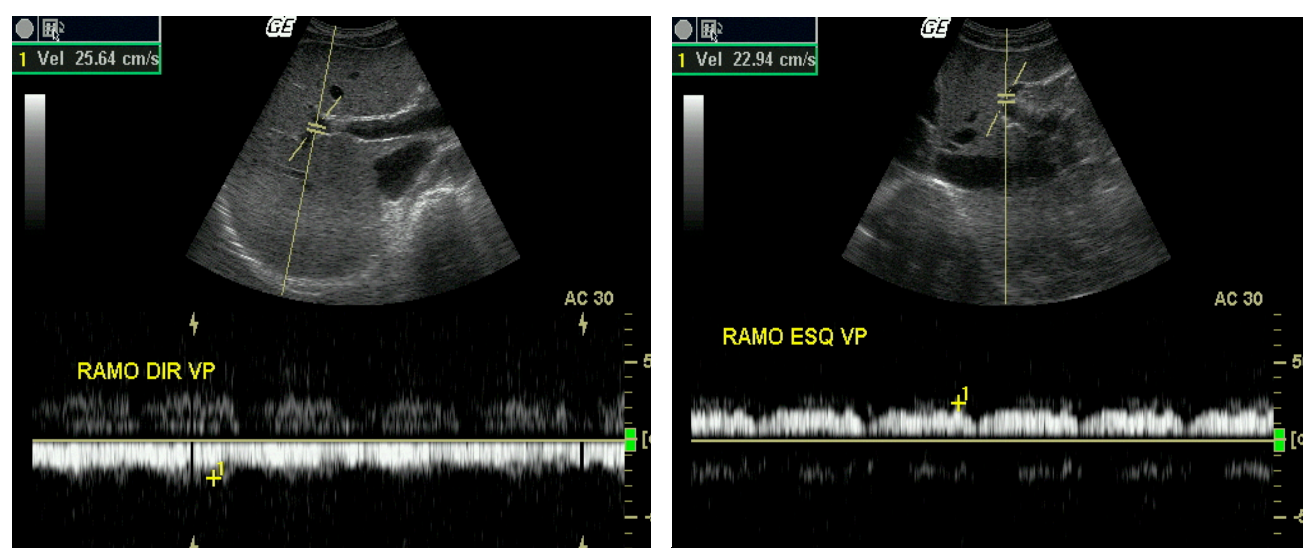

Figura 15. Análise dopplervelocimétrica dos ramos portais direito e esquerdo

A veia esplênica foi analisada em secção transversa subesternal ligeiramente obliquada. A aquisição da curva espectral se deu no segmento ascendente do vaso, onde era obtido o ângulo $<60^{\circ}$. A veia mesentérica superior foi insonada aproximadamente $2 \mathrm{~cm}$ abaixo da sua confluência com a veia esplênica, com transdutor posicionado longitudionalmente na linha mediana (Figura 16).
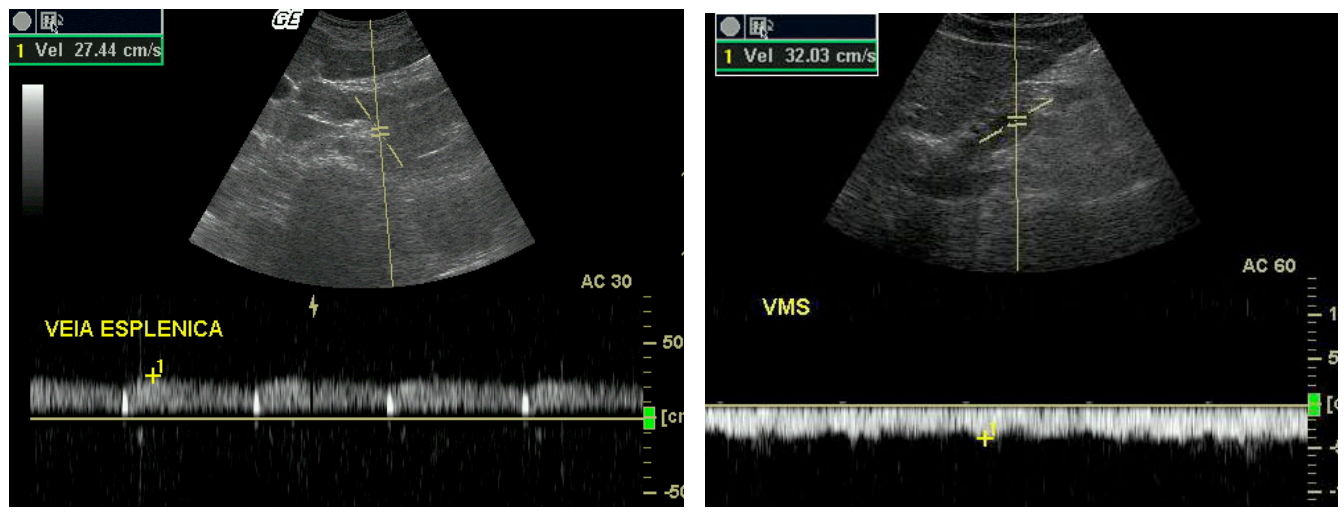

Figura 16. Análise dopplervelocimétrica das veias esplênica e mesentérica superior 
Em todos os vasos descritos, a amostra de volume do Doppler pulsado foi posicionada no centro da veia para aquisição da curva espectral; e com o "cáliper" colocado no ponto mais alto desta curva, foi medida a velocidade máxima do fluxo.

\subsubsection{Análise dopplervelocimétrica das artérias hepática e esplênica}

Nas artérias hepática e esplênica foram medidos o pico de velocidade sistólica e a velocidade diastólica final. O índice de resistividade foi calculado automaticamente pelo software específico do equipamento (operador independente).

A artéria hepática foi estudada no hilo hepático em posição anterior à veia porta, no mesmo corte utilizado na análise desta veia. A artéria esplênica foi avaliada em secção transversa subesternal ligeiramente obliquada, em seu segmento descendente junto à veia esplênica (Figura 17).
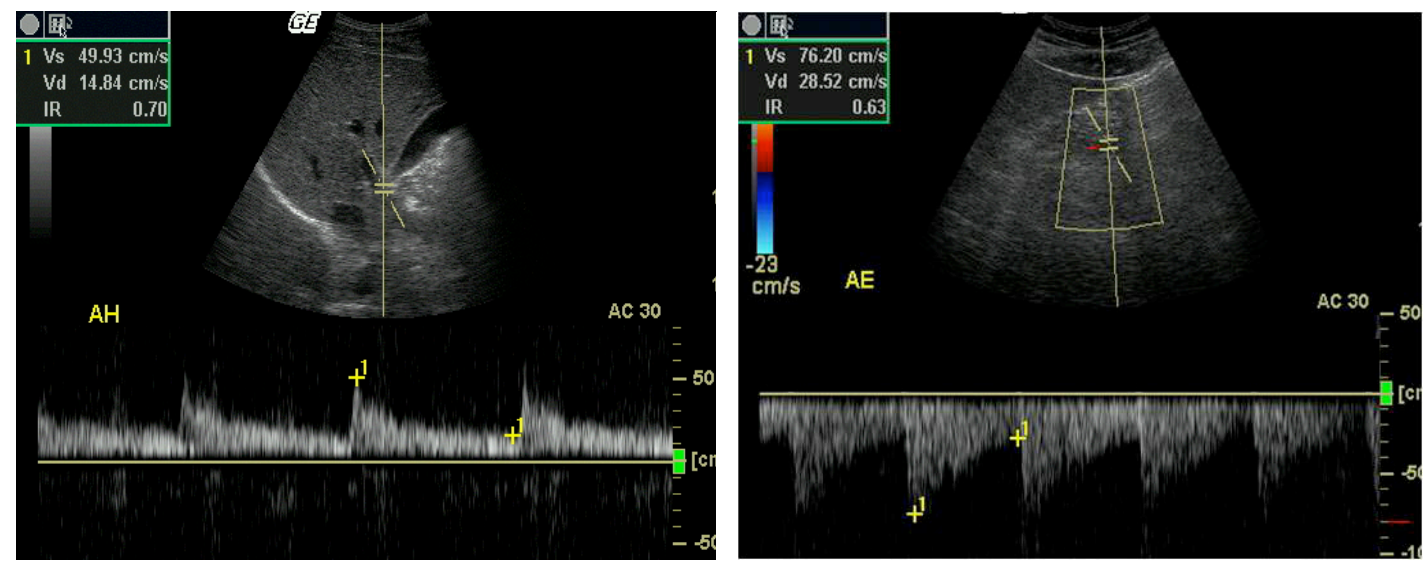

Figura 17. Análise dopplervelocimétrica das artérias hepática e esplênica 


\subsubsection{Análise dopplervelocimétrica da circulação colateral}

As colaterais foram investigadas quanto à localização, calibre, trajeto, direção e velocidade máxima de fluxo.

Uma vez identificado o vaso colateral e determinada sua localização e calibre, este foi insonado ao modo Doppler colorido e pulsado. A definição da direção e velocidade máxima de fluxo foi realizada da mesma maneira que nos vasos portais.

\subsubsection{Análise dopplervelocimétrica das veias hepáticas}

A análise das veias hepáticas foi realizada em corte oblíquo subcostal, onde são identificadas as três veias. Preferencialmente, foi insonada a veia hepática média e, quando não era possível obter um traçado espectral satisfatório nesta veia, foram insonadas as veias direita ou esquerda.

As veias hepáticas apresentam normalmente fluxo trifásico, com oscilação modulada pelo ciclo cardíaco. O traçado espectral característico apresenta duas ondas anterógradas (sístole e diástole ventricular) e uma retrógrada (contração atrial) (Bolondi et al., 1991).

Neste estudo, o traçado espectral foi classificado como: trifásico (presença de onda reversa); bifásico (redução da amplitude oscilatória com perda da onda reversa); ou monofásico (fluxo retificado), sendo o padrão trifásico considerado normal e os padrões bifásico e monofásico tidos como alterados (Figuras 18,19 e 20). 


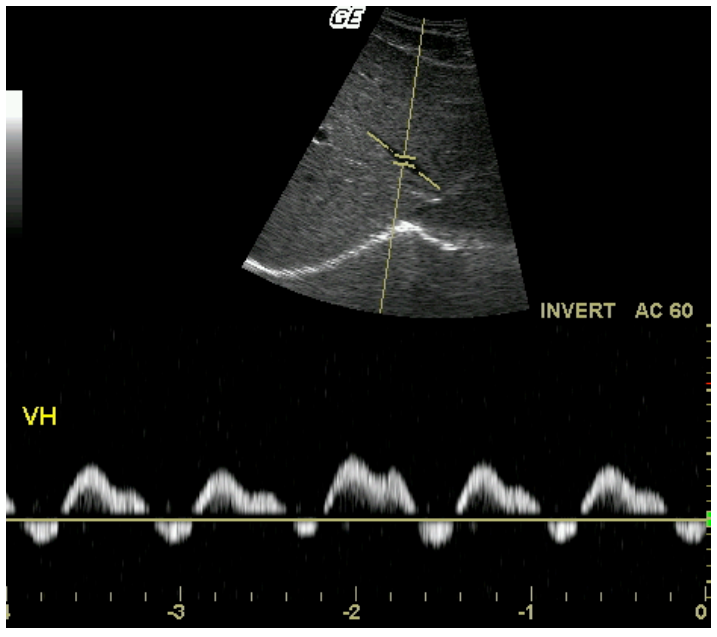

Figura 18. Padrão trifásico na veia hepática média

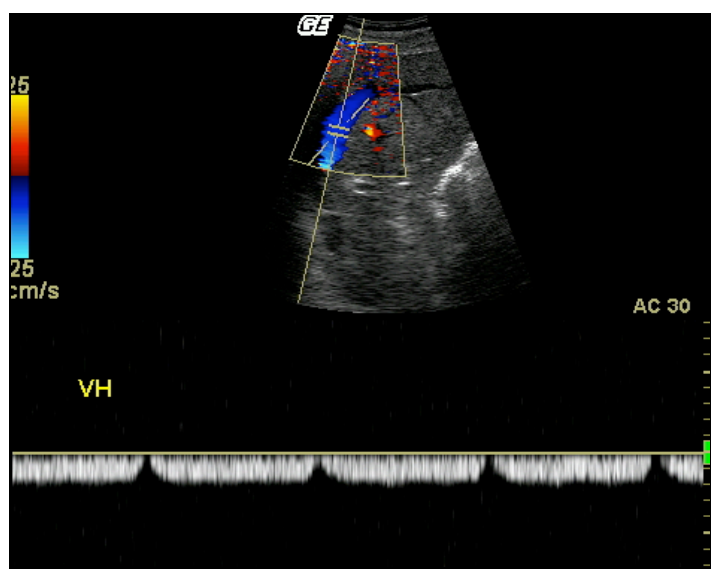

Figura 19. Padrão bifásico na veia hepática direita

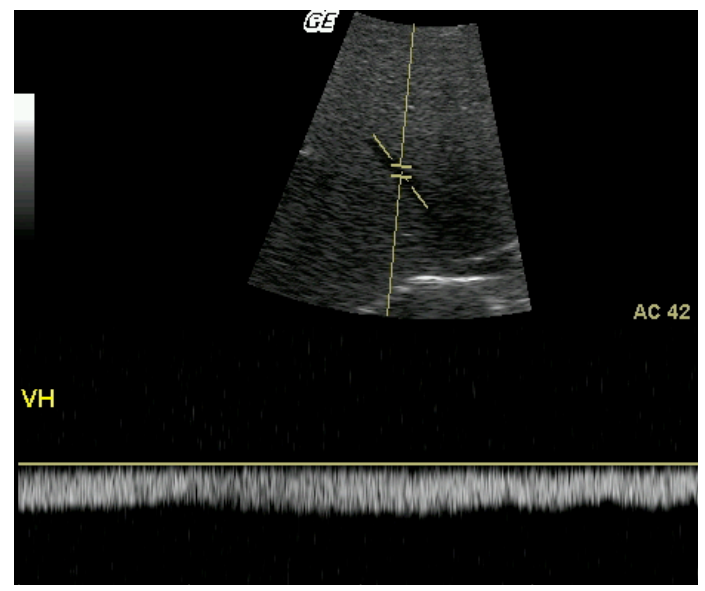

Figura 20. Padrão monofásico na veia hepática média 


\subsubsection{Aquisição e armazenamento das imagens}

A aquisição das imagens foi feita no formato Digital Imaging and Communications in Medicine. Foram armazenadas no equipamento por software específico para este fim e processadas para posterior reavaliação. As imagens encontram-se arquivadas no formato joint pictures expert group.

\subsubsection{Análise estatística}

\subsubsection{Estatísticas descritivas}

Para caracterização da amostra, fez-se uma análise descritiva das variáveis utilizadas no estudo. Para as variáveis qualitativas ou categóricas, foram elaboradas tabelas de distribuição de frequências. Já para as variáveis quantitativas ou contínuas empregaram-se medidas de tendência central e variabilidade.

\subsubsection{Comparação por área}

A caracterização da amostra também foi feita por local de realização dos exames (áreas de baixa, média ou alta endemicidade). Foram empregados o teste do qui-quadrado de Pearson para comparação de proporções ou teste exato de Fisher para comparação de proporções com 
pequenas frequências. $\mathrm{Na}$ avaliação de variáveis contínuas adotou-se o teste não-paramétrico de Kruskall-Walis para comparação de três grupos.

Optou-se por utilizar testes não-paramétricos para as variáveis contínuas, devido ao caráter assimétrico das variáveis testadas.

\subsubsection{Associações estatísticas}

Para as associações estatísticas entre as variáveis, foram utilizados o teste do qui-quadrado de Pearson para comparação de proporções ou o teste exato de Fisher para comparação de proporções com pequenas frequências.

$\mathrm{Na}$ associação de variáveis contínuas, empregou-se o teste nãoparamétrico de Mann-Whitney para comparação de dois grupos ou KruskallWalis para comparação de três ou mais grupos. Usou-se ainda o coeficiente de correlação de Spearman na comparação entre duas variáveis contínuas.

Optou-se por testes não-paramétricos para as variáveis contínuas, devido ao caráter assimétrico das variáveis testadas.

Foi utilizado o software Statistical Package for Social Sciences 12.0. Em todas as análises foi considerado o nível de $5 \%$ de significância. 
5. RESULTADOS 


\subsection{Resultados do exame ultrassonográfico modo $B$}

Observou-se no exame ultrassonográfico, número considerável de pacientes com acentuada presença de gases intestinais. Em uma parte dos casos, os artefados gerados pela interposição gasosa dificultaram a execução do estudo, chegando a impossibilitar a medida de algumas estruturas de interesse.

\subsubsection{Avaliação do figado}

As medidas dos lobos hepáticos encontram-se resumidas na Tabela 1. As médias das dimensões dos dois lobos foram mais altas na área de baixa endemicidade e mais baixas na área de alta endemicidade, com diferença significativa entre os grupos $(p<0,001)$.

Tabela 1 - Médias das dimensões, em milímetros, dos lobos direito e esquerdo do fígado, por área de endemicidade

\begin{tabular}{llcccccc}
\hline Área/ & & \multicolumn{3}{c}{ Lobo direito do fígado $^{1}$} & \multicolumn{2}{c}{ Lobo esquerdo do fígado $^{2}$} \\
\cline { 3 - 8 } endemicidade & & Média & $\begin{array}{l}\text { Desvio- } \\
\text { padrão }\end{array}$ & Mediana & Média & $\begin{array}{c}\text { Desvio- } \\
\text { padrão }\end{array}$ & Mediana \\
\hline Baixa & $\mathrm{n}=109$ & 139,9 & 13,4 & 142,0 & 89,8 & 15,3 & 88,0 \\
Média & $\mathrm{n}=255$ & 129,8 & 18,8 & 130,0 & 89,1 & 16,9 & 89,0 \\
Alta & $\mathrm{n}=190$ & 115,3 & 19,5 & 117,0 & 81,0 & 18,6 & 81,0 \\
TOTAL & $\mathrm{n}=554$ & 126,9 & 20,3 & 128,0 & 86,5 & 17,7 & 86,5 \\
\hline
\end{tabular}

*Teste Kruskall-Wallis $\quad 1-p<0,001 \quad 2-p<0,001$ 
Com valor de referência da normalidade de $110 \mathrm{~mm}$ (Machado et al., 2002), o aumento do lobo esquerdo do figado foi mais frequente na área de média endemicidade, sem, no entanto, apresentar diferença significativa entre os grupos $(p=0,130)$ (Tabela 2$)$.

O lobo direito do fígado mostrou-se reduzido, segundo os critérios do Niamey Working Group (2000), em maior número de pacientes da área de alta endemicidade, verificando-se diferença significativa entre os grupos $(p<0,001)($ Tabela 2).

Tabela 2 - Avaliação das dimensões do fígado, por área de endemicidade

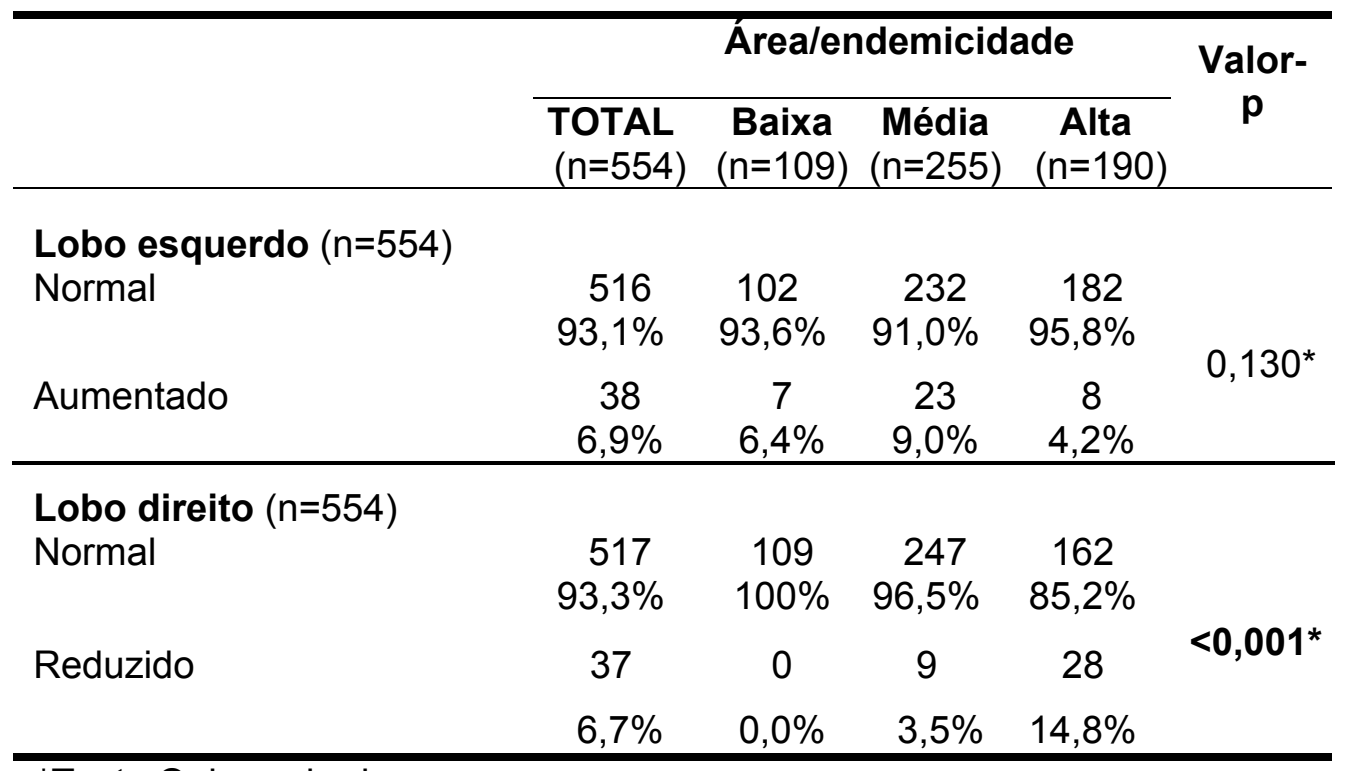

${ }^{*}$ Teste Qui-quadrado

Os contornos hepáticos estavam lisos em 544 pacientes e rugosos em dez $(1,8 \%)$, sendo um da área de baixa endemicidade, quatro da área de média endemicidade e cinco da área de alta endemicidade, sem diferença entre os grupos $(p=0,111)$. 
A análise das alterações hepáticas não relacionadas à EM feita em comparação com as pranchas de referência do Niamey Working Group (2000) evidenciou 47/554 (8,5\%) pacientes com aumento difuso da ecogenicidade do parênquima hepático (padrão Y-aspecto esteatótico), classificado como leve em 24 indivíduos e moderado em 23. Em 2/554 pacientes $(0,4 \%)$ foram encontradas lesões hepáticas focais (padrão Z), sendo um cisto simples e um nódulo sólido. Os pacientes com padrão $X$ (aspecto cirrótico) e padrão Y com aumento acentuado da ecogenicidade já haviam sido excluídos do estudo, conforme detalhado no capítulo 4.

\subsubsection{Avaliação do espessamento das paredes dos vasos portais}

\section{- Avaliação qualitativa}

Os resultados da avaliação qualitativa subjetiva da presença, grau e distribuição do espessamento periportal e sua classificação de acordo com as pranchas do Niamey Working Group (2000) (Figuras 21 a 26) estão disponibilizados na Tabela 3.

Quando comparados por área de endemicidade, os resultados da avaliação subjetiva quanto à presença e à intensidade de espessamento periportal demonstraram diferença significativa entre os grupos $(p<0,001)$, constatando-se a lesão mais prevalente e de graus mais acentuados na área de alta endemicidade. A distribuição do espessamento periportal ocorreu de 
forma semelhante entre os grupos, não havendo diferença estatisticamente significativa $(p=0,034)$ (Tabela 3$)$.

A distribuição dos padrões da OMS por área de endemicidade ocorreu com diferença significativa entre os grupos, observando-se nos pacientes da área de alta endemicidade percentual mais alto das formas mais graves de envolvimento hepático $(p<0,001)$. 
Tabela 3 - Avaliação qualitativa do espessamento periportal, por área de endemicidade

\begin{tabular}{|c|c|c|c|c|c|}
\hline & \multicolumn{4}{|c|}{ Área/ endemicidade } & \multirow{2}{*}{ Valor-p* } \\
\hline & TOTAL & Baixa & Média & Alta & \\
\hline \multicolumn{6}{|c|}{$\begin{array}{l}\text { Espessamento periportal } \\
(n=554)\end{array}$} \\
\hline Não & $\begin{array}{c}436 \\
78,7 \%\end{array}$ & $\begin{array}{c}104 \\
95,4 \%\end{array}$ & $\begin{array}{c}218 \\
85,5 \%\end{array}$ & $\begin{array}{c}114 \\
60,0 \%\end{array}$ & \multirow{2}{*}{$<0,001^{*}$} \\
\hline Sim & $\begin{array}{c}118 \\
21,3 \% \\
\end{array}$ & $\begin{array}{c}5 \\
4,6 \% \\
\end{array}$ & $\begin{array}{c}37 \\
14,5 \% \\
\end{array}$ & $\begin{array}{c}76 \\
40,0 \% \\
\end{array}$ & \\
\hline \multicolumn{6}{|c|}{$\begin{array}{l}\text { Grau do espessamento } \\
\text { periportal }(n=118)\end{array}$} \\
\hline Leve & $\begin{array}{c}80 \\
14,4 \%\end{array}$ & $\begin{array}{c}5 \\
4,6 \%\end{array}$ & $\begin{array}{c}31 \\
12,2 \%\end{array}$ & $\begin{array}{c}44 \\
23,2 \%\end{array}$ & \multirow{3}{*}{$<0,001^{*}$} \\
\hline Moderado & $\begin{array}{c}30 \\
5,4 \%\end{array}$ & $\begin{array}{c}0 \\
0,0 \%\end{array}$ & $\begin{array}{c}6 \\
2,4 \%\end{array}$ & $\begin{array}{c}24 \\
12,6 \%\end{array}$ & \\
\hline Intenso & $\begin{array}{c}8 \\
1,4 \% \\
\end{array}$ & $\begin{array}{c}0 \\
0,0 \% \\
\end{array}$ & $0,0 \%$ & $\begin{array}{c}8 \\
4,2 \% \\
\end{array}$ & \\
\hline \multicolumn{6}{|c|}{$\begin{array}{l}\text { Distribuição do espessamento } \\
\text { periportal }(n=118)\end{array}$} \\
\hline Central & $\begin{array}{c}61 \\
51,7 \%\end{array}$ & $\begin{array}{c}2 \\
40,0 \%\end{array}$ & $\begin{array}{c}24 \\
64,9 \%\end{array}$ & $\begin{array}{c}38 \\
50,0 \%\end{array}$ & \multirow{3}{*}{$0,034^{* *}$} \\
\hline Periférico & $\begin{array}{c}1 \\
0,8 \%\end{array}$ & $\begin{array}{c}1 \\
20,0 \%\end{array}$ & $\begin{array}{c}0 \\
0,0 \%\end{array}$ & $\begin{array}{c}0 \\
0,0 \%\end{array}$ & \\
\hline Central e periférico & $\begin{array}{c}56 \\
47,5 \% \\
\end{array}$ & $\begin{array}{c}2 \\
40,0 \% \\
\end{array}$ & $\begin{array}{c}13 \\
35,1 \% \\
\end{array}$ & $\begin{array}{c}38 \\
50,0 \% \\
\end{array}$ & \\
\hline \multicolumn{6}{|c|}{ Padrão da OMS $(n=554)$} \\
\hline \multirow[t]{2}{*}{ A } & 436 & 104 & 218 & 114 & \multirow{14}{*}{$<0,001^{* *}$} \\
\hline & $78,7 \%$ & $95,4 \%$ & $85,5 \%$ & $60,0 \%$ & \\
\hline \multirow[t]{2}{*}{ C } & 1 & 1 & 0 & 0 & \\
\hline & $0,2 \%$ & $0,9 \%$ & $0,0 \%$ & $0,0 \%$ & \\
\hline \multirow[t]{2}{*}{ D } & 55 & 2 & 22 & 31 & \\
\hline & $9,9 \%$ & $1,8 \%$ & $8,6 \%$ & $16,3 \%$ & \\
\hline \multirow[t]{2}{*}{ Dc } & 25 & 2 & 10 & 13 & \\
\hline & $4,5 \%$ & $1,8 \%$ & $3,9 \%$ & $6,8 \%$ & \\
\hline \multirow[t]{2}{*}{$E$} & 6 & 0 & 2 & 4 & \\
\hline & $1,1 \%$ & $0,0 \%$ & $0,8 \%$ & $2,1 \%$ & \\
\hline \multirow[t]{2}{*}{ Ec } & 24 & 0 & 3 & 21 & \\
\hline & $4,3 \%$ & $0,0 \%$ & $1,2 \%$ & $11,1 \%$ & \\
\hline \multirow[t]{2}{*}{ Fc } & 7 & 0 & 0 & 7 & \\
\hline & $1,3 \%$ & $0,0 \%$ & $0,0 \%$ & $3,7 \%$ & \\
\hline
\end{tabular}

*Teste Qui-quadrado **Teste exato de Fisher 

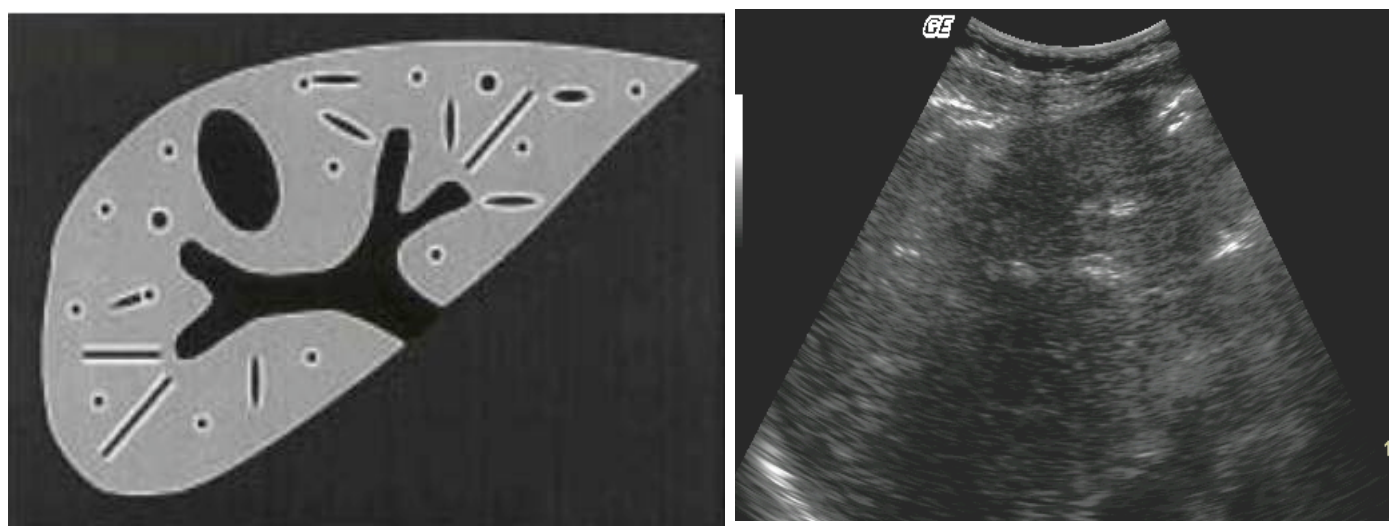

Figura 21. Desenho esquemático e imagem ultrassonográfica do padrão de acometimento " $C$ " - espessamento periportal apenas periférico (Niamey Working Group, 2000)
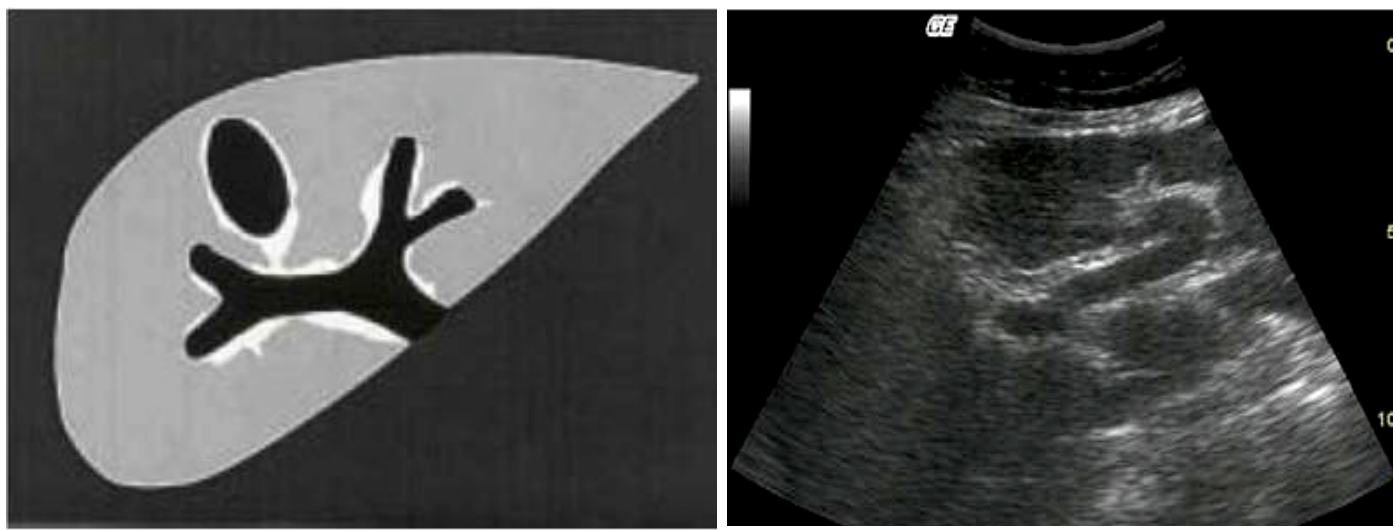

Figura 22. Desenho esquemático e imagem ultrassonográfica do padrão de acometimento " $D$ "- espessamento periportal central leve (Niamey Working Group, 2000)
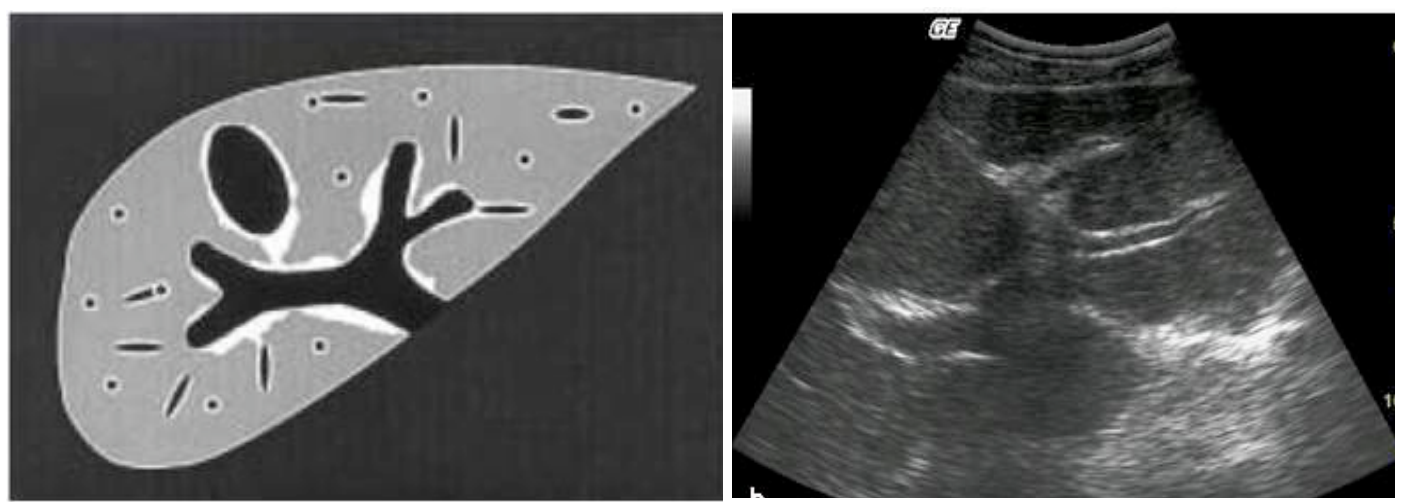

Figura 23. Desenho esquemático e imagem ultrassonográfica do padrão de acometimento "Dc" - central e periférico leve (Niamey Working Group, 2000) 

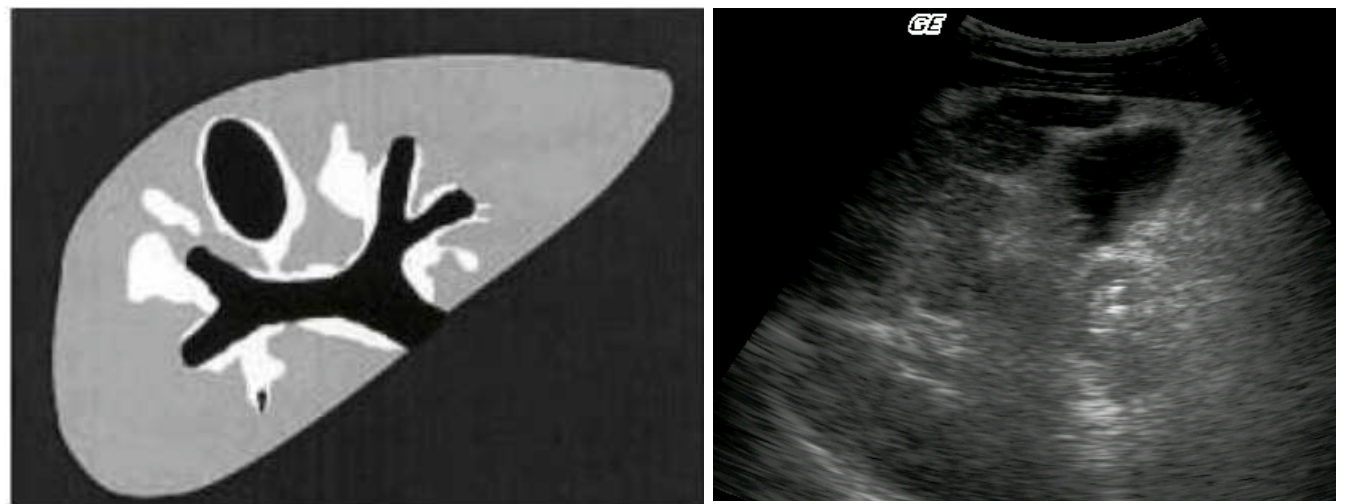

Figura 24. Desenho esquemático e imagem ultrassonográfica do padrão de acometimento "E"- espessamento periportal central moderado (Niamey Working Group, 2000)
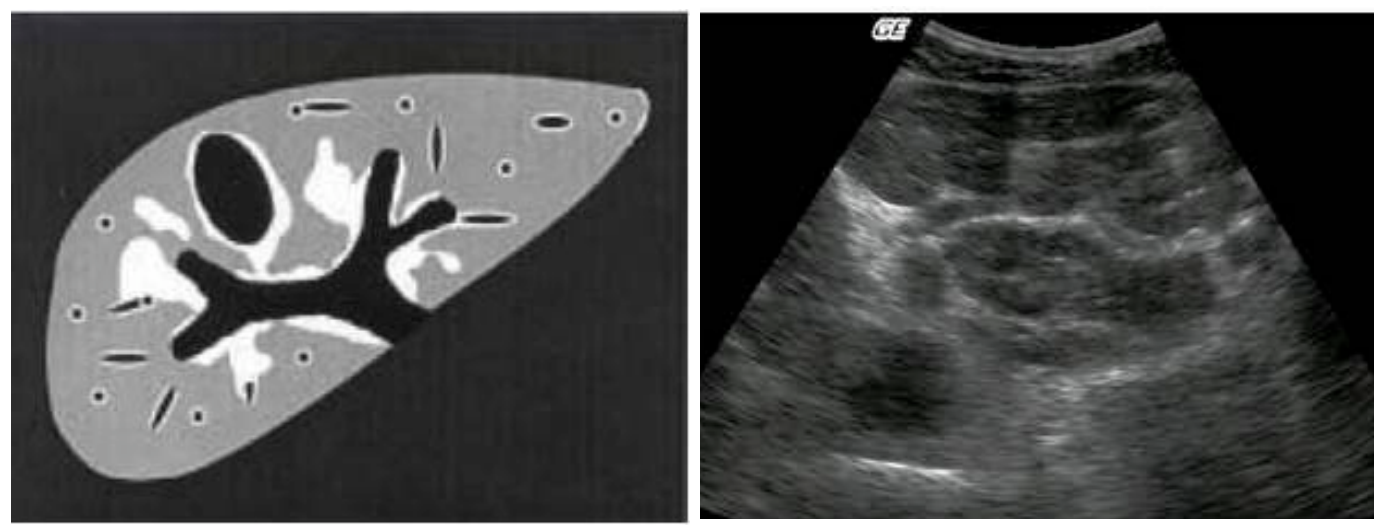

Figura 25. Desenho esquemático e imagem ultrassonográfica do padrão de acometimento "Ec"- central e periférico moderado (Niamey Working Group, 2000)
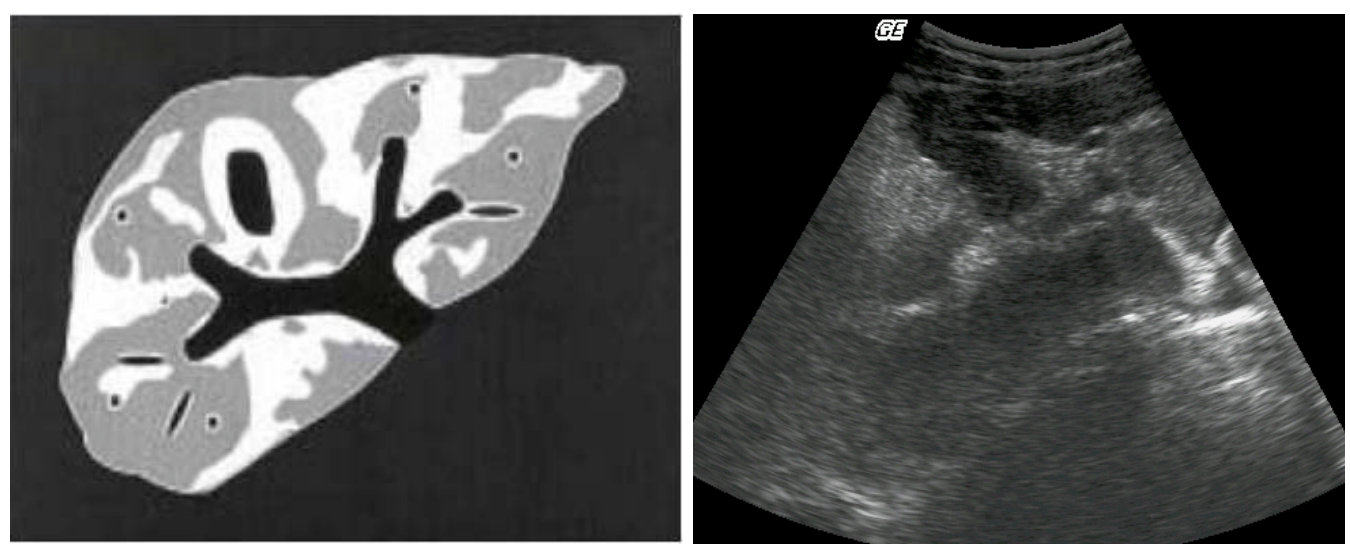

Figura 26. Desenho esquemático e imagem ultrassonográfica do padrão de acometimento "Fc"- central e periférico acentuado (Niamey Working Group, 2000) 


\section{- Avaliação quantitativa}

As medidas da espessura da parede portal obtidas nos três locais de referência do protocolo do Niamey Working Group apresentaram valores médios mais altos na área de alta endemicidade (hilo hepático: 3,9 versus 2,7 versus $2,5 \mathrm{~mm}$; bifurcação: 4,0 versus 2,9 versus $2,6 \mathrm{~mm}$ e ramo portal de segunda ordem: 2,9 versus 1,8 versus $1,8 \mathrm{~mm}$ ), salientando diferença significativa entre os grupos ( $p<0,001)$ (Anexo D, Tabelas A5 e A6).

Levando-se em conta a correção por altura adotada pelo Niamey Working Group (2000), a área de alta endemicidade apresentou o mais elevado número de pacientes com espessamento no ramo portal de segunda ordem (20/187-10,7\% entre 2 e 4 desvios e 20/187-10,7\% acima de 4 desvios), sendo a diferença significativa entre os grupos $(p<0,001)$.

\subsubsection{Avaliação dos vasos portais}

Os diâmetros médio e mediano da veia porta foram de 10,2 e 10,0 mm, respectivamente, com desvio-padrão de 1,8 mm e variação de 2,0 a 19,0 $\mathrm{mm}$, não demonstrando diferença significativa entre as áreas $(p=0,523)$ (Anexo D, Tabelas A5 e A6).

Tomando-se o valor de até $12 \mathrm{~mm}$ como referência da normalidade (Cerri, 1984a), 44/552 pacientes (8,0\%) apresentaram calibre aumentado na veia porta (Figura 27). 


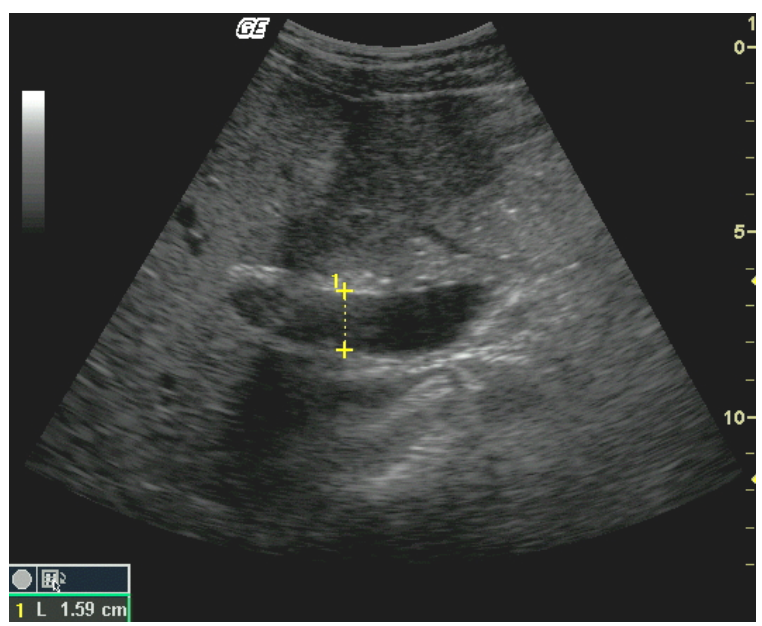

Figura 27. Veia porta de calibre aumentado $(15,9 \mathrm{~mm})$

Em dois pacientes $(0,4 \%)$ não foi possível obter o diâmetro da veia porta, em um caso por razões técnicas na realização do exame e no outro por trombose portal.

Na estratificação por área, o aumento do calibre da veia porta foi mais frequente na área de alta endemicidadade, com diferença significativa entre os grupos $(p<0,001)$ (Tabela 4$)$.

Os diâmetros médio e mediano da veia esplênica foram de 6,8 e 7,0 $\mathrm{mm}$, respectivamente, com desvio-padrão de $1,8 \mathrm{~mm}$, sem diferença significativa entre as áreas $(p=0,322)$ (Anexo $D$, Tabelas A5 e A6).

Os diâmetros médio e mediano da veia mesentérica superior mediram 7,4 e 7,0 mm, respectivamente, com desvio-padrão de 1,6 mm. $\mathrm{Na}$ comparação por área, o diâmetro foi maior na de alta endemicidade $(7,7$ $\mathrm{mm}$ ), com diferença significativa entre os grupos $(p=0,024)$ (Anexo $D$, Tabelas A5 e A6).

Considerando-se os valores de referência de até $9 \mathrm{~mm}$ para ambos os vasos (Cerri, 1984a), a área de alta endemicidade ressaltou número mais 
alto de pacientes com dilatação das veias esplênica e mesentérica superior, sendo a diferença significativa entre os grupos $(p<0,001)$ (Tabela 4).

Não foi possível avaliar a veia mesentérica superior em seis pacientes $(1,1 \%)$ nem a veia esplênica em quatro $(0,7 \%)$, devido à interposição gasosa de alças intestinais.

Tabela 4 - Análise do calibre das veias porta, esplênica e mesentérica superior, por área de endemicidade

\begin{tabular}{|c|c|c|c|c|c|}
\hline & & & Área & & \\
\hline & TOTAL & $\begin{array}{l}\text { Baixa } \\
n=109\end{array}$ & $\begin{array}{l}\text { Média } \\
\mathrm{n}=255\end{array}$ & $\begin{array}{c}\text { Alta } \\
\mathrm{n}=188\end{array}$ & paluita \\
\hline $\begin{array}{l}\text { Calibre da } \\
(n=552)\end{array}$ & & & & & \\
\hline Normal & 508 & 105 & 237 & 166 & \\
\hline & $92,0 \%$ & $96,3 \%$ & $92,9 \%$ & $88,3 \%$ & $<0,001$ \\
\hline Aumentado & 44 & 4 & 18 & 22 & \\
\hline & $8,0 \%$ & $3,7 \%$ & $7,1 \%$ & $11,7 \%$ & \\
\hline $\begin{array}{l}\text { Calibre da } \\
(n=550)\end{array}$ & & & & & \\
\hline Normal & 524 & 108 & 251 & 165 & \\
\hline & $95,3 \%$ & $99,1 \%$ & $98,4 \%$ & $88,7 \%$ & $<0,001$ \\
\hline Aumentado & 26 & 1 & 4 & 21 & \\
\hline & $4,7 \%$ &, $9 \%$ & $1,6 \%$ & $11,3 \%$ & \\
\hline $\begin{array}{l}\text { Calibre da } \\
\text { superior }(n=\end{array}$ & & & & & \\
\hline Normal & $\begin{array}{c}517 \\
94,3 \%\end{array}$ & $\begin{array}{c}106 \\
97,2 \%\end{array}$ & $\begin{array}{c}243 \\
96,1 \%\end{array}$ & $\begin{array}{c}168 \\
89,8 \%\end{array}$ & $<0,001$ \\
\hline Aumentado & $\begin{array}{c}31 \\
5,7 \%\end{array}$ & $\begin{array}{c}3 \\
2,8 \%\end{array}$ & $\begin{array}{c}9 \\
3,6 \%\end{array}$ & $\begin{array}{c}19 \\
10,2 \%\end{array}$ & \\
\hline
\end{tabular}

*Teste exato de Fisher

Os diâmetros dos ramos direito e esquerdo da veia porta tiveram média e mediana de 6,8 e 6,7 mm, respectivamente, variando de 3,5 a 11,2 
mm e de 3,7 a 11,0 mm, com desvio-padrão de 1,1 mm. Na distribuição por áreas, houve diferença significativa entre os grupos, sendo encontrados valores mais elevados na área de média endemicidade (Anexo D, Tabelas A5 e A6). Por razões técnicas na realização do exame, não foi possível avaliar o ramo portal direito em dez pacientes e o ramo esquerdo em nove.

\subsubsection{Avaliação das artérias hepática e esplênica}

O diâmetro da artéria hepática teve média de 3,5 mm e mediana de 3,5 $\mathrm{mm}$, com variação de 2,1 a 5,4 mm e desvio-padrão de 0,6 mm (Anexo D, Tabela A5). Levando-se em conta o valor de referência para a normalidade $(3,8 \mathrm{~mm} \pm 0,8)$ (Tziafalia et al., 2006), destacaram-se apenas 5/481 pacientes $(1,0 \%)$ com o diâmetro da artéria hepática aumentado: dois na área de média e três na área de alta endemicidade.

O diâmetro da artéria esplênica teve média de $3,9 \mathrm{~mm}$ e mediana de 3,8 mm, mínimo de 2,2 e máximo de $12,3 \mathrm{~mm}$ e desvio-padrão de $0,7 \mathrm{~mm}$ (Anexo D, Tabela A5).

A distribuição desses resultados entre as áreas ocorreu de forma semelhante, não havendo diferença estatisticamente significativa entre os grupos (Anexo D, Tabela A6).

A maior dificuldade técnica do protocolo ocorreu na avaliação das artérias. O calibre pequeno dos vasos associado às suas localizações, geralmente com sobreposição acentuada de gases, impossibilitou a identificação da artéria esplênica em $80 / 554$ pacientes $(14,4 \%)$. Em relação 
à artéria hepática, além da interposição gasosa, a presença de fibrose na região do hilo hepático nos casos avançados da doença, impediu sua visibilização em 73/554 pacientes (13,2\%).

\subsubsection{Avaliação do baço}

O diâmetro longitudinal do baço variou de 34 a 232 mm, com média de $91,8 \mathrm{~mm}$, mediana de $90 \mathrm{~mm}$ e desvio-padrão de 23,6 mm. O diâmetro foi maior na área de alta endemicidade, sem, contudo, apresentar diferença significativa entre as áreas $(p=0,768)$ (Anexo $D$, Tabelas A5 e A6).

Com base no valor de referência de até 120 mm (Cerri, 1984a; Hatz et al., 1992), a esplenomegalia foi mais evidente na área de alta endemicidade (Figura 28), com diferença significativa entre as áreas $(p<0,001)$ (Tabela 5).

Tabela 5 - Avaliação do diâmetro longitudinal do baço, por área de endemicidade

\begin{tabular}{lccccc}
\hline & TOTAL & \multicolumn{3}{c}{ Área } & \multirow{2}{*}{$\begin{array}{c}\text { Valor- } \\
\mathbf{p}^{*}\end{array}$} \\
\cline { 3 - 5 } & & Baixa & Média & Alta & \\
\hline $\begin{array}{l}\text { Diâmetro longitudinal do baço } \\
(\mathrm{n}=554)\end{array}$ & & & & & \\
Normal & 512 & 108 & 242 & 162 & \\
& $92,4 \%$ & $99,1 \%$ & $94,9 \%$ & $85,3 \%$ & \\
Aumentado & 42 & 1 & 13 & 28 & $<0,001$ \\
& $7,6 \%$ & $0,9 \%$ & $5,1 \%$ & $14,7 \%$ & \\
\hline
\end{tabular}

*Teste exato de Fisher 


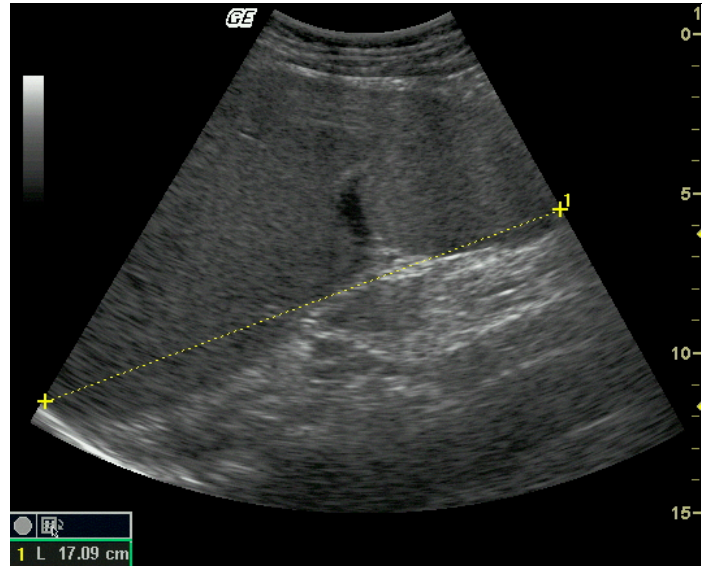

Figura 28. Esplenomegalia (baço com diâmetro longitudinal de $17,1 \mathrm{~mm}$ )

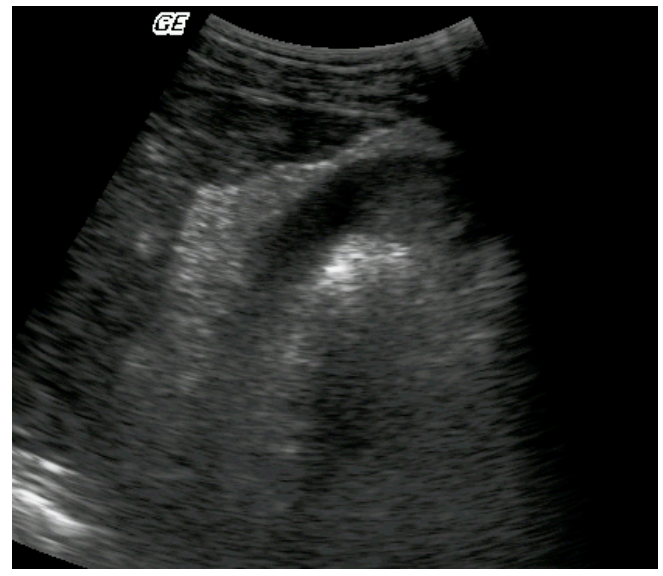

Figura 29. Acentuado espessamento da da parede da vesícula biliar

\subsubsection{Avaliação da vesícula biliar}

A vesícula biliar foi avaliada em 548 pacientes, já que seis eram colecistectomizados. A espessura da parede variou de 1 a $22 \mathrm{~mm}$, com média de 3,0 mm, mediana de $2,0 \mathrm{~mm}$ e desvio-padrão de 2,5 mm. A estratificação por área de endemicidade apresentou diferença significativa $(p<0,001)$ e as maiores medidas foram encontradas na área de alta endemicidade (média de 4,3 mm) (Anexo D, Tabelas A5 e A6).

Quando se adotou o valor de referência para a espessura da parede da vesícula biliar de até 5 mm (Cerri, 1984a; Pinto-Silva, 1992; Gerspacher-Lara et al., 1997), foram identificados 50/548 $(9,1 \%)$ pacientes com paredes espessadas (Figura 29).

Quando analisados por área de endemicidade, observou-se frequência de espessamento significativamente mais alta na área de alta endemicidade, com diferença entre os grupos ( $p<0,001)$ (Tabela 6). 
Tabela 6 - Avaliação da espessura da parede da vesícula biliar, por área de endemicidade

\begin{tabular}{|c|c|c|c|c|c|}
\hline & \multirow[b]{2}{*}{ TOTAL } & \multicolumn{3}{|c|}{ Área } & \multirow{2}{*}{$\begin{array}{c}\text { Valor- } \\
p^{*}\end{array}$} \\
\hline & & $\begin{array}{c}\text { Baixa } \\
(n=108)\end{array}$ & $\begin{array}{c}\text { Média } \\
(n=252)\end{array}$ & $\begin{array}{c}\text { Alta } \\
(n=188)\end{array}$ & \\
\hline \multicolumn{6}{|c|}{$\begin{array}{l}\text { Parede da vesícula biliar } \\
(n=548)\end{array}$} \\
\hline \multirow[t]{2}{*}{ Normal } & 498 & 107 & 245 & 146 & \multirow{4}{*}{$<0,001$} \\
\hline & $90,9 \%$ & $99,1 \%$ & $97,2 \%$ & $77,7 \%$ & \\
\hline \multirow[t]{2}{*}{ Espessada } & 50 & 1 & 7 & 42 & \\
\hline & $9,1 \%$ & $0,9 \%$ & $2,7 \%$ & $22,3 \%$ & \\
\hline
\end{tabular}

*Teste exato de Fisher

Também foi avaliada a presença de cálculos no interior da vesícula e de nódulos parietais sugestivos de pólipos, tendo sido encontrados 14/548 $(2,5 \%)$ pacientes com colelitíase (cinco da área de média endemicidade e nove da área de alta endemicidade) e 1/548 (0,2\%) da área de alta endemicidade com nódulo parietal sugestivo de pólipo vesicular.

\subsubsection{Avaliação da circulação colateral}

Em 10/554 pacientes (1,8\%) foi observado algum tipo de vaso colateral ao modo B.

A colateral mais frequente foi a veia gástrica esquerda, percebida em oito casos. Além destas, foram registrados dois casos de colaterais retroperitoneais e dois de veias gástricas curtas. Em dois pacientes havia mais de um tipo de colateral (gástrica esquerda e gástricas curtas). 
Todas as colaterais foram identificadas em pacientes da área de alta endemicidade, sendo a diferença estatisticamente significativa entre os grupos $(p<0,001)$.

\subsubsection{Avaliação da cavidade abdominal}

Em nenhum paciente evidenciou-se linfonodomegalia ou ascite.

\subsection{Exame ultrassonográfico Doppler}

\subsubsection{Análise dopplervelocimétrica dos vasos do sistema portal}

Os resultados dopplervelocimétricos das veias porta, esplênica, mesentérica superior e ramos portais direito e esquerdo encontram-se na Tabela 7. A distribuição por área de endemicidade revelou diferença significativa entre os grupos, com valores inferiores na área de alta endemicidade (Anexo D, Tabela A7).

De acordo com o valor de referência $(\geq 15 \mathrm{~cm} / \mathrm{s}$ ) para a velocidade normal na veia porta (Zironi et al., 1992), foram registrados $14 / 552$ casos $(2,5 \%)$ com velocidade portal reduzida, todos na área de alta endemicidade. Em três pacientes, a redução da velocidade estava associada à presença de colaterais gástricas esquerdas com fluxo hepatofugal. 
Em um paciente da área de alta endemicidade não houve detecção de sinal Doppler colorido ou pulsado, caracterizando-se trombose total da veia porta. Nesse paciente foi constatada colateral gástrica esquerda, com fluxo hepatofugal com velocidade de $22,4 \mathrm{~cm} / \mathrm{s}$.

Por razões técnicas, não foi possível obter a velocidade de fluxo na veias porta em um paciente, esplênica em treze pacientes, mesentérica superior em 22 pacientes, no ramo portal direito em quatorze e no esquerdo em treze.

Tabela 7 - Médias das velocidades máximas de fluxo na veia porta, ramos portais direito e esquerdo, veias esplênica e mesentérica superior $(\mathrm{cm} / \mathrm{s})$

\begin{tabular}{lcccccc}
\hline & N & Média & Mediana & DP & Mínimo & Máximo \\
\hline Veia porta & 552 & 23,1 & 22,2 & 6,3 & 12,0 & 55,6 \\
Ramo direito & 540 & 20,4 & 19,3 & 4,7 & 10,8 & 43,9 \\
Ramo esquerdo & 541 & 20,0 & 18,9 & 4,8 & 11,2 & 47,3 \\
Veia esplênica & 541 & 22,4 & 22,0 & 5,0 & 11,9 & 44,5 \\
Veia mesentérica superior & 532 & 27,6 & 27,4 & 6,0 & 14,4 & 55,2 \\
\hline
\end{tabular}

Quanto à direção do fluxo, em 553/554 (99,8\%) pacientes este era hepatopetal na veia porta e em seus ramos. Em apenas um $(0,2 \%)$ detectouse fluxo hepatofugal de baixa velocidade na veia porta e no ramo portal direito. Em todos os casos o fluxo foi hepatopetal nas veias esplênica e mesentérica superior. 


\subsubsection{Análise dopplervelocimétrica das artérias hepática e esplênica}

A Tabela 8 traz os resultados dopplervelocimétricos das artérias hepática e esplênica.

Considerando-se os valores normais de 0,69 \pm 0,16 (Paulson et al., 1997), todos os pacientes apresentaram valores do índice de resistividade da artéria hepática dentro dos limites da normalidade.

As artérias não foram identificadas ou não foi obtida a curva espectral adequada para mensuração das velocidades em 84/554 pacientes $(15,1 \%)$ no caso da artéria hepática e em $83 / 554$ pacientes $(15,0 \%)$ no caso da artéria esplênica.

Tabela 8 - Médias das velocidades de pico sistólico, diástole final e índice de resistividade das artérias hepática e esplênica $(\mathrm{cm} / \mathrm{s})$

\begin{tabular}{lcccccc}
\hline & N & Média & Mediana & DP & Mínimo & Máximo \\
\hline Pico sistólico da artéria hepática & 470 & 80,1 & 77,7 & 23,6 & 33,8 & 195,3 \\
Diástole final da artéria hepática & 470 & 23,6 & 22,7 & 7,0 & 8,9 & 52,3 \\
$\begin{array}{l}\text { Índice de resistividade da artéria } \\
\text { hepática }\end{array}$ & 470 & 0,70 & 0,70 & 0,0 & 0,60 & 0,80 \\
$\begin{array}{l}\text { Pico sistólico da artéria esplênica } \\
\text { Diástole final da artéria esplênica }\end{array}$ & 471 & 82,0 & 81,1 & 18,6 & 38,3 & 129,5 \\
$\begin{array}{l}\text { Índice de resistividade da artéria } \\
\text { esplênica }\end{array}$ & 471 & 0,60 & 0,60 & 0,1 & 0,50 & 0,70 \\
\hline
\end{tabular}

$\mathrm{Na}$ distribuição por área de endemicidade, as velocidades de pico sistólico da artéria hepática e diástole final de ambas as artérias 
apresentaram diferença significativa entre os grupos. As demais medidas tiveram valores semelhantes nas três áreas (Anexo $D$, Tabela A7).

\subsubsection{Análise dopplervelocimétrica dos vasos colaterais}

Foram identificados, ao Doppler, quinze vasos colaterais em onze pacientes (quatro com mais de um tipo de colateral) da área de alta endemicidade, representando $2,7 \%$ da amostra total e $7,9 \%$ dessa área. A colateral mais frequente foi a veia gástrica esquerda (sete casos), seguida pelas colaterais retroperitoneais (quatro), gástricas curtas (dois), paraumbilical (um) e shunt porto-sistêmico intra-hepático espontâneo (um caso) (Gráfico 1).

Gráfico 1 - Frequência dos tipos de colaterais

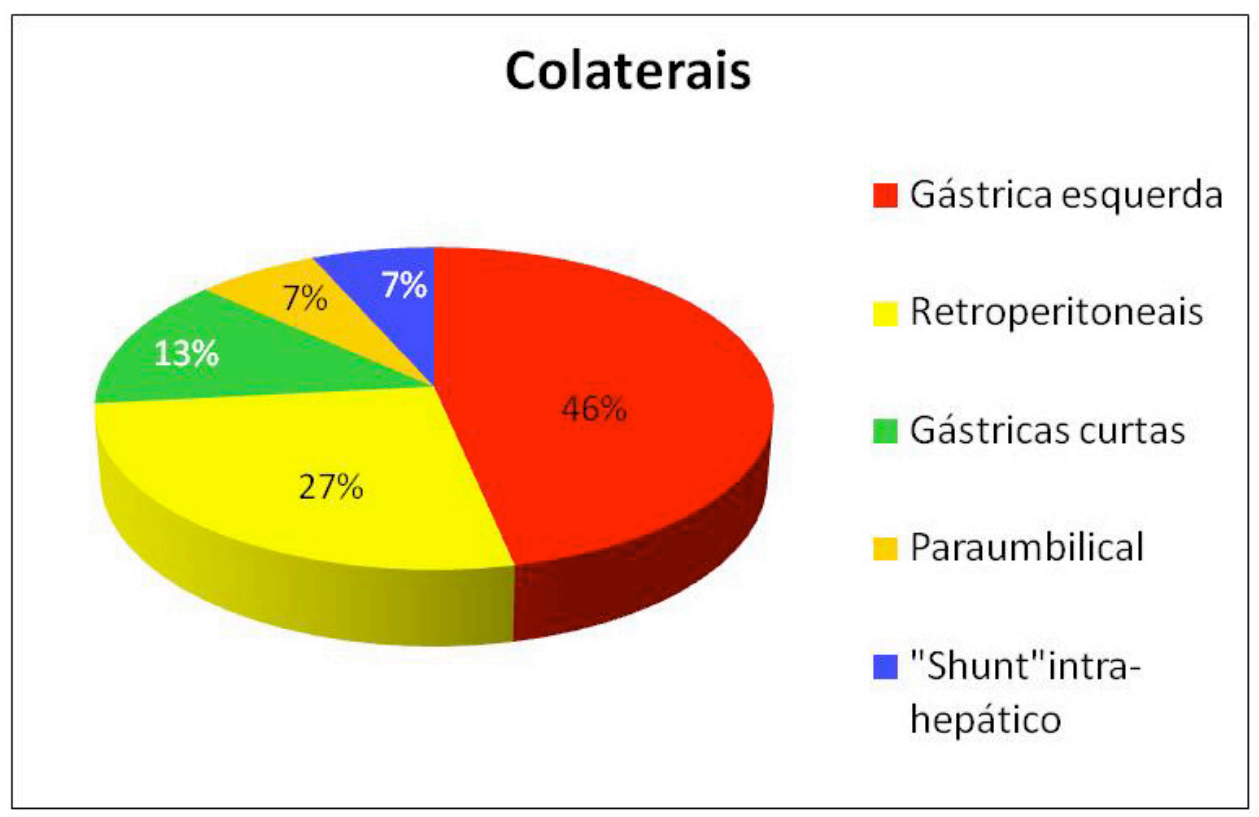

A veia paraumbilical dilatada, dois casos de colaterais retroperitoneais e dois shunts porto-sistêmicos intra-hepáticos (em um mesmo paciente) foram 
identificados apenas ao Doppler, não tendo sido visibilizados ao modo B. Os shunts haviam sido diagnosticados como cistos hepáticos ao exame convencional.

As veias gástricas esquerdas mostraram diâmetros bastante variados (de 6,6 a 24,2 mm). Quanto à direção do fluxo, em todas era hepatofugal, com velocidades máximas que variaram de 17,4 a $27,8 \mathrm{~cm} / \mathrm{s}$ (Figuras 30 e 31). Em todos os casos, a velocidade máxima da colateral era superior à da veia porta.
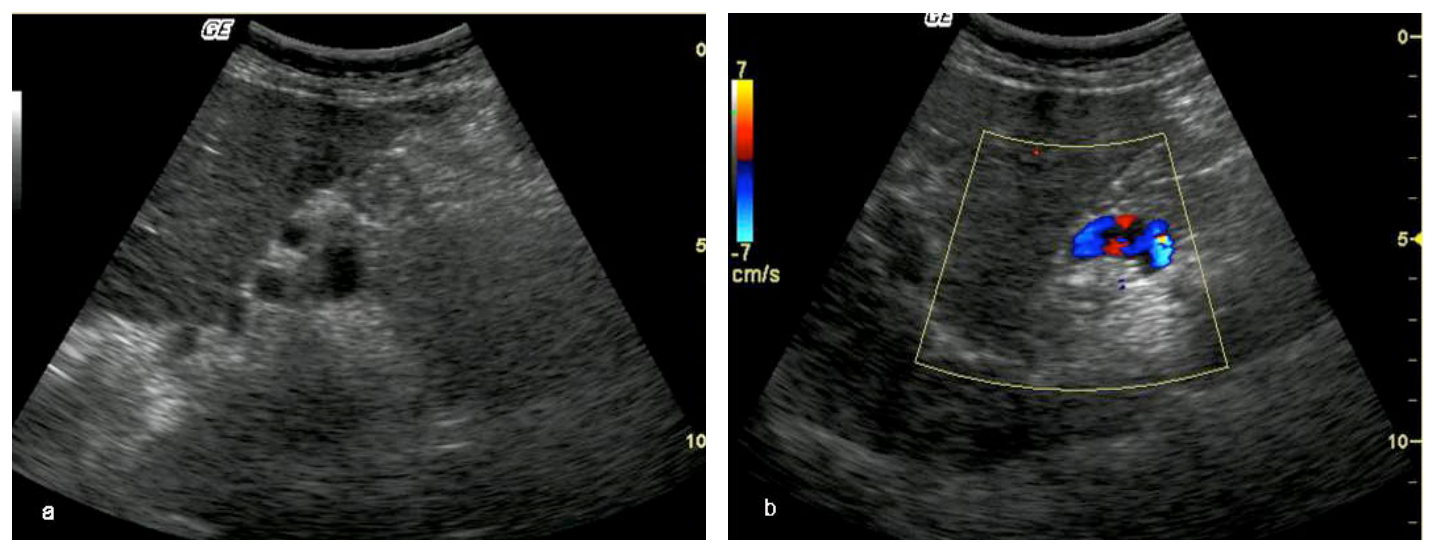

Figura 30. Colateral gástrica esquerda. Vaso serpiginoso adjacente ao lobo esquerdo do figado ao modo B (a). Fluxo hepatofugal ao modo colorido (b)
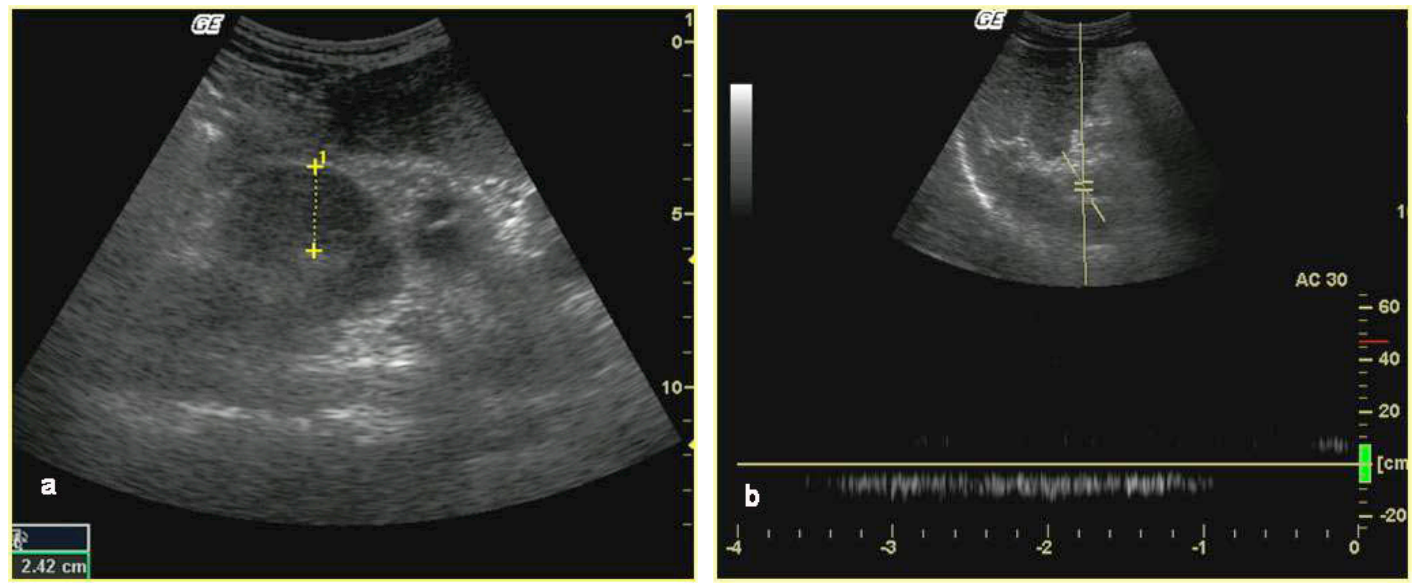

Figura 31. Veia gástrica esquerda calibrosa $(24,2 \mathrm{~mm})(\mathrm{a})$. Veia porta com fluxo hepatofugal de baixa velocidade $(b)$ 
A veia paraumbilical foi visibilizada como estrutura vascular emergindo do ramo esquerdo da veia porta e abandonando o fígado com trajeto caudal em topografia subcutânea até a cicatriz umbilical. Apresentou calibre de 7,6 mm e fluxo hepatofugal com velocidade máxima de 18,2 cm/s (Figura 32).

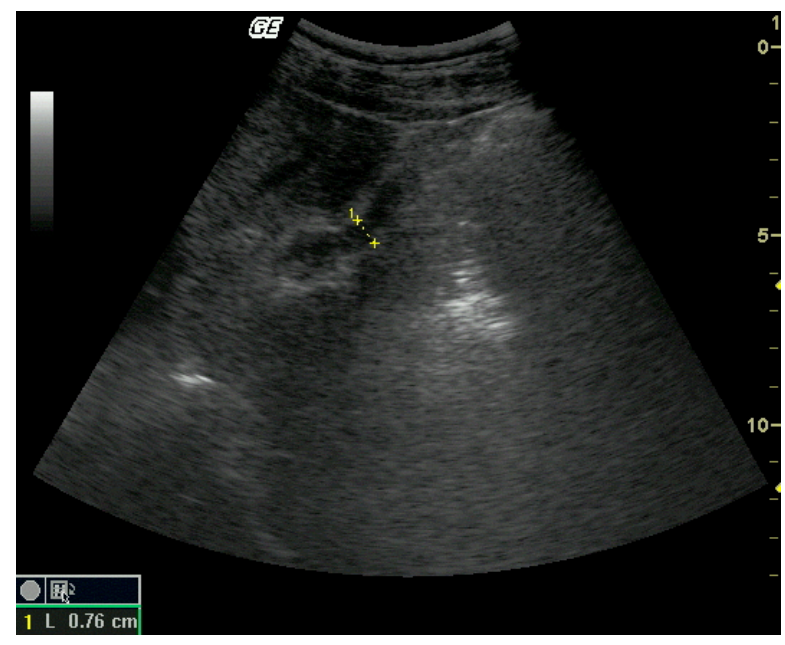

Figura 32. Veia paraumbilical dilatada com 7,6 mm de diâmetro

As colaterais retroperitoneais foram identificadas como enovelado de vasos calibrosos, tortuosos, com fluxo de velocidade máxima de $15,5 \mathrm{~cm} / \mathrm{s}$, em média (Figura 33).
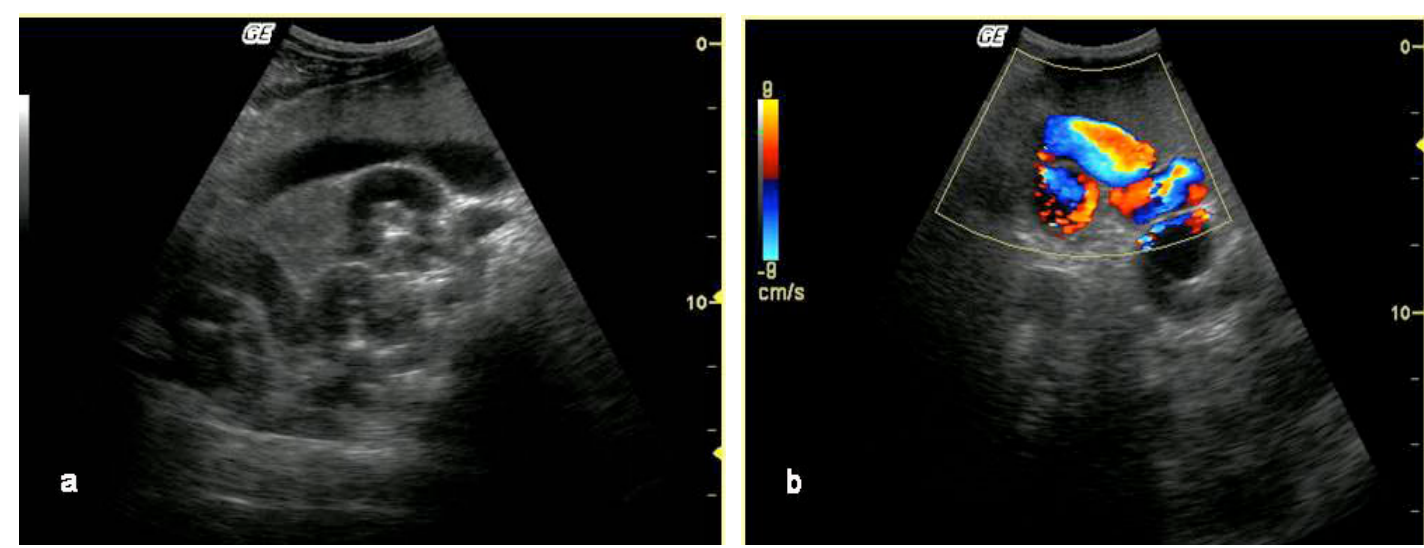

Figura 33. Colaterais retroperitoneais. Enovelado de vasos de grosso calibre ao modo B (a) e ao modo colorido (b) 
Os shunts porto-sistêmicos intra-hepáticos espontâneos foram identificados como formações anecoicas no parênquima hepático, de contornos regulares, com finas septações, localizadas no lobo direito com 26 x 20 mm (Figura 34) e no lobo esquerdo com 23 x 15 mm de diâmetro. A insonação com Doppler colorido evidenciou preenchimento de cor nas duas estruturas, demonstrando suas origens vasculares. No caso do shunt do lobo esquerdo, foi possível identificar a comunicação do ramo portal com o ramo da veia hepática esquerda (Figura 35).
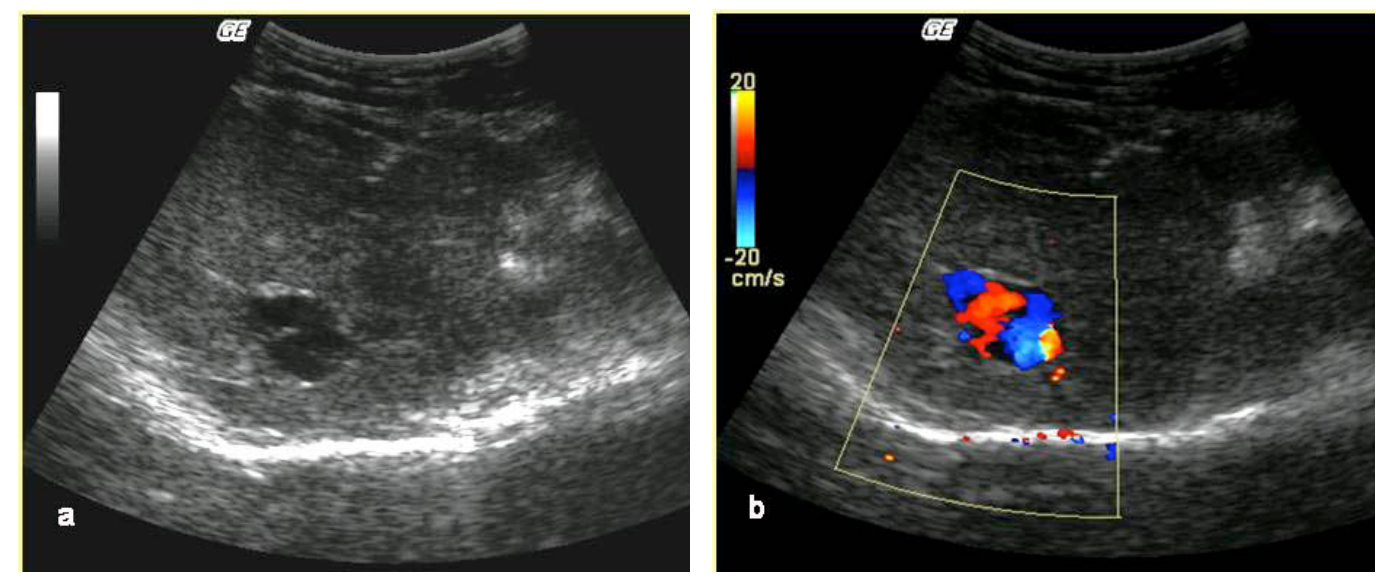

Figura 34. Formação anecóica no lobo direito do fígado, diagnosticada como cisto hepático ao modo B (a). Ao modo colorido, preenchimento de cor demonstrando origem vascular (b)

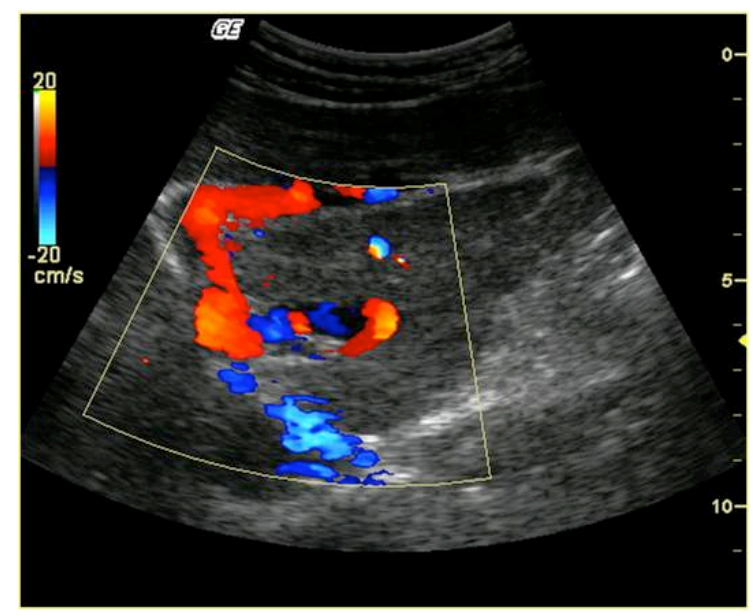

Figura 35. Anastomose espontânea do ramo portal esquerdo com a veia hepática esquerda 
As colaterais gástricas curtas, visibilizadas como estruturas anecoicas serpiginosas localizadas medialmente ao polo superior do baço, mostraram preenchimento de cor ao Doppler colorido e fluxo de baixa velocidade ao Doppler pulsado.

\subsubsection{Análise dopplervelocimétrica das veias hepáticas}

Os resultados da análise do padrão espectral das veias hepáticas estão representados na Tabela 9. Por dificuldades técnicas na obtenção da curva espectral adequada, a classificação do padrão de fluxo das veias hepáticas foi feita em 274 pacientes (91 da área de alta, 126 da área de média e 57 da área de baixa endemicidade). Encontrou-se padrão alterado (bifásico ou monofásico) (Figura 36) em 65/274 (23,7\%) dos casos na amostra total.
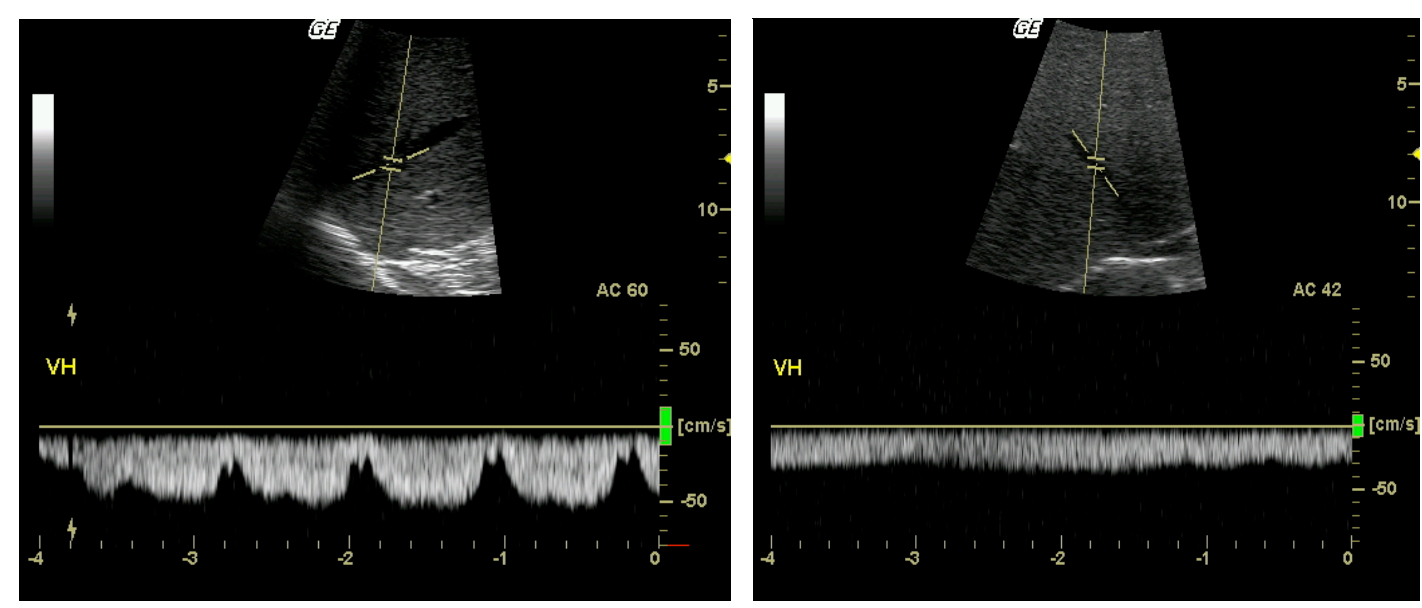

Figura 36. Padrões espectrais alterados: bifásico na veia hepática direita e monofásico na veia hepática média 
$\mathrm{Na}$ distribuição por área de endemicidade, os resultados revelaram diferença estatisticamente significativa entre os grupos $(p=0,030)$.

Tabela 9 - Padrão de fluxo nas veias hepáticas, por área de endemicidade

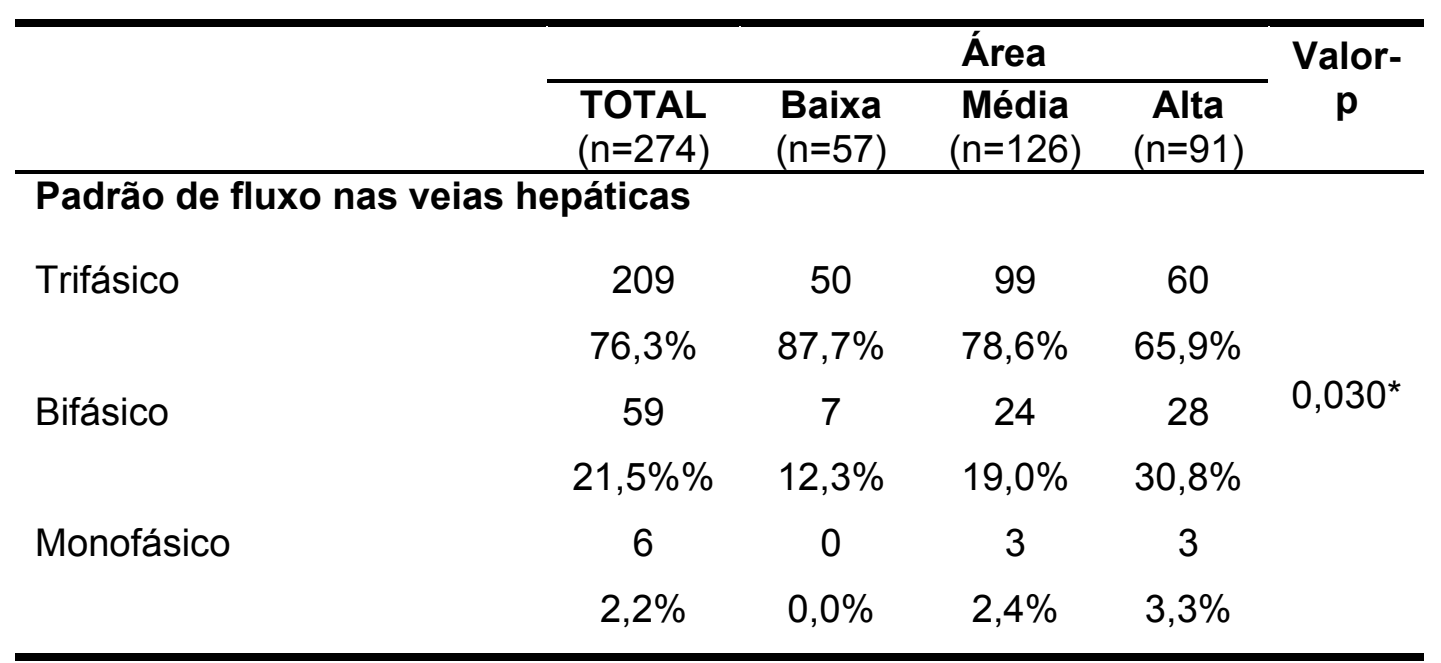

*Teste exato de Fisher

\subsection{Associações estastisticas}

A associação entre os dois parâmetros ecográficos mais fidedignos para determinar-se o estágio da doença - esplenomegalia e espessamento periportal (Magalhães et al, 2005) - demonstrou prevalência de espessamento periportal de apenas $17,6 \%$ entre os pacientes que não apresentavam esplenomegalia e de $66,6 \%$ entre os que a apresentavam (Tabela 10). 
Tabela 10 - Associação entre esplenomegalia e espessamento periportal

\begin{tabular}{llll}
\hline & \multicolumn{2}{c}{ Esplenomegalia } & \multirow{2}{*}{ Valor-p } \\
\cline { 2 - 3 } & Não & Sim & \\
\hline Espessamento periportal & & & \\
Não & 422 & 14 & \multirow{2}{*}{$<0,001^{*}$} \\
\multirow{2}{*}{ Sim } & $82,4 \%$ & $33,3 \%$ & \\
& 90 & 28 & \\
& $17,6 \%$ & $66,6 \%$ & \\
\hline
\end{tabular}

*Teste Qui-quadrado de Pearson

Com estes resultados a doença foi classificada nas seguintes formas: a) intestinal (sem espessamento periportal e sem esplenomegalia); b) hepatointestinal (com espessamento periportal e sem esplenomegalia); c) hepatoesplênica (com espessamento periportal e com esplenomegalia); d) com esplenomegalia, sem sinais de espessamento periportal.

A Tabela 11 informa a frequência dessas formas na amostra total e na distribuição por áreas.

Os resultados apresentaram diferença estatisticamente significante entre as áreas $(p<0,001)$, sendo as formas hepatointestinal e hepatoesplênica mais frequentes na área de alta endemicidade. 
Tabela 11 - Classificação das formas da doença, por área de endemicidade

\begin{tabular}{|c|c|c|c|c|c|}
\hline & \multicolumn{4}{|c|}{ Área } & \multirow[b]{2}{*}{ Valor-p } \\
\hline & $\begin{array}{l}\text { TOTAL } \\
(n=554)\end{array}$ & $\begin{array}{c}\text { Baixa } \\
(n=109)\end{array}$ & $\begin{array}{c}\text { Média } \\
(n=255)\end{array}$ & $\begin{array}{c}\text { Alta } \\
(n=190)\end{array}$ & \\
\hline \multicolumn{6}{|l|}{ Forma da doença } \\
\hline \multirow[t]{2}{*}{ Intestinal } & 422 & 103 & 209 & 110 & \\
\hline & $76,2 \%$ & $94,5 \%$ & $82,0 \%$ & $57,8 \%$ & \\
\hline \multirow[t]{2}{*}{ Hepatointestinal } & 90 & 5 & 33 & 52 & \\
\hline & $16,2 \% \%$ & $4,6 \%$ & $12,9 \%$ & $27,4 \%$ & $<0,001^{*}$ \\
\hline \multirow[t]{2}{*}{ Hepatoesplênica } & 28 & 0 & 4 & 24 & \\
\hline & $5,1 \%$ & $0,0 \%$ & $1,6 \%$ & $12,6 \%$ & \\
\hline \multirow[t]{2}{*}{ Esplenomegalia apenas } & 14 & 1 & 9 & 4 & \\
\hline & $2,5 \%$ & $0,9 \%$ & $3,5 \%$ & $2,1 \%$ & \\
\hline
\end{tabular}

${ }^{*}$ Teste exato de Fisher

$\mathrm{Na}$ área de alta endemicidade, houve associação significativa entre esplenomegalia e dilatação das veias porta e esplênica $(p<0,001)$ (Tabela 12). A prevalência de calibre aumentado na veia porta foi de apenas $9 / 161$ (5,6\%) dos pacientes com baço normal e de $13 / 27$ (48,2\%) dos com esplenomegalia. A veia esplênica estava dilatada em apenas 2/161 (1,3\%) dos pacientes sem esplenomegalia e em 19/26 (73,0\%) dos pacientes com esplenomegalia. O diâmetro médio da veia esplênica foi maior entre os pacientes com esplenomegalia $(10,7 \mathrm{~mm})$, se comparados aos sem esplenomegalia (6,4 mm). Também o diâmetro médio da veia porta foi maior entre os pacientes com esplenomegalia $(11,8 \mathrm{~mm})$ na comparação com os sem esplenomegalia $(10,0 \mathrm{~mm})$. As velocidades máximas do fluxo em ambas as veias foram menores nos pacientes com esplenomegalia $(18,3 \mathrm{e}$ 
20,7 versus 20,3 e $21,4 \mathrm{~cm} / \mathrm{s}$ ), porém a diferença não se mostrou estatisticamente significativa ( $p=0,068$ e $p=0,77$ respectivamente).

Na área de média endemicidade, essas variáveis não se associaram de forma significativa. Na área de baixa endemicidade verificou-se apenas um caso de esplenomegalia, motivo pelo qual não foi feita associação dessas variáveis.

Tabela 12 - Associação entre esplenomegalia e calibre das veias porta e esplênica na área de alta endemicidade

\begin{tabular}{lccc}
\hline & \multicolumn{2}{c}{ Esplenomegalia } & \multirow{2}{*}{ Valor-p } \\
\cline { 2 - 3 } & Não & Sim & \\
\hline Calibre da veia porta & 152 & 14 & \\
Normal & $94,4 \%$ & $51,8 \%$ & \multirow{2}{*}{$\mathbf{0 , 0 0 1 ^ { * }}$} \\
Aumentado & 9 & 13 & \\
& $5,6 \%$ & $48,2 \%$ & \\
Calibre da veia esplênica & & & \\
Normal & 158 & 7 & \\
& $98,7 \%$ & $27,0 \%$ & $<0,001^{* *}$ \\
Aumentado & 2 & 19 & \\
\hline
\end{tabular}

"Teste Qui-quadrado de Pearson $\quad$ **Teste exato de Fisher

A associação entre a existência ou não de esplenomegalia e o diâmetro, o índice de resistividade e a velocidade de pico sistólico da artéria esplênica apresentou diferença significativa $(p<0,001)$ nas áreas de média e alta endemicidades. O diâmetro médio da artéria esplênica aumentou de 3,8 
$\mathrm{mm}$ entre os pacientes que não apresentavam esplenomegalia para 5,3 mm entre aqueles que a apresentavam (Tabela 13).

A média do índice de resistividade e a média da velocidade do pico sistólico da artéria esplênica foram maiores $(0,70$ e $101,4 \mathrm{~cm} / \mathrm{s})$ entre os pacientes com esplenomegalia, se comparados com aqueles sem essa característica $(0,60$ e $80,5 \mathrm{~cm} / \mathrm{s})$.

Não foi feita associação dessas variáveis na área de baixa endemicidade porque nesse grupo se constatou apenas um caso de esplenomegalia.

Tabela 13 - Associação entre esplenomegalia e: diâmetro, índice de resistividade e velocidade de pico sistólico da artéria esplênica, nas áreas de média e alta endemicidades

\begin{tabular}{lccc}
\hline & \multicolumn{2}{c}{ Esplenomegalia } & Valor- \\
\cline { 2 - 3 } & Não & Sim & $\mathbf{p}^{*}$ \\
\hline $\begin{array}{l}\text { Diâmetro da artéria esplênica }(\mathrm{mm}) \\
\text { Média }\end{array}$ & 3,8 & 5,3 & $<\mathbf{0 , 0 0 1}$ \\
$\begin{array}{l}\text { índice de resistividade da artéria esplênica } \\
\text { Média }\end{array}$ & 0,60 & 0,70 & $<\mathbf{0 , 0 0 1}$ \\
$\begin{array}{l}\text { Velocidade de pico sistólico na artéria esplênica } \\
\text { (cm/s) }\end{array}$ & & & \\
Média & 80,5 & 101,4 & $<\mathbf{0 , 0 0 1}$ \\
\hline *Teste Mann-Whitney & & &
\end{tabular}

$\mathrm{Na}$ área de alta endemicidade observou-se associação significativa entre a presença e o grau de espessamento periportal e a identificação da artéria hepática $(p<0,001)$ (Tabela 14). A artéria foi identificada em 106/161 $(65,8 \%)$ dos pacientes que não apresentavam espessamento periportal e em 
apenas 55/161 (34,2\%) dos que tinham a lesão. A não-visibilização também mostrou-se relacionada ao grau do espessamento periportal, ou seja, quanto mais intensa a lesão, mais baixa a taxa de visibilização. Nas áreas de baixa e média endemicidades não houve associação significativa entre essas variáveis.

Tabela 14 - Associação entre identificação da artéria hepática e: espessamento periportal e seu grau na área de alta endemicidade

\begin{tabular}{|c|c|c|c|}
\hline & \multicolumn{2}{|c|}{$\begin{array}{c}\text { Identificação da artéria } \\
\text { hepática }\end{array}$} & \multirow[t]{2}{*}{ Valor-p } \\
\hline & $\underset{(n=161)}{\operatorname{Sim}}$ & $\begin{array}{c}\text { Não } \\
(n=29)\end{array}$ & \\
\hline \multicolumn{4}{|c|}{ Espessamento periportal } \\
\hline \multirow[t]{2}{*}{ Ausente $(n=114)$} & 106 & 8 & \multirow{4}{*}{$<0,001^{*}$} \\
\hline & $65,8 \%$ & $27,6 \%$ & \\
\hline \multirow[t]{2}{*}{ Presente $(n=76)$} & 55 & 21 & \\
\hline & $34,2 \%$ & $72,4 \%$ & \\
\hline \multicolumn{4}{|c|}{$\begin{array}{l}\text { Grau do espessamento } \\
\text { periportal }(n=76)\end{array}$} \\
\hline \multirow[t]{2}{*}{ Leve } & 35 & 9 & \multirow{6}{*}{$<0,001^{* *}$} \\
\hline & $63,6 \%$ & $42,8 \%$ & \\
\hline \multirow[t]{2}{*}{ Moderado } & 16 & 8 & \\
\hline & $29,1 \%$ & $38,1 \%$ & \\
\hline \multirow[t]{2}{*}{ Intenso } & 4 & 4 & \\
\hline & $7,2 \%$ & $19,1 \%$ & \\
\hline
\end{tabular}

No entanto, nos casos em que a artéria foi identificada e mensurada, não houve correlação significativa $(p=0,223)$ entre a presença e o grau da fibrose com o diâmetro da artéria. A média do diâmetro da artéria hepática 
não sofreu alteração pela existência ou pela intensidade do espessamento periportal (3,6 mm em ambas as situações).

Verificou-se correlação significativa positiva entre os diâmetros da veia porta e artéria hepática $(0,411-p=0,011)$, velocidade máxima de fluxo na veia porta e pico sistólico da artéria hepática $(0,179-p<0,001)$, demonstrando-se que os diâmetros e as velocidades de fluxo desses vasos aumentam ou reduzem-se paralelamente. A mesma correlação foi registrada entre os diâmetros das veias porta e esplênica $(0,269-p<0,001)$. A correlação foi inversamente significativa entre diâmetro e a velocidade máxima de fluxo na veia porta, ou seja, à medida que o diâmetro da veia aumentou, a velocidade diminuiu (Tabela 15).

Tabela 15 - Coeficiente de correlação de Spearman entre algumas variáveis da amostra total

\begin{tabular}{lcc}
\hline & Coeficiente & Valor-p \\
\hline Diâmetro da veia porta x diâmetro da artéria hepática & $\mathbf{0 , 4 1 1}$ & $\mathbf{0 , 0 1 1}$ \\
Velocidade max de fluxo veia porta x pico sistólico da & $\mathbf{0 , 1 7 9}$ & $<0,001$ \\
artéria hepática & & \\
Diâmetro da veia porta x diâmetro da veia esplênica & $\mathbf{0 , 2 6 9}$ & $<0,001$ \\
Diâmetro da veia porta x velocidade max de fluxo veia & $-0,262$ & $<0,001$ \\
porta & & \\
\hline
\end{tabular}


6. DISCUSSÃO 
A partir da primeira descrição ultrassonográfica da fibrose periportal feita por Abdel-Latif et al. (1978) e Abdel-Wahab et al. (1978) e da contribuição de Cerri (1984a), que relata os sinais ecográficos específicos da doença, a USG representou um marco no diagnóstico da EM.

Em 1988, quando Homeida et al. (1988b), em trabalho de campo pioneiro, detectou graus leves de fibrose periportal não observados em pacientes hospitalizados, abriram-se novas perspectivas para o uso da USG na esquistossomose, ampliando sua aplicação para estudos populacionais.

A partir de então, o método tem sido amplamente utilizado nas áreas endêmicas, principalmente no estudo da morbidade e na avaliação da eficácia dos tratamentos em massa. Várias investigações buscaram estabelecer a correlação entre morbidade/endemicidade a partir dos achados ecográficos, definindo níveis de acometimento da doença.

O que se objetivou neste trabalho foi estabelecer essa correlação não só pelas alterações ecográficas do fígado, baço e sistema vascular, mas também pelos aspectos funcionais da hemodinâmica portal, obtidos pelo Doppler.

Ao planejar esta pesquisa, buscou-se contemplar os vários estágios da doença, realizando-se exames em áreas com níveis distintos de endemicidade. Desta forma, em um só trabalho, utilizando o mesmo método, os mesmos equipamentos e com os mesmos observadores, obtiveram-se informações para avaliar as repercussões hemodinâmicas e sua correlação com as alterações ecográficas das diferentes fases da doença. 
Na concepção do estudo, não foi objetivo parear os grupos em relação ao tamanho da amostra, sexo e dados antropométricos. A maioria dos autores concorda que é desprezível a influência do sexo, peso, altura e índice de massa corpórea sobre as medidas das vísceras e dos vasos e que não é necessária a correção dessas medidas pelos dados físicos (Weinreb et al., 1982; Niederau et al., 1983). Portanto, entende-se que a heterogenicidade dos grupos em relação a essas características não interfere nos resultados obtidos.

No presente estudo, a frequência dos sinais ecográficos da morbidade relacionada à EM mostrou correlação estatisticamente significante com o nível de endemicidade das áreas em praticamente todos os parâmetros avaliados.

O espessamento periportal indicativo de fibrose de Symmers constitui um dos principais marcadores para a EM. Seu aspecto típico à USG permite distingui-la da fibrose de outras hepatopatias crônicas. Na esquistossomose, esse espessamento é caracterizado por bandas hiperecogênicas com projeções ao longo dos ramos portais, tornando seu aspecto praticamente patognomônico da doença (Cerri, 1984b; Pinto-Silva, 1992).

A importância desse parâmetro e seu caráter eminentemente subjetivo fizeram com que a OMS definisse dois critérios de avaliação do espessamento periportal esquistossomótico: um qualitativo e outro quantitativo, na tentativa de reduzir a variação intra e interobservador. A avaliação do espessamento periportal em nossa série foi feita pela análise subjetiva e pelos dois critérios do protocolo de Niamey. 
A frequência de espessamento periportal apresentou significativa correlação com a endemicidade da área. O resultado aqui encontrado foi concordante com o de Abdel-Wahab et al. (1989), que, após estudo de campo, concluíram que a fibrose periportal detectada à USG é um parâmetro fidedigno do nível de prevalência e da morbidade da esquistossomose em uma população, fornecendo informações importantes, principalmente quando os achados laboratoriais e clínicos são contraditórios.

Como resultado da avaliação subjetiva, foram encontrados, na amostra total, $118 / 554(21,3 \%)$ pacientes com algum grau de espessamento periportal. A lesão foi mais frequente na área de alta endemicidade $(40,0 \%)$ versus $14,5 \%$ na área de média endemicidade e $4,6 \%$ na área de baixa endemicidade, sendo a diferença significativa entre os grupos $(p<0,001)$.

Alguns trabalhos relatam frequência de espessamento periportal em torno de $39 \%$ em áreas endêmicas de alta prevalência para EM (Gerspacher-Lara et al., 1997; Cota et al., 2006). Malenganisho et al. (2008), avaliando duas áreas com níveis de endemicidade distintos na Tanzânia, referiram resultados semelhantes aos nossos. Encontraram espessamento periportal em $41,5 \%$ dos indivíduos da área de alta endemicidade e em $16,7 \%$ da área de menor endemicidade, concluindo que a frequência da fibrose periportal está associada à prevalência e à intensidade da infecção.

Quanto ao grau da lesão, do mesmo modo, a área de alta endemicidade apresentou espessamento periportal mais intenso $(4,2 \%$ de espessamento acentuado e $12,6 \%$ de espessamento moderado), com diferença significativa entre as áreas $(p<0,001)$. 
Alguns autores demonstraram que a presença e a intensidade da fibrose periportal aumentam com a idade (Houston et al, 1993; Lambertucci et al, 2001). Como no presente estudo, a idade mediana foi significativamente mais alta na área de alta endemicidade, poderia-se aventar uma possível variável de confusão na frequência e no grau de espessamento periportal deste grupo. Entretanto, a análise pareada por faixa etária, mostrou que os portadores de fibrose periportal têm idade acima da mediana em 100\% dos casos da área de baixa endemicidade, em $76 \%$ da área de média e em $90 \%$ da área de alta. Também os graus da lesão apresentaram frequência acima da idade mediana semelhante nas três áreas. Portanto, a prevalência mais alta de fibrose periportal na área de alta endemicidade, ao contrário de constituir um viés, corrobora os relatos de que a frequência e a intensidade dessa lesão aumentam com a idade.

Identificou-se relação significativa $(p<0,001)$ entre a forma da doença e a intensidade do espessamento periportal, sendo que nos hepatoesplênicos registrou-se espessamento acentuado em 5/28 (18\%) pacientes, moderado em $14 / 28(50 \%)$ e leve em $9 / 28(32 \%)$, enquanto nos hepatointestinais a frequência de espessamento acentuado foi de apenas 3,0\% (3/90), moderado de $18 \%(16 / 90)$ e leve de $79 \%(71 / 90)$.

A hipertrofia do lobo esquerdo, considerando-se $110 \mathrm{~mm}$ o limite da normalidade (Machado et al., 2002), foi a única variável ao modo B que não apresentou diferença significativa entre as áreas.

Embora atribuida ao hiperfluxo esplênico e descrita inicialmente na forma hepatoesplênica (Mies et al., 1980a), alguns autores já haviam 
ressaltado a hipertrofia do lobo esquerdo também nas formas brandas da doença (Mackenjee et al., 1984; Paranaguá-Vezozzo,1992; Ruiz et al., 2002).

A frequência dessa alteração em nossa série, embora sem significância estatística, foi maior nas áreas de média e baixa endemicidades, onde se encontra maioria de formas brandas. Nessas áreas não houve correlação significativa entre o aumento do lobo esquerdo e algumas variáveis indicativas de hiperfluxo esplênico, como a esplenomegalia e a dilatação das veias porta e esplênica, indicando não ser essa a causa da hipertrofia nesses pacientes. Na estratificação por forma da doença, a prevalência de hipertrofia foi maior no grupo hepatoesplênico, porém sem diferença significativa entre os grupos $(p=0,291)$.

Além de ser o único parâmetro a não registrar diferença entre as áreas, a hipertrofia do lobo esquerdo também foi a única alteração a apresentar prevalência menor na área de alta endemicidade. Correlacionando a presença de hipertrofia com o grau de espessamento periportal, constatouse que dos pacientes com espessamento acentuado, todos da área de alta endemicidade, nenhum apresentou aumento do lobo esquerdo. Esse resultado indica que nas formas avançadas da doença, a fibrose periportal intensa retrai a cápsula de Glisson, reduzindo as dimensões hepáticas, explicando assim, a menor frequência de hipertrofia do lobo esquerdo na área de alta endemicidade.

Portanto, pode-se concluir, que o aumento do lobo esquerdo ocorre em todos os estágios da doença, porém com frequência menor nos casos mais 
avançados, e que, como afirmado por Paranaguá-Vezozzo (1992), esse aumento não pode ser atribuído exclusivamente ao hiperfluxo esplênico.

Em relação ao lobo direito, sua redução demonstrou estar fortemente associada às formas avançadas da doença. Cerri (1984a) reporta esse dado associado à hipertrofia do lobo esquerdo em $81 \%$ dos pacientes hepatoesplênicos acompanhados em sua série. No entanto, como no estudo feito em áreas endêmicas prevalecem as formas brandas da doença, Hatz et al. (1992) encontraram frequência bem inferior à de Cerri, mesmo na área de alta endemicidade. $\mathrm{Na}$ presente pesquisa, verificou-se redução do lobo direito, segundo os critérios do Niamey Working Group (2000), em 28/554 pacientes $(14,8 \%)$ da área de alta endemicidade, em 9/255 $(3,5 \%)$ da área de média endemicidade e em nenhum paciente da área de baixa endemicidade, sendo a diferença significativa entre os grupos $(p<0,001)$.

O volume do baço constitui importante marcador da esquistossomose hepatoesplênica, que, por definição, encontra-se aumentado nessa forma da doença. As avaliações realizadas em pacientes hepatoesplênicos utilizando a medida ultrassonográfica do baço notificam $100 \%$ de esplenomegalia (Cerri, 1984a; Pinto-Silva, 1992). Nos estudos de campo, os pacientes hepatoesplênicos têm sido diferenciados daqueles com forma hepatointestinal basicamente pela presença de esplenomegalia diagnosticada pela palpação abdominal (Lambertucci et al., 2001).

Barkun et al.(1991) investigando a acurácia da palpação abdominal para o diagnóstico da esplenomegalia, apontaram limitações nas várias manobras de palpação e percussão esplênica, mesmo quando usadas 
associadas. Gerspacher-Lara et al. (1998), comparando o exame físico à USG, concluíram que a palpação abdominal é um método insatisfatório para o diagnóstico da esplenomegalia em áreas endêmicas e consideraram padrão ouro, a medida ultrassonográfica do eixo longitudinal do baço. Nessa mesma linha, Lambertucci et al. (2001) e Marinho et al. (2006) propõem a associação dos dois métodos como forma de aumentar a acurácia do diagnóstico dos pacientes hepatoesplênicos em estudos de campo.

Apesar dessas limitações mencionadas, vários estudos de campo ainda utilizam o exame físico como único método para diagnosticar a esplenomegalia, impossibilitando que os resultados sejam comparados aos nossos. No entanto, investigações feitas com a mesma metodologia apuraram resultados semelhantes aos aqui apresentados. Gerspacher-Lara et al. (1997) identificaram esplenomegalia em 15\% dos esquistossomóticos em área de alta prevalência, mesma frequência encontrada na área de alta endemicidade desta pesquisa $(14,7 \%)$. Nas outras áreas a frequência foi significativamente menor, indicando haver relação significante entre a presença de esplenomegalia e o nível de endemicidade da área $(p<0,001)$.

De acordo com classificação das formas de acometimento da doença, a amostra total salientou $28 / 554(5,1 \%)$ dos pacientes com a forma hepatoesplênica, frequência concordante com a da literatura (Coutinho, 1968; Tavares-Neto \& Prata, 1989).

$\mathrm{Na}$ distribuição por áreas, o estágio da doença mostrou correlação significativa com o nível de endemicidade. As formas hepatoesplênica e hepatointestinal foram mais frequentes na área de alta endemicidade (12,6 e 
$32,1 \%$ ) versus 1,6 e $12,9 \%$ na área de média endemicidade e 0,9 e 4,6\% na de baixa endemicidade.

Nossos resultados, no que diz respeito à área de alta endemicidade, são semelhantes aos de Cota et al. (2006) que, estudando 739 esquistossomóticos em uma área hiperendêmica, identificaram 84 (11,4\%) portadores da forma hepatoesplênica.

Neste estudo identificou-se um grupo de indivíduos (14/554 -2,5\%) com esplenomegalia sem sinais ecográficos de lesões no fígado. Este achado já havia sido descrito por Martins et al. (1998) e Lambertucci et al. (2000, 2001), que também encontraram em suas séries pacientes com aumento do baço sem comprometimento hepático. Segundo os autores, a esplenomegalia nesses casos poderia ser atribuída a outras doenças não investigadas, a processo reacional secundário à infecção esquistossomótica ou, ainda, a hepatoesplênicos que ainda não haviam desenvolvido fibrose periportal.

O grupo de pacientes hepatoesplênicos apresentou diâmetro médio da veia porta maior $(12,2 \mathrm{~mm})$ que os grupos hepatointestinal $(10,3 \mathrm{~mm}) \mathrm{e}$ intestinal (10,0 mm), sendo a diferença significativa entre os grupos. Também as veias esplênica e mesentérica superior tinham calibres maiores nos hepatoesplênicos (10,3 e 10,7 mm respectivamente).

O aumento do calibre dos vasos portais tem sido referido como frequente nos pacientes com hipertensão portal de várias etiologias (Bolondi et al., 1982). A pressão no interior do sistema porta é determinada pela relação entre o volume do fluxo esplâncnico e a resistência intra-hepática 
que se opõe a esse fluxo. Desta forma, o aumento de um desses dois fatores ou de ambos condiciona a instalação do quadro hipertensivo.

$\mathrm{Na}$ cirrose, como o principal fator hipertensivo é o aumento da resistência intra-hepática secundária à fibrose e o volume de fluxo esplênico é menor que na esquistossomose, a frequência de dilatação é semelhante nos três vasos portais, com discreto predomínio da veia mesentérica superior (Bolondi et al., 1982; Zoli et al., 1986).

$\mathrm{Na}$ hipertensão portal esquistossomótica, aos dois componentes de aumento da resistência intra-hepática (fibrose periportal e redução do leito vascular devido à trombose de pequenos ramos portais) associa-se o hiperfluxo esplênico secundário à esplenomegalia, geralmente mais volumosa do que na cirrose, dilatando preferencialmente as veias porta e esplênica (Mies, 1980a; Abdel-Latif et al., 1981; Cerri, 1984a; Pinto-Silva et al., 1994).

Identificou-se neste trabalho dilatação da veia porta em 44/552 (8,0\%) dos pacientes, da veia esplênica em $26 / 550(4,7 \%)$ e da veia mesentérica superior em $31 / 548(5,7 \%)$. Como a maioria dos participantes da série não apresentou esplenomegalia, não houve predominância, na amostra total, do eixo esplênico-portal.

No grupo de hepatoesplênicos, a frequência de dilatação dos vasos portais foi bem maior, sendo a diferença significativa entre os grupos $(p<0,001)$. Nesses pacientes, verificou-se dilatação da veia porta em 14/28 $(51,2 \%)$ casos, da veia esplênica em $20 / 28$ (74,0\%) e da veia mesentérica superior em 9/28 (32,1\%), confirmando predomínio do eixo esplênico-portal. 
A incidência menor de dilatação da veia porta em relação à veia esplênica nesse grupo justificou-se pela presença de sete casos de colaterais gástricas esquerdas hepatofugas que, descomprimindo o sistema venoso portal, reduziram o calibre da veia porta.

No grupo hepatointestinal, houve dilatação predominante das veias porta (13/89-14,6\%) e da veia mesentérica superior (15/89-16,8\%), enquanto a veia esplênica apresentou-se dilatada em apenas 4,5\% (4/89) dos pacientes. Estes resultados permitiram supor que a fibrose periportal identificada nesse grupo, embora leve na maioria dos casos, condicionou algum grau de resistência intra-hepática, levando à dilatação preferencial das veias porta e mesentérica superior nos quadros em que o componente do hiperfluxo esplênico não estava presente.

Segundo Pinto-Silva et al. (1994), diâmetros maiores que $14 \mathrm{~mm}$ para a veia porta e $12 \mathrm{~mm}$ para a veia esplênica fornecem $100 \%$ de acurácia no diagnóstico de hipertensão portal. Quando associados esses parâmetros à presença de colaterais, sinal patognomônico de hipertensão portal, dos 28 pacientes hepatoesplênicos da nossa série, 22 (78,5\%) tinham quadro hipertensivo portal, representando $4,0 \%$ da amostra total. No grupo de hepatointestinais, identificaram-se $2 / 90(2,2 \%)$ pacientes com sinais de hipertensão portal, diagnosticada pela constatação de vasos colaterais. Nesses indivíduos, o tamanho normal do baço pode ser explicado pela descompressão do sistema venoso portal promovido pelas colaterais.

Apesar de presente em várias outras doenças que envolvem o fígado, a vesícula biliar e mesmo sistêmicas, o espessamento perivesicular na 
esquistosomose, assim como o espessamento periportal, apresenta características peculiares. Nos esquistossomóticos, a fibrose da parede vesicular encontra-se densa, homogeneamente hiperecogênica, exceto pela possível existência de capilares ectásicos (vasos císticos), com típicas projeções em forma de raios que penetram no parênquima hepático. Além disto, não apresentam halos hipoecogênicos sugestivos de edema, como na cirrose ou na ascite. Esse quadro foi reportado por Cerri (1984a) em 60\% dos pacientes de seu estudo, ressaltando que na esquistossomose, diferentemente do que acontece em outras doenças, o espessamento vesicular estende-se em direção ao hilo hepático nas formas avançadas da doença. Doehring-Schwerdtfeger et al. (1990), em sua série para avaliação da morbidade relacionada às formas brandas da esquistossomose, informam espessamento perivesicular apenas no colo da vesícula biliar.

No presente trabalho, o espessamento perivesicular foi detectado em 42/188 (22,3\%) pacientes da área de alta endemicidade, com frequência bem menor nas outras áreas (7/252-2,7 e 1/108-0,9\%). Estes resultados apresentaram diferença significativa entre os grupos $(p<0,001)$, mostrando ser este parâmetro um marcador das formas avançadas da doença. Além disto, o espessamento perivesicular associou-se a espessamento periportal em $92 \%$ dos casos.

No tocante ao estudo Doppler, enfatiza-se aqui a sua viabilidade e aplicabilidade em estudos de campo. Apesar das condições precárias, os exames transcorreram sem contratempos. Uma preocupação constante, principalmente nas áreas de média e alta endemicidades (Minas Gerais e 
Bahia), foi com a possibilidade de superaquecimento dos equipamentos, uma vez que não havia refrigeração ambiental e as temperaturas locais eram bastante altas. Isto foi contornado com o uso de ventiladores direcionados para os aparelhos que, apesar de permanecerem ligados, em média, por doze horas consecutivas, não apresentaram problemas.

O tempo necessário para execução do exame Doppler variou de acordo com a gravidade do caso e com o biotipo do paciente. Em média, realizou-se o estudo de todos os vasos previstos no protocolo (modo B, colorido e pulsado) em aproximadamente quinze minutos, não estando aí incluído o protocolo de Niamey.

Os problemas técnicos enfrentados foram a não-identificação de alguns vasos, a não-captação de fluxo em artérias de pequeno calibre ou, ainda, a impossibilidade de se obter o ângulo adequado para a medida de velocidade. Na maioria dos casos, essas dificuldades estavam relacionadas à obesidade ou falta de preparo dos pacientes, ou ainda, à limitações do equipamento. Nesta pesquisa obteve-se sucesso na visibilização e mapeamento de fluxo em quase a totalidade das veias (veia porta: $99,6 \%$; veia esplênica: 99,3\% e veia mesentérica superior: 98,9\%).

Entre as veias, a maior dificuldade foi em relação à mesentérica superior, que, por sua localização, apresentou maior sobreposição gasosa. Nas artérias, o índice de sucesso foi mais baixo (artéria hepática: 84,8\%; e artéria esplênica: $85,0 \%$ ), principalmente devido ao pequeno calibre desses vasos ou à interposição gasosa. No caso da artéria hepática, surgiu dificuldade adicional nos pacientes com fibrose no hilo hepático. Em alguns 
desses casos foi possível medir o calibre da artéria, mas não se detectou o sinal Doppler pulsado adequado para a medida da velocidade.

A trombose espontânea da veia porta tem sido descrita como pouco frequente na esquistossomose. Sua maior frequência está relacionada às cirurgias para descompressão portal.

A trombose da veia porta foi observada em apenas um caso da área de alta endemicidade, representando $0,5 \%$ dos pacientes daquele grupo e $0,2 \%$ da amostra total. Nesse paciente, a trombose portal estava relacionada à presença de colateral gástrica esquerda, com fluxo hepatofugal e velocidade de $22,4 \mathrm{~cm} / \mathrm{s}$. Cerri (1984a) evidenciou esse achado em seis $(5,8 \%)$ e PintoSilva (1992) em três (5\%) pacientes de suas séries de hepaoesplênicos ao exame modo B. Paranaguá-Vezozzo (1992), em estudo Doppler, relatou trombose da veia porta em $9 \%$ dos hepatoesplênicos. Em nosso trabalho, analisando apenas os pacientes com essa forma da doença, a frequência foi de $3,6 \%(1 / 28)$.

O valor médio da velocidade máxima da veia porta na presente avaliação foi de $23,1 \pm 6,3 \mathrm{~cm} / \mathrm{s}$. Em 14/552 (2,5\%) pacientes a velocidade máxima encontrada estava abaixo do limite de normalidade $(15 \mathrm{~cm} / \mathrm{s})($ Zironi et al., 1992). Na estratificação pela forma de acometimento, oito deles apresentavam forma hepatointestinal e quatro forma hepatoesplênica, sendo que, destes, três tinham colaterais hepatofugas.

Associando o diâmetro à velocidade de fluxo da veia porta, a correlação foi inversamente significativa entre essas duas variáveis (coeficiente de Spearman -0,262; $p<0,001$ ). Desta forma, à medida que o 
diâmetro da veia aumentou, sua velocidade tendeu a diminuir. O diâmetro médio da veia porta foi maior nos hepatoesplênicos, com diferença significativa entre os grupos $(p<0,001)$, enquanto a média da velocidade, apesar de menor $(18,9 ; 20,7$ e $23,9 \mathrm{~cm} / \mathrm{s}$, respectivamente), não diferiu significativamente. Assim como na veia porta, também as veias esplênica e mesentérica superior revelaram calibres maiores e velocidades menores nos hepatoesplênicos. Embora não se tenha calculado o volume de fluxo neste trabalho, estes resultados permitiram concluir, em concordância com Paranaguá-Vezozzo \& Cerri (1992), que o hiperfluxo portal descrito na forma hepatoesplênica está relacionado ao aumento do diâmetro dos vasos, já que os valores da velocidade, não apresentaram diferença significativa entre os grupos.

Da mesma forma, obteve-se correlação significativa entre as dimensões do baço e o diâmetro da veia esplênica na área de alta endemicidade (os diâmetros aumentaram de 6,42 $\mathrm{mm}$ nos pacientes com baço normal para $10,73 \mathrm{~mm}$ naqueles com esplenomegalia) $(p<0,001)$, enquanto nas velocidades, embora sem significância estatistica, a relação foi inversa, ou seja, à medida que o calibre do vaso aumentou, a velocidade diminuiu (de $21,45$ para $20,71 \mathrm{~cm} / \mathrm{s}-\mathrm{p}=0,770)$. Portanto, nas situações em que supõe-se haver aumento do volume de fluxo venoso, este esteve relacionado ao aumento do diâmetro do vaso.

A direção do fluxo na veia porta foi hepatopetal em todos os casos, à exceção de um paciente da área de alta endemicidade, que apresentou fluxo hepatofugal de baixa velocidade $(13,9 \mathrm{~cm} / \mathrm{s})$, relacionado à presença de 
colateral gástrica esquerda calibrosa. Este achado representa 3,6\% (1/28) dos pacientes hepatoesplênicos e 4,2\% (1/22) daqueles com sinais de quadro hipertensivo, o que coincide com os dados da literatura, que referencia baixa incidência de inversão de fluxo na hipertensão portal. Gaiani et al. (1991), em estudo Doppler de pacientes com hipertensão portal de causas variadas, relataram prevalência de $3,1 \%$ de fluxo hepatofugal no tronco da veia porta e Kawasaki et al. (1989) constataram fluxo hepatofugal em 2,6\% de pacientes cirróticos avaliados pelo Doppler.

O padrão espectral do fluxo nas veias hepáticas é modulado pelas fases do ciclo cardíaco e está diretamente associado à complacência do parênquima hepático.

No presente estudo, considerando-se normal o padrão trifásico e alterados os padrões bifásico e monofásico (Bolondi et al., 1991), os resultados demonstraram curva espectral normal em 209/274 (76,3\%) dos pacientes e alterada em 59/274 (23,7\%), sendo que, destes, $21,5 \%$ tinham padrão bifásico e 2,2\% padrão monofásico retificado.

$\mathrm{Na}$ estratificação por área de endemicidade, foi encontrada diferença significativa entre os grupos $(p=0,030)$, com frequência de alteração maior na área de alta endemicidade (31/91-34,0\%). A relação foi significativa quando se associou a alteração do padrão espectral à presença e à intensidade de espessamento periportal $(p<0,001)$. Também nas formas mais avançadas da doença, a prevalência de fluxo alterado foi mais alta, chegando a 8/14 (57\%) dos pacientes hepatoesplênicos, com diferença significante entre os grupos $(p<0,001)$. Estes resultados comprovaram que $\circ$ 
espessamento periportal fibrótico presente na EM, apesar de não invadir os lóbulos hepáticos (Bogliolo, 1954), reduz a complacência do parênquima, alterando o traçado espectral das veias hepáticas. Em seu estudo, Paranaguá-Vezozzo (1992) acentua a alteração do padrão de onda das veias hepáticas nos hepatoesplênicos, com diferença significativa entre os grupos investigados.

Constatou-se no presente estudo, circulação colateral em onze pacientes da área de alta endemicidade, correspondendo a 5,9\% dos pacientes daquele grupo e a 2,0\% da amostra total. Quando se analisou pela forma de acometimento, os vasos colaterais foram visibilizados em nove pacientes do grupo hepatoesplênico, correspondendo a $32 \%$ desses pacientes, resultado bastante semelhante ao de Cerri (1984a), que relatou colaterais em $35 \%$ de sua série, sendo a veia gástrica esquerda também a mais frequente. As outras duas colaterais foram identificadas em indivíduos com a forma hepatointestinal, como já discutido anteriormente.

A US-Doppler demonstrou mais acurácia no diagnóstico da circulação colateral do que a USG convencional, resultado concordante com o de Sugiura et al. (1992). Além de identificar maior número de colaterais, o Doppler detectou um caso falso-positivo de colateral gástrica esquerda descrita ao modo B. A veia paraumbilical recanalizada, dois casos de colaterais retroperitoneais e dois shunts porto-sistêmicos intra-hepáticos não haviam sido diagnosticados ao exame convencional.

Foi observada relação inversa, embora não significativa, entre a velocidade de fluxo na colateral e a velocidade de fluxo na veia porta, ou 
seja, quanto maior a velocidade na colateral, menor a velocidade na veia porta, confirmando-se o importante papel da colateral na redução do fluxo portal. Essa relação não foi verificada apenas no caso da colateral paraumbilical, que, ao contrário, apresentou velocidade pouco maior na veia porta e no seu ramo esquerdo.

Os estudos do comportamento da artéria hepática na hipertensão portal cirrótica indicam que paralelamente ao aumento da pressão portal ocorre aumento do índice de resistividade da artéria (Sacerdoti et al., 1995; Piscaglia et al., 1997; Colli et al., 1998; Schneider et al., 1999). No entanto, Erden et al. (1999) demonstraram que, enquanto nos pacientes com hipertensão sinusoidal, como na cirrose, essa resistência encontra-se significativamente aumentada, a resistência arterial hepática nos pacientes com quadro hipertensivo pré-sinusoidal permanece inalterada.

A participação da artéria hepática na hemodinâmica da hipertensão portal esquistossomótica é assunto controverso, como visto no tópico de revisão da literatura.

Paranaguá-Vezozzo (1992), referindo índice de detecção de sinal Doppler na artéria hepática com diferença significativa entre os grupos avaliados (hepatoesplênicos: 40\%; e intestinal: 94\%), concluiu que a taxa mais baixa de visibilização dessa artéria no grupo hepatoesplênico sugere componente arterial diminuído.

$\mathrm{Na}$ presente investigação, a frequência de visibilização da artéria hepática foi menor na área de alta endemicidade $(84,7 \%)$, sem, no entanto, apresentar diferença significativa entre os grupos. Nessa área, a não- 
identificação da artéria mostrou-se relacionada à presença e ao grau de espessamento periportal $(p<0,001)$. Quando a amostra foi segmentada por forma de acometimento, encontrou-se percentual de 90,5\% de visibilização da artéria no grupo intestinal; $77,8 \%$ no grupo hepatointestinal; e $60,7 \%$ no grupo hepatoesplênico, confirmando dificuldade maior nas formas avançadas da doença. No entanto, uma vez identificada, o diâmetro médio e os valores dopplervelocimétricos da artéria, mostravam-se dentro dos limites normais e sem diferença entre os grupos. Esses resultados demonstram que nesses pacientes, a limitação na visibilização da artéria foi de ordem técnica, causada pelo aumento da ecogenicidade no hilo hepático devido à fibrose e não pela redução do diâmetro do vaso.

Entende-se, portanto, que não houve influência do estágio da doença no sistema arterial hepático.

Além disto, observou-se correlação significativa e direta entre os diâmetros da veia porta e os da artéria hepática (coeficiente de correlação de Spearman =0,411), o que significou que os valores dos diâmetros desses vasos aumentaram ou diminuíram paralelamente. Também houve correlação significativa positiva entre a velocidade máxima de fluxo na veia porta e a velocidade de pico sistólico da artéria hepática (coeficiente $=0,179$ ). Isto atestou não existir na esquistossomose, como na cirrose, relação inversa entre os fluxos portal e arterial: quando o fluxo portal diminui, o arterial aumenta, ou vice-versa.

Em estudo com voluntários sadios, Paulson et al. (1997) encontraram índice de resistividade na artéria hepática de $0,69 \pm 0,16$. No nosso estudo, 
o valor médio do índice de resistividade de 0,70 foi percebido em todos os grupos, tanto na subdivisão por área quanto por forma da doença. Portanto, os presentes resultados foram indicativos de que a artéria hepática, assim como afirmaram Bogliolo (1956b), Coutinho et al. (1964) e Speranzini (1971, apud Cerri, 1984a), estava dentro dos limites normais em todos os parâmetros avaliados e acompanhou passivamente a hemodinâmica do processo patogênico esquistossomótico.

Em relação às alterações da artéria esplênica na EM, vários autores são unânimes em referir aumento de calibre dessa artéria nas formas hepatoesplênicas, como nos estudos angiográficos realizados por Coutinho (1964), Andrade \& Ferraz (1971), Speranzini (1971, apud Cerri,1984a), Yamauchi et al. (1973 ${ }^{9}$, apud Cerri, 1984a) e Alves et al. (1977).

Bolognesi et al. (1996), encontraram nos pacientes cirróticos aumento significativo dos índices de resistividade e pulsatilidade da artéria esplênica, concluindo que, na cirrose, os índices de impedância dessa artéria refletem a resistência do fluxo venoso portal. O mesmo foi defendido por Piscaglia et al. (2002), ao avaliarem o índice de resistividade da artéria esplênica em hepatopatas crônicos e pacientes com esplenomegalia por outras causas, apurando significativo aumento desse índice nos pacientes cirróticos.

$\mathrm{Na}$ esquistossomose, o único estudo Doppler que contempla a investigação da artéria esplênica é o de Widman et al. (2002), que analisa as alterações tardias no território esplênico de pacientes submetidos à anastomose esplenorenal distal. 
O presente trabalho é o primeiro a investigar pela US-Doppler o comportamento da artéria esplênica na esquistossomose em seus vários estágios evolutivos. Observou-se correlação significativa $(p<0,001)$ entre a esplenomegalia e o aumento do diâmetro, da velocidade do pico sistólico e do índice de resistividade dessa artéria. Ao avaliar pelo critério de apresentação da doença, verificou-se no grupo hepatoesplênico aumento significativo desses parâmetros. Nesses pacientes, o aumento do diâmetro e da velocidade de pico sistólico da artéria pode ser explicado pela demanda de maior aporte sanguíneo capaz de suprir a necessidade de um baço volumoso.

Se, por um lado, o aumento do diâmetro e da velocidade de pico sistólico condicionam maior volume de fluxo arterial, por outro, a elevação do índice de resistividade reflete a dificuldade da passagem desse fluxo pelo leito capilar esplênico. Essa dificuldade de escoamento está diretamente relacionada à congestão venosa intra-esplênica causada pelo aumento da pressão portal. Esses resultados indicam que na esquistossomose hepatoesplênica, assim como na cirrose (Bolognesi et al., 1996; Piscaglia et al., 2002), o índice de resistividade da artéria esplênica reflete a resistência do fluxo venoso portal, podendo ser parâmetro auxiliar no diagnóstico do quadro de hipertensão portal. 


\section{CONCLUSÕES}


- A US-Doppler mostrou-se viável e adequada para avaliação nãoinvasiva das alterações hemodinâmicas da esquistossomose mansônica em estudos de campo.

- Houve relação estatisticamente significante entre as frequências de: espessamento periportal, esplenomegalia, dilatação dos vasos portais, espessamento da parede da vesícula biliar, redução do lobo direito e o nível de endemicidade das áreas e o estágio da doença.

- Não houve relação estatisticamente significante entre a frequência de hipertrofia do lobo esquerdo e o nível de endemicidade das áreas e o estágio da doença.

- A velocidade máxima da veia porta apresentou-se dentro dos limites da normalidade em $97,5 \%$ dos casos.

- As veias hepáticas apresentaram padrão de fluxo alterado em 1/4 dos casos, havendo relação estatisticamente significativa com a presença e a intensidade de espessamento periportal.

- A artéria hepática não apresentou alterações significativas nos parâmetros avaliados.

- A artéria esplênica apresentou alterações (aumento do calibre, da velocidade de pico sistólico e do índice de resistividade) mais frequentes na área de alta endemicidade e na forma hepatoesplênica, com diferença significativa entre os grupos. 
8. ANEXOS 
Anexo A - Caracterização da amostra

Tabela A1 - Distribuição dos pacientes por local de realização do exame

\begin{tabular}{l|c|c}
\hline \multicolumn{1}{c|}{ Área/Endemicidade } & Pacientes & $\%$ \\
\hline Baixa & 109 & 19,7 \\
Média & 255 & 46,0 \\
Alta & 190 & 34,3 \\
TOTAL & 554 & 100,0 \\
\hline
\end{tabular}

Tabela A2 - Distribuição dos pacientes por sexo

\begin{tabular}{lcccc}
\hline & \multicolumn{4}{c}{ SEXO } \\
\cline { 2 - 5 } Área/endemicidade & \multicolumn{2}{c}{ Masculino } & \multicolumn{2}{c}{ Feminino } \\
\cline { 2 - 5 } & $\mathbf{N}$ & $\%$ & $\mathbf{N}$ & $\%$ \\
\hline Baixa & 82 & 75,2 & 27 & 24,8 \\
Média & 147 & 57,6 & 108 & 42,4 \\
Alta & 96 & 50,5 & 94 & 49,5 \\
TOTAL & 325 & 58,7 & 229 & 41,3 \\
*Teste Qui-quadrado & \multicolumn{2}{c}{$\mathrm{p}^{*}<0,001$} & &
\end{tabular}

Tabela A3 - Análise descritiva da idade dos pacientes

\begin{tabular}{lcccc}
\hline Área/endemicidade & $\mathbf{N}$ & Média & $\begin{array}{c}\text { Desvio - } \\
\text { Padrão }\end{array}$ & Mediana \\
\hline Baixa & 109 & 33,3 & 16,0 & 32,0 \\
Média & 255 & 31,2 & 14,0 & 27,0 \\
Alta & 190 & 45,8 & 16,8 & 45,5 \\
TOTAL & 554 & 36,7 & 16,8 & 36,0 \\
\hline
\end{tabular}

*Teste Kruskall-Wallis

Valor-p ${ }^{*}<0,001$ 
Anexo B - Protocolo do exame ultrassonográfico modo B

FICHA No:

\section{PROTOCOLO DE PESQUISA}

\section{Avaliação ultrassonográfica e dopplervelocimétrica da EM}

\section{Exame ultrassonográfico em campo}

\section{1- IDENTIFICAÇÃo}

1.1 - Nome do paciente:

Data: .................

1.2 - Número: /....../...../ - | |............................../ - /............/

1.3 - Naturalidade:

1.4 - Idade: /..../.../ a /..../.../m 1.5 -Sexo: /..../Masculino /..../Feminino

\section{3 - EXAME FÍSICO}

3.1 - Peso: $/ \ldots / \ldots . / \ldots / \mathrm{Kg}: / \ldots . / \ldots / \ldots . / \mathrm{g} \quad 3.2$ - Altura: $/ \ldots / \ldots / \ldots / \mathrm{cm}$

4 - EXAMES COMPLEMENTARES

4.1 - Controle de realização de exames:

EPF: /....../Sim em /............../ US: /...../ Sim em /............../

4.2 - Parasitológico de fezes:

Ovos de S. mansoni /..../ Não /..../Sim Média de ovos/g: /..../.../......../g

OBS:

\section{5 - ULTRASSOM ABDOMINAL EM CAMPO}

\section{1 - ULTRASSONOGRAFIA HEPÁTICA E BILIAR}

5.1.1 - Dimensões do lobo direito longitudinal ( ) $\mathrm{mm}$

5.1 .2 - Dimensões do lobo esquerdo longitudinal ( ) $\mathrm{mm}$

5.1 .3 - Contornos ( ) lisos ( ) rugosos

$\begin{array}{lll}5.1 .4 \text { - Espessamento periportal } & (\text { ) ausente } & (\quad) \text { moderado } \\ & (\text { ) leve } & (\text { ) intenso }\end{array}$

5.1.5 - Distribuição do espessamento ( ) central ( ) periférica

5.1.6 - Espessura da parede da vesícula biliar ( ) $\mathrm{mm}$

5.1.7 - Padrão de acometimento (OMS) ( )

5.1.8 - Outros achados:

\section{2 - ULTRASSONOGRAFIA DO SISTEMA PORTA}
5.2.1 - Veia porta
Calibre ( ) $\mathrm{mm}$
5.2.2 - Espessura da parede portal no hilo hepático ( ) $\mathrm{mm}$
5.2 .3 - Espessura da parede portal na bifurcação ( ) $\mathrm{mm}$
5.2.4 - Espessura da parede do ramo portal de segunda ordem ( ) $\mathrm{mm}$
5.2 .5 - Veia esplênica
Calibre (
) $\mathrm{mm}$
5.2.6 - Veia mesentérica superior
Calibre ( ) $\mathrm{mm}$ 
5.2.7 - Colaterais: ( ) não ( ) sim assinalar qual: ( ) v. gástrica esquerda

( ) v. gástrica curta

( ) v. paraumbilical

( ) v. esplenorrenal ( ) Outras:

5.3 - ULTRASSONOGRAFIA ESPLÊNICA

5.3.1 - Diâmetro longitudinal ( ) $\mathrm{mm}$

\section{4 - LINFONODOS}

$1($ ) não 2( ) sim

5.5 - LÍQUIDO LIVRE

1 ( ) não 2( ) sim

6 - OUTRAS OBSERVAÇÕES: 
Anexo C - Protocolo do exame US-Doppler

FICHA No:

PROTOCOLO DE PESQUISA

Avaliação ultrassonográfica e dopplervelocimétrica da EM

Exame US-Doppler em campo

1 - IDENTIFICAÇÃO

1.1- Nome do paciente:

Data:.................. 1.2 - Idade: .................... 1.3 -Sexo: ( ) M ( ) F

2 - SISTEMA PORTA

\begin{tabular}{|c|c|c|c|c|}
\hline Veias & $\begin{array}{l}\text { Direção do } \\
\text { Fluxo }\end{array}$ & $\begin{array}{l}\text { Diâmetro } \\
\text { (mm) }\end{array}$ & $\begin{array}{c}\text { Vel. máxima } \\
(\mathrm{cm} / \mathrm{s})\end{array}$ & Trombose \\
\hline 2.1 - Porta & $P(\quad) \quad F(\quad)$ & & & $\mathrm{P}(\quad) \mathrm{T}(\quad)$ \\
\hline 2.2 - Ramo direito & $\mathrm{P}(\mathrm{f}) \mathrm{F}(\mathrm{)}$ & & & $\mathrm{P}(\quad) \mathrm{T}(\quad)$ \\
\hline 2.3 -Ramo esquerdo & $\mathrm{P}(\mathrm{f}) \mathrm{F}(\mathrm{)}$ & & & $\mathrm{P}(\quad) \mathrm{T}(\quad)$ \\
\hline 2.4 - Esplênica & $P(\quad) \quad F(\quad)$ & & & $\mathrm{P}(\quad) \mathrm{T}(\quad)$ \\
\hline $\begin{array}{c}2.5 \text { - Mesentérica } \\
\text { superior }\end{array}$ & $\mathrm{P}(\mathrm{f}) \mathrm{F}(\mathrm{)}$ & & & $\mathrm{P}(\quad) \mathrm{T}(\quad)$ \\
\hline
\end{tabular}

\begin{tabular}{|c|c|c|c|}
\hline Colaterais & Direção do Fluxo & Diâmetro & Vel. máxima \\
\hline 2.6-Gástrica esq. & $P()$ & & \\
\hline 2.7-Paraumbilical & $P(\quad)$ & & \\
\hline 2.8-Esplenorrenal & $P(\quad)$ & & \\
\hline 2.9-Gástricas curtas ( ) & $P()$ & & \\
\hline 2.10-Outras & $P(1)$ & & \\
\hline
\end{tabular}

\section{3 - ARTÉRIAS HEPÁTICA E ESPLÊNICA}

\begin{tabular}{c|c|c|c|c}
\hline Artérias & $\begin{array}{c}\text { Diâmetro } \\
(\mathbf{m m})\end{array}$ & $\begin{array}{c}\text { Pico sistólico } \\
(\mathbf{c m} / \mathbf{s})\end{array}$ & $\begin{array}{c}\text { Vel diastólica } \\
\text { final }(\mathbf{c m} / \mathbf{s})\end{array}$ & $\begin{array}{c}\text { Índice de } \\
\text { Resistividade }\end{array}$ \\
\hline 3.1-Hepática & & & & \\
\hline 3.2-Esplênica & & & & \\
\hline
\end{tabular}

4 - VEIAS HEPÁTICAS: estudar pelo menos uma (de preferência a média). Caracterizar fluxo como:

\begin{tabular}{|c|c|}
\hline ifás & (3) = monofásicc \\
\hline Veias Hepáticas & Padrão do fluxo \\
\hline 4.1 -Direita & 1() 2() 3() \\
\hline 4.2 -Média & 1( ) 2( ) 3( ) \\
\hline 4.3 -Esquerda & 1() 2() 3() \\
\hline
\end{tabular}

5 - ESPESSAMENTO PERIPORTAL

5.1 -Ausente ( ) Leve ( ) Moderado ( ) Intenso ( )

5.2 - Padrão de acometimento Organização Mundial de Saúde ( ) 
Anexo D - Outros resultados dos exames modo B e Doppler

Tabela A5 - Descritivas das variáveis quantitativas medidas em milímetros na amostra total

\begin{tabular}{lccc|c|c|c|c}
\hline \hline & N & Média & Mediana & DP & Mín & Máx \\
\hline Espessura da parede da vesícula & 548 & 3,0 & 2,0 & 2,5 & 1,0 & 22,0 \\
Diâmetro da veia porta & 552 & 10,2 & 10,0 & 1,5 & 3,0 & 19,0 \\
Diâmetro ramo direito da veia porta & 544 & 6,8 & 6,8 & 1,1 & 3,5 & 11,2 \\
Diâmetro ramo esquerdo veia porta & 545 & 6,7 & 6,7 & 1,2 & 3,6 & 11,0 \\
Diâmetro da veia esplênica & 550 & 6,9 & 7,0 & 1,8 & 3,0 & 21,0 \\
Diâmetro veia mesentérica superior & 548 & 7,4 & 7,0 & 1,5 & 4,0 & 17,0 \\
Espessura parede veia porta no hilo & 552 & 3,1 & 3,0 & 1,8 & 1,0 & 20,0 \\
Espessura parede veia porta na bifurcação & 552 & 3,2 & 3,0 & 2,2 & 1,0 & 16,0 \\
Espessura parede ramo portal de segunda & 551 & 2,2 & 2,0 & 1,3 & 1,0 & 10,0 \\
ordem & & & & & & \\
Diâmetro longitudinal do baço & 554 & 91,8 & 90,0 & 23,6 & 34,0 & 232,0 \\
Diâmetro da artéria hepática & 481 & 3,5 & 3,5 & 0,6 & 2,1 & 5,4 \\
Diâmetro da artéria esplênica & 474 & 3,9 & 3,8 & 0,7 & 2,2 & 12,3 \\
\hline \hline
\end{tabular}

Tabela A6 - Comparação das variáveis quantitativas, medidas em milímetros, por área

\begin{tabular}{|c|c|c|c|c|c|c|c|c|c|c|}
\hline & \multicolumn{4}{|c|}{ Baixa } & \multicolumn{3}{|c|}{ Média } & \multicolumn{3}{|c|}{ Alta } \\
\hline & $\begin{array}{c}\text { Valor- } \\
p^{*}\end{array}$ & Média & Mediana & DP & Média & Mediana & DP & Média & Mediana & DP \\
\hline Espessura parede vesíc & $<0,001$ & 2,3 & 2,0 & 0,9 & 2,3 & 2,0 & 1,1 & 4,3 & 3,0 & 3,7 \\
\hline Diâmetro veia porta & 0,523 & 10,0 & 10,0 & 1,5 & 10,4 & 10,0 & 1,5 & 10,6 & 10,0 & 2,2 \\
\hline $\begin{array}{l}\text { Diâmetro veia esplênica } \\
\text { Diâmetro da veia }\end{array}$ & 0,322 & 6,6 & 7,0 & 1,3 & 6,8 & 7,0 & 1,2 & 7,0 & 7,0 & 2,5 \\
\hline $\begin{array}{l}\text { mesentérica superior } \\
\text { Diâmetro do ramo direito }\end{array}$ & 0,024 & 7,0 & 7,0 & 1,3 & 7,4 & 7,0 & 1,2 & 7,7 & 7,0 & 2,0 \\
\hline $\begin{array}{l}\text { da veia porta } \\
\text { Diâmetro do ramo }\end{array}$ & $<0,001$ & 6,4 & 6,4 & 1,1 & 7,1 & 7,2 & 1,0 & 6,7 & 6,6 & 1,2 \\
\hline $\begin{array}{l}\text { esquerdo da veia porta } \\
\text { Espessura da parede da }\end{array}$ & $<0,001$ & 6,1 & 6,0 & 1,1 & 7,0 & 7,0 & 1,0 & 6,7 & 6,5 & 1,4 \\
\hline $\begin{array}{l}\text { veia porta no hilo } \\
\text { Espessura parede veia }\end{array}$ & $<0,001$ & 2,3 & 3,0 & 1,0 & 2,5 & 2,0 & 1,3 & 3,9 & 3,0 & 2,4 \\
\hline porta na bifurcação & $<0,001$ & 2,6 & 3,0 & 0,8 & 3,0 & 2,0 & 2,2 & 4,0 & 3,0 & 2,4 \\
\hline $\begin{array}{l}\text { Espessura parede ramo } \\
\text { portal de } 2^{\mathrm{a}} \text {. ordem }\end{array}$ & $<0,001$ & 1,8 & 2,0 & 0,8 & 1,8 & 2,0 & 1,0 & 2,9 & 2,0 & 1,6 \\
\hline Diâmetro longitudinal baço & 0,078 & 90,7 & 91,0 & 15,1 & 90,3 & 90,0 & 18,8 & 94,5 & 88,0 & 31,8 \\
\hline Diâmetro artéria hepática & 0,417 & 3,4 & 3,4 & 0,5 & 3,4 & 3,5 & 0,6 & 3,6 & 3,6 & 0,5 \\
\hline Diâmetro artéria esplênica & $<0,001$ & 3,5 & 3,6 & 0,5 & 3,8 & 3,7 & 0,5 & 4,2 & 4,0 & 0,9 \\
\hline
\end{tabular}


Tabela A7 - Comparação das variáveis quantitativas medidas pela US-Doppler $(\mathrm{cm} / \mathrm{s})$ por área

\begin{tabular}{|c|c|c|c|c|c|c|c|c|c|c|}
\hline & \multirow{2}{*}{$\begin{array}{c}\text { Valor- } \\
p^{*}\end{array}$} & \multicolumn{3}{|c|}{ Baixa } & \multicolumn{3}{|c|}{ Média } & \multicolumn{3}{|c|}{ Alta } \\
\hline & & Média & Mediana & DP & Média & Mediana & DP & Média & Mediana & DP \\
\hline $\begin{array}{l}\text { Vel máx do fluxo da } \\
\text { veia porta }\end{array}$ & $<0,001$ & 20,9 & 20,0 & 4,3 & 26,4 & 25,0 & 6,4 & 19,8 & 18,5 & 4,9 \\
\hline $\begin{array}{l}\text { Vel max do fluxo na } \\
\text { veia porta-RD }\end{array}$ & $<0,001$ & 18,9 & 18,5 & 3,4 & 22,9 & 22,2 & 4,8 & 17,7 & 17,3 & 3,4 \\
\hline $\begin{array}{l}\text { Vel max do fluxo na } \\
\text { veia porta-RE }\end{array}$ & $<0,001$ & 18,1 & 17,9 & 3,0 & 22,5 & 21,4 & 5,0 & 17,3 & 16,8 & 3,4 \\
\hline $\begin{array}{l}\text { Vel max do fluxo na } \\
\text { veia esplêica }\end{array}$ & $<0,001$ & 21,8 & 22,2 & 3,8 & 24,2 & 23,2 & 5,1 & 20,4 & 19,2 & 4,6 \\
\hline $\begin{array}{l}\text { Vel max do fluxo na } \\
\text { veia mesentérica } \\
\text { superior }\end{array}$ & $<0,001$ & 27,9 & 28,4 & 4,6 & 29,3 & 28,6 & 6,1 & 25,0 & 23,9 & 6,1 \\
\hline $\begin{array}{l}\text { Pico sistólico da } \\
\text { artéria hepática }\end{array}$ & $<0,001$ & 75,0 & 73,4 & 20,6 & 86,5 & 85,8 & 21,8 & 74,7 & 72,4 & 25,7 \\
\hline $\begin{array}{l}\text { Diástole final na } \\
\text { artéria hepática }\end{array}$ & $<0,001$ & 22,2 & 22,3 & 6,1 & 25,6 & 24,7 & 6,4 & 21,8 & 21,2 & 7,6 \\
\hline $\begin{array}{l}\text { Índice de resistência } \\
\text { na artéria hepática }\end{array}$ & 0,052 & 0,7 & 0,7 & 0,0 & 0,7 & 0,7 & 0,0 & 0,7 & 0,7 & 0,0 \\
\hline $\begin{array}{l}\text { Pico sistólico da } \\
\text { artéria esplênica }\end{array}$ & 0,880 & 81,2 & 81,1 & 19,0 & 82,3 & 81,0 & 18,5 & 82,2 & 81,4 & 18,7 \\
\hline $\begin{array}{l}\text { Diástole final na } \\
\text { artéria esplênica }\end{array}$ & 0,004 & 32,1 & 31,6 & 8,7 & 32,2 & 32,4 & 8,1 & 29,7 & 29,3 & 6,6 \\
\hline $\begin{array}{l}\text { Índice de resistência } \\
\text { na artéria esplênica }\end{array}$ & 0,060 & 0,6 & 0,6 & 0,1 & 0,6 & 0,6 & 0,1 & 0,6 & 0,6 & 0,0 \\
\hline
\end{tabular}

*Teste Kruskall-Wallis 


\section{REFERÊNCIAS}


Abdalla P. \& Queiroz B. Esplenoportografia. Bol Cent Est Hosp Serv Est. (RJ) 1959; 11: 424-54.

Abdel-Latif Z, Abdel-Wahab MF \& El-Kady NM. Evaluation of portal hypertensionin cases of hepatosplenic schistosomiasis using ultrasonography. In: Proceedings of the Third International Workshop on Diagnostic Ultrasound Imaging. Cairo, Egito 1978.

Abdel-Latif Z, Abdel-Wahab MF \& El-Kady NM. Evaluation of portal hypertension in cases of hepatoesplenic schistosomiasis using ultrasound. JCU Journal of Clinical Ultrasound. 1981; 9: 409-12.

Abdel-Wahab MF, Abdel-Latif Z, El-Kady NM, Arafa NM. The use of ultrasonography in diagnosis of different schistosomal syndromes. In: Proceedings of the Third International Workshop on Diagnostic ultrasound Imaging. Cairo, Egito 1978.

Abdel-Wahab MF, Esmat G, Milad M et al. Characteristic sonografic pattern of schistosomal hepatic fibrosis. Am J Trop Med Hyg; 1989;40:72.

Abdel-Wahab MF, Esmat G, Narooz SI, Yorsery A, Struewing JP, Strickland GT. Sonographic studies of schoolchildren in a village endemic for Schistosoma mansoni. Trans Royal Soc Trop Med Hyg. 1990; 84: 69-73.

Abdel-Wahab MF \& Esmat G. The value of ultrasonography in assessment of portal hypertension in hepatosplenic schistosomiasis. Mem Inst Oswaldo Cruz. 1992; 87 (IV): 143-7.

Alves CAP, Alves AR, Abreu WN, Andrade ZA. Hepatic artery hypertrophy and sinusoidal hypertension in advanced schistosomiasis. Gastroenterology. 1977; 72: 126.

Alves Jr. A, Alves MDNT, Gonçalves KRA, Cruz JF, Melo VA, Machado MCC. Hipertensão portal esquistossomótica. Avaliação do fluxo sanguíneo portal antes e após tratamento cirúrgico. Rev Col Bras Cir. 2001; 28 (5).

Alves Jr. A, Fontes DA, Melo VA, Machado MCC, Cruz JF, Santos EAS. Hipertensão portal esquistossomótica: influência do fluxo sanguíneo portal nos níveis séricos das enzimas hepáticas. Arq Gastroenterol. 2003; 40 (4).

Andrade ZA. \& Cheever AW. Alterations of the intra-hepatic vasculature in hepatosplenic schistosomiasis mansoni. Am J Trop Med. 1971; 20 (3): 425-32.

Andrade ZA. \& Ferraz GS. A hepatopatia esquistossomótica. Arq Gastroenterol. 1971; 8: 131.

Arruda SMB, Barreto VST. \& Amaral FJ. Duplex sonography study in schistosomiasis portal hypertension: characterization of patients with and without a history of variceal bleeding. Arq Gastroenterol. 2008; 45 (1).

Barkun AN, Camus M, Green L, Meagher T, Coupal L, De Stempel J. et al. The bedside assessment of splenic enlargement. Am J Trop Med. 1991; 91: 512-8. 
Barros J. \& Borrotchin M. A esplenoportografia na esquistossomose mansônica. Rev Ass Med MG. 1960; 11: 185-9.

Bezerra ASA, D'Ippolito G, Caldana RP, Cecin AO, Ahmed M, Szejnfeld J. Chronic hepatosplenic schistosomiasis mansoni: magnetic resonance imaging and magnetic resonance angiography findings. Acta Radiol. 2007; 48 (2): 125-34.

Bina JC. \& Prata A. A evolução natural de esquistossomose mansoni em uma área endêmica. In: Bina JC, Prata A. Aspectos peculiares da infecção por Schistosoma mansoni. Salvador: Centro editorial e didático da Universidade Federal da Bahia, 1984; p. 13-33.

Bogliolo L. Sobre o quadro anatômico do figado na forma hepatoesplênica da esquistossomose mansônica. O Hospital. 1954; 45: 29-58.

Bogliolo L. Patogênese da esquistossomose mansônica. Resen Clin Cient. 1956a; 35:97.

Bogliolo L. Terceira contribuição ao conhecimento do quadro anatômico do figado na esquistossomose mansônica hepato-esplênica. O comportamento da artéria hepática. Hospital. 1956b; 50: 485.

Bogliolo L. The anatomical picture of the liver in hepato-splenic schistosomiasis mansoni. Ann Trop Med Parasit. 1957a; 51: 1-14.

Bogliolo L. A esplenoportografia da esquistossomíase mansônica hepatoesplênica, forma de Symmers. Rev Ass Med Brás. 1957b; 3: 263.

Bogliolo L. Splenoportography in hepato-splenic schistosomiasis mansoni. Ann Trop Med Parasitol. 1958; 52: 181-5.

Bolognesi M, Sacerdoti D, Merkel C, Gerunda G. et al. Splenic Doppler impedance indices: influence of different portal hemodynamic conditions. Hepatology. 1996; 23 (5): 1035-40.

Bolondi L, Gandolfi L, Ariente V, Caletti GC. et al. Ultrasonography in diagnosis of portal hypertension: diminished response of portal vessels to resperation. Radiology. 1982; 142 (1): 167-72.

Bolondi L, Gaiani S. \& Barbara L. Ecografia funzionale ed eco-Doppler in gastroenterologia. Emodinamics splancnica. 1989: 79-219.

Bolondi L, Li Bassi S, Gaiani S, Zironi G, Benzi G, Santi V. et al. Liver cirrhosis:changes of Doppler waveform of hepatic veins. Radiology. 1991;178:513-6.

Brandt CT, Caneca OAF, Tavares DJS, Avila Jr. L. Surgical hepatosplenic schistosomiasis mansoni in chlidren: a Doppler duplex study of the portal vein and the hepatic artery. Trans Royal Soc Trop Med Hyg. 1995; 89: 70-1.

Cairo Working Group. The use of diagnostic ultrasound in schistosomiasis-attempts at standartization of methodology. Acta Tropica. 1992; 51: 45-63. 
Cerri GG. Contribuição da ultra-sonografia no diagnóstico da forma hepatoesplênica da esquistossomose mansônica [tese]. São Paulo: Faculdade de Medicina, Universidade de São Paulo; 1984a.

Cerri GG. A ultra-sonografia no diagnóstico da forma hepatoesplênica da esquistossomose mansônica. Rev Imagem. 1984b; 6: 116-34.

Cerri GG, Alves VAF. \& Magalhães A. Hepatosplenic schistosomiasis mansoni: ultrasound manifestations. Radiology. 1984c; 153: 777-80.

Cleva R, Herman P, Saad WA, Pugliese V, Zilberstein B, Rodrigues JJ. et al. Postoperative portal vein thrombosis in patients with hepatosplenic mansonic schistosomiasis: relationship with intraoperative portal pressure and flow. A prospective study. Hepatogastroenterol. 2005; 52 (65): 1529-33.

Cleva R, Pugliese V, Zilberstein B. et al. Estado hiperdinâmico sistêmico na forma hepatoesplênica da esquistossomose mansônica. Rev Hosp Clin Fac Med S Paulo. 1998; 53 (1): 6-10.

Colli A, Cocciolo M, Munoli N, Cattalini N, Fraquelli M, Conte D. Hepatic artery resistance in alcholic liver disease. Hepatology. 1998; 28 (5): 1182-6.

Cota GF, Pinto-Silva RA, Antunes CMF, Lambertucci JR. Ultrasound and clinical investigation oh hepatosplenic schistosomiasis:evaluation of splenomegaly and liver fibrosis four years after mass chemotherapy with oxamniquine. AM J Trop Med Hyg. 2006; 74 (1): 103-7.

Coura JR \& Amaral RS. Epidemiological and control aspects of schistosomiasis in Brazilian endemic areas. Mem Inst Oswaldo Cruz. 2004; 99 (1): 13-19.

Coutinho A. A hipertensão porta na síndrome hepatoesplênica esquistossomótica: estudo clínico e hemodinâmico [tese]. Recife: Faculdade de Medicina, Universidade do Recife; 1960.

Coutinho A. Alterações hemodinâmicas na esquistossomose mansônica hepatoesplênica. J Bras Med. 1964; 8: 209.

Coutinho A, Pereira R. \& Costa A. A manometria hepática transparietal na syndrome hepatoesplênica esquistossomótica. J Bras Méd. 1964; 8: 311.

Coutinho AD. Hemodynamic studies of porta hypertension in schistosomiasis. Am J Med. 1968; 44: 547-57.

Dias LCS, Glasser CM, Marçal Jr. O, Bossesso PIP. Epidemiologia da esquistossomose mansônica em área de baixa endemicidade. Cad Saúde Pública. 1994; 10 (2): 254-60.

Doehring-Schwerdtfeger E, Abdel-Raim IM, Moahmed-Ali Q, Elsheikh M, Schlake J, Kardorff R. et al. Ultrasonographical investigation of periportal fibrosis in children with Schistosoma mansoni infection: evaluation of morbidity. Am J Trop Med Hyg. 1990; 42 (6): 581-6. 
Downey DB. The retroperitoneum and great vessels. In: Rumack CM, Wilson SR, Charboneau JW. Diagnostic ultrasound. 2nd ed. St Louis: Morby,1998, p.453.

El-Rooby A. Management of hepatic schistosomiasis. Semin Liver Dis. 1985; 5: 26376.

Erden A, Altuntaş B, Olçer T, Cumhur T. Presinusoidal portal hypertension does not affect hepatic artery resistance index. Eur Radiol. 1999; 9 (6): 1131-4.

Espírito Santo MCC, Azeredo LM, Teles HMS, Gryschek RCB, Ferreira CS, Amato Neto $\mathrm{V}$. Abdominal ultrasound in the evaluation of fibrosis and portal hypertension in an area of schistosomiasis low endemicity. Rev Inst Med Trop São Paulo. 2008; 50 (2).

Faatar S, Bassiony H, Satyanath S, Vassileva J, Hanna RM. Characteristic sonographic features of schistosomal periportal fibrosis. Am J Roentgenol. 1984; 143: 69-71.

Ferreira CS. Esplenoportografia e manometria na forma hepatoesplênica da esquistossomose mansônica [dissertação]. Belo Horizonte: Faculdade de Medicina, Universidade Federal de Minas Gerais; 1976.

Ferreira FG, Kin Chin EW, Santos MF, Carvalho DLM, De Capua Jr. A. Índice de congestão portal e a ocorrência de trombose portal pós-DAPE. Rev Ass Med Bras. 2005; 51 (4).

Gaiani S, Bolondi L, Li Bassi S, Santi V, Zironi G, Barbara L. Effect of meal on portal hemodynamics in healthy humans and in patients with chronic liver disease. Hepatology. 1989; 9: 815-9.

Gaiani S, Bolondi L, Li Bassi S, Zironi G, Siringo S, Barbara L. Prevalence of spontaneous hepatofugal portal flow in liver cirrhosis. Clinical and endoscopic correlation in 228 patients. Gastroenterology. 1991; 101 (4): 1141-2.

Gerspacher-Lara R, Pinto-Silva RA, Rayes AA, Drummond SC, Lambertucci JR. Ultrasonography of periportal fibrosis in schistosomiasis mansoni in Brazil. Trans Royal Soc Trop Med Hyg. 1997; 91 (3): 307-9.

Gerspacher-Lara R, Pinto-Silva RA, Serufo JC, Rayes AA, Drummond SC, Lambertucci JR. Splenic palpation for the evaluation of morbidity due to Schistosomiasis mansoni. Mem Inst Oswaldo Cruz. 1998; 93 (1): 245-8.

Hatz C, Jenkins JM, Ali QM, Abdel-Wahab MF, Cerri GG, Tanner M. A review of the literature on the use of ultrasound in schistosomiasis with special references to its use in field studies. 2-Schistosoma mansoni. Acta Tropica. 1992; 51 (1): 15-28.

Homeida MMA, Abdel-Gadir AF, Cheever AW, Bennet JL, Arbad BMO. et al. Diagnosis of pathologically confirmed Symmer's periportal fibrosis by ultrasonography: a prospective blinded study. Am J Trop Med Hyg. 1988a;38: 8691. 
Homeida NMA, Ahmed S, Dafalla AA, Suliman S, El-Tom I, Nash TE. et al. Morbidity associated with Schistosoma mansoni infection as determined by ultrasound. Am J Trop Med Hyg. 1988b; 38: 196-201.

Homeida MMA, El-Tom I, Nash T, Bennett JL. Association of the therapeutic activity of Praziquantel with the reversal of Symmer's fibrosis induced by Schistosoma mansoni. Am J Trop Med Hyg, 1991; 45: 360-5.

Hussain S, Hawass ND. \& Zaidi AJ. Ultrasonographic diagnosis of schistosomal periportal fibrosis. J Ultrasound Med. 1984; 3: 449-52.

Houston S, Munjoma M, Kanyimo K. et al. Use of ultrasound in a study of schistosomal periportal fibrosis in rural Zimbabwe. Acta Tropica. 1993; 53(1): 51-58.

Iwao T, Toyonaga A, Oho K, Tayama C. et al. Value of Doppler ultrasound parameters of portal vein and hepatic artery in the diagnosis of cirrosis and portal hypertension. Am J Gastroenterol. 1997; 92 (6): 1012-7.

Katz N \& Almeida K. Esquistossomose, xistosa, barriga dágua. Cienc Cult. 2003; 55 (1).

Katz N, Chaves A. \& Pellegrino J. A simple device for quantitative stool thick-smear technique in schistosomiasis mansoni. Rev Inst Med Trop São Paulo. 1972; 14: 397-400.

Kawasaki T, Moriyasu F, Nishida O, Ban N, Nakamura T, Tamada T. et al. Analisys of hepatofugal flow in portal venous system using ultrasonic Doppler duplex system. Am J Gastroenterol. 1989; 84: 937-41.

King $\mathrm{CH}$, Magak $\mathrm{P}$, Salam AE, Ouma JH. et al. Measuring morbitidy in schistosomiasis mansoni: relationship between image patttern, vein portal diameter and portal branch thickness in large-scale surveys using new WHO coding guidelines for ultrasound in schistomiasis. Trop Med Intern Health. 2003; 8 (2): 10917.

Lambertucci JR, Gesparcher-Lara R, Pinto-Silva RA, Barbosa MM, Teixeira R, Barbosa HF. et al. The Queixadinha Project: morbidity and control of schistosomiasis in an endemic area in the northeast of Minas Gerais, Brazil. Rev Soc Bras Med Trop. 1996; 29 (2): 127-135.

Lambertucci JR, Serufo JC, Gerspacher-Lara R, Rayes AAM, Teixeira R, Nobre V. et al. Schistosoma mansoni: assessment of morbidity before and after control. Acta Tropica. 2000; 77: 101-9.

Lambertucci JR, Cota GF, Pinto-Silva RA, Serufo JC, Gerspacher-Lara R, Drummond SC. et al. Hepatoesplenic schistosomiasis in field-based studies: a combined clinical and sonographic definition. Mem Inst Oswaldo Cruz. 2001; Sup: 147-150.

Lambertucci JR, Andrade LM, Pinto-Silva RA. Magnetic resonance imaging of the liver in hepatosplenic schistosomiasis mansoni. Rev Soc Bras Med Trop. 2002; 35:679-80. 
Lambertucci JR, Silva LCS, Andrade LM, Queiroz LC, Pinto-Silva RA. Magnetic resonance imaging and ultrasound in hepatosplenic schistosomiasis mansoni. Rev Soc Bras Med Trop. 2004; 37: 333-34.

Leão ARS, Santos JEM, Moulin DS. et al. Mensuração do volume de fluxo portal em pacientes esquistossomóticos: avaliação da reprodutibilidade do ultra-som Doppler. Radiol Bras. 2008; 41 (5).

Machado M, Rosa ACF. \& Cerri GG. Doenças hepáticas difusas, hipertensão portal e transplante de fígado. In: Cerri GG, Oliveira IRS: Ultra-sonografia abdominal. São Paulo: Revinter, 2002, pp 56-124.

Mackenjee MKR, Coovadia HM. \& Chutte CHJ. Clinical recognition of mild hepatic schistosomiasis in an endemic area. Trans $R$ Soc Trop Med Hyg. 1984; 78: 13-5.

Magalhães $F^{\circ} A$, Menezes $H$. \& Barros Coelho R. Patogênese da fibrose hepática na esquistossomose mansoni: estudo das alterações vasculares portais mediante modelo plástico. Rev Ass Med Brás. 1960; 6: 284.

Magalhães TVB, Gazinelli G, Alvarez MCB, et al. Estudo clínico comparativo e ultrasonografia entre indivíduos negativos e positivos para Schistosoma mansoni em áreas endêmicas de baixa morbidade e pacientes hospitalizados com doença hepatosplênica. Rev Soc Bras Med Trop. 2005; 38: 33-7.

Malenganisho WLM, Magnussen P, Friis $\mathrm{H}$, Siza. et al. Schistosoma mansoni morbidity among adults in two villages along Lake Victoria shores in Mwanza District, Tanzania. Trans R Soc Trop Med Hyg. 2008; 102 (6): 523-41.

Marinho CC, Voieta I, Azeredo LM, Nishi MP, Batista TS, Pereira ACF. et al. Clinical versus ultrasound examination in the evaluation of hepatosplenic schistosomiasis mansoni in endemic areas. Mem Inst Oswaldo Cruz. 2006; 101 (1).

Martins MJ, Pinto-Silva RA, Serufo JC, Rayes AAM, Damasceno MPS, Martins MLV. et al. Morbidity of schistosomiasis in an endemic area of the northeast of the state of Minas Gerais in Brazil: a clinical and sonographic study. Mem Inst Oswaldo Cruz. 1998; 93 (I): 243-4.

Martins RD, Szejnfeld J, Lima FG, Ferrari AP. Endoscopic, ultrasonographic and ultrassonografia Doppler parameters as indicators of variceal bleeding in patients with schistosomiasis. Dig Dis Sci. 2000; 45: 1013-8.

Mies S, Larsson E, Mori T, et al. O sistema porta e as artérias hepatica, esplênica e mesentérica superior na esquistossomose hepatoesplênica: estudo angiográfico. Rev Hosp Clin Fac Med S Paulo. 1980a; 35: 121.

Mies S, Braghirolli Neto O, Beer A. et al. Systemic and hepatic hemodynamics inhepatosplenic Manson`s schistosomiasis with and without propanolol. Dig Dis Sci. 1997; 42 (4): 751-61.

Mostbeck GH, Wittich GR, Herold C. et al. Hemodynamic significance of the paraumbilical vein in portal hypertension: assessment with duplex US. Radiology. 1989; 170: 339-42. 
Mouriyasu F, Ban N, Nishida O, Nakamura T. et al. Clinical application of na ultrasonic duplex system in the quantitative measurement of portal blood flow. $J$ Clin Ultrasound. 1986a; 14: 579-88.

Mouriyasu F, Nishida O, Ban N, Nakamura T, Sakai M, Miyake T. et al. "Congestion Index" of the portal vein. Am J Roentgenol. 1986b; 146: 735-9.

Nelson RC, Lovett KE, Chezmar JL, Moyers JH, Torres WE, Murphy FB. Et al. Comparison of pulsed Doppler sonography and angiography in patients with portal hypertension. Am J Roentgenol. 1986; 149: 77-81.

Niamey Working Group. Ultrasound in Schistosomiais: A practical guide to the standardized use of ultrasonography for the assessment of Schistosomiasis-related morbidity. WHO, 2000. 49 p.

Nieredau C, Sonnemberg A, Muller JE. et al. Sonographic measurements of the normal liver, spleen, pancreas and portal vein. Radiology. 1983; 149: 537-40.

Ohnishi K, Saito M, Koen H, Nakayama T, Nomura F, Okuda K. Pulsed Doppler flow as a criterion of portal venous velocity: comparison with cineangiographic measurements. Radiology. 1985a; 154: 495-8.

Ohnishi K, Saito M, Sato S, Nakayama T, Takashi M, lida S. et al. Direction of splenic venous flow assessed by pulsed Doppler flowmetry in patients with a large splenorenal shunt. Gastroenteroly. 1985b; 89: 180-5.

Oliveira IR, Widman A, Fukushima JT, Saad WA, Gama-Rodrigues JJ, Cerri GG. Doppler ultrasonography evaluation of paraumbilical vein and portal hypertension. $J$ Radiol. 2001; 82 (11): 1627-31.

Paranaguá-Vezozzo DC. Avaliação hepática e hemodinâmica portal com Doppler duplex na esquistossomose mansônica [tese]. São Paulo: Faculdade de Medicina, Universidade de São Paulo; 1992.

Paranaguá-Vezozzo DC. \& Cerri GG. Duplex hemodinamic evaluation of hepatoesplenic mansoni schistosomiasis. Mem Inst Oswaldo Cruz. 1992; 87 (IV): 149-51.

Paranaguá-Vezozzo DC, Farias AQ, Cerri GG, Da Silva LC, Carrilho FJ. Assessment of portal hemodynamics by Doppler ultrasound and of liver morphology in the hepatosplenic and hepatointestinal forms of schistosomiasis mansoni. Dig Dis Sci. 2006; 518 (1) 413-9.

Paulson EK, Kliewer MA, Frederick MG, Keorgan MT, Delong DM, Nelson RC. Hepatic artery: variability in measurement of resistive index and systolic acceleration time in healthy volunteers. Radiology. 1996; 200: 725-9.

Pinto-Silva RA. A ultra-sonografia no diagnóstico da forma hepatesplênica da esquistossomose mansônica e de sua hipertensão portal [dissertação]. Belo Horizonte: Faculdade de Medicina, Universidade Federal de Minas Gerais; 1992. 
Pinto-Silva RA, Abrantes WL, Antunes CM, Lambertucci JR. Sonographic features of portal hypertension in schistosomiasis mansoni. Rev Inst Med Trop São Paulo. 1994; 36: 355-61.

Piscaglia F, Gaiani S, Zironi G, Gramantieri L, Casali A, Sirinco A. et al. Intra and extrahepatic arterial resistances in chronic hepatitis and liver cirrhosis. Ultrasound Med Biol. 1997; 23 (5): 675-82.

Piscaglia G, Donati G, Cecilioni L, Celli N. et al. Influence of the spleen on portal haemodynamics: a non-invasive study with Doppler ultrasound in chronic liver and haematological disorders. Scand J Gastroenterol. 2002; 10: 1220-7.

Queiroz LC. Eficácia do praziquantel no tratamento da esquistossomose mansônica: comparação de duas dosagens orais $(50 \mathrm{vs} 80 \mathrm{mg} / \mathrm{Kg}$ de peso corporal) [dissertação]. Belo Horizonte: Faculdade de Medicina, Universidade Federal de Minas Gerais; 2006.

Ricther J, Domingues ALC, Barata CH, Prat A, Lambertucci JR. Report of the second satellite symposium on ultrasound in schistosomiasis. Mem Inst Oswaldo Cruz. 2001; 96: 151-6.

Ruiz R, Candia P, Garassini M, Tombazi C, Certad G, Bruces AC. et al. Schistosomiasis mansoni in low transmission áreas. Abdominal ultrasound. Mem Inst Oswaldo Cruz. 2002; 97: 153-9.

Ruiz-Guevara R. Esquistossomose na área hiperendêmica de Brejo do Espírito Santo, com seguimento de 29 anos [tese]. Uberaba: Faculdade de Medicina, Universidade Federal do Triângulo Mineiro; 2005.

Sacerdoti D, Merkel C, Bolognesi M, Piero A, Angeli P, Gatta A. Hepatic arterial resistance in cirrhosis with and without portal vein thrombosis: relationships with portal hemodynamics. Gastroenterology. 1995; 108: 1152-8.

Satomura S. Ultrasonic Doppler method for the inspection of cardiac function. $J$ Acoust Soc Am. 1957; 29: 1181.

Schneider AW, Kalk JF. \& Klein CP. Hepatic arterial pulsatility index in cirrhosis: correlation with portal pressure. J Hepatology. 1999; 30: 876-81.

Shiroma M, Ferreira JM. \& Meira JA. Esplenoportografia percutânea e manometria intra-esplênica na esquistossomose mansônica hepatosplênica. Rev Hosp Clin Fac Méd. São Paulo 1963; 18: 462-8.

Silveira AC. Controle da esquistossomose no Brasil. Mem Inst Oswaldo Cruz. 1989; 84 (1): 91-104.

Sugiura N, Karasawa E, Saotome N, Miki M. et al. Portsystemic collateral shunts originating from the left portal veins in portal hypertension: demonstration by color Doppler flow imaging. J Clin Ultrasound. 1992; 20: 427-32.

Symmers W St C. Note on a new form of liver cirrhosis due the presence of the ova of bilharzias haematobia. J Path Bact. 1904; 9: 237.

Tavares-Neto J. \&, Prata A. Coeficiente de endocruzamento em portadores de esquistossomose mansônica. Rev Soc Bras Med Trop. 1989; 22: 9-45. 
Taylor JW, Burns PN, Woodcok JP, Wells PNT. Blood flow in deep abdominal and pelvic vessels: ultrasonic pulsed-Doppler analysis. Radiology. 1985; 154: 487-93.

Teles HMS, Carvalho ME, Ferreira CS, Zacharias F, Lima VR, Fadel MLC. Schistosomiasis Mansoni in Bananal (State of São Paulo, Brazil).I. Efficiency of diagnostic and treatment procedures. Mem Inst Oswaldo Cruz. 2002; 97 (1): 182-6.

Tziafalia C, Ulychov M, Tepetes K, Kelekis N, Fezoulidis I. Echo-Doppler measurements of portal vein and hepatic artery in asymptomatic patients with hepatitis B virus and healthy adults. J Gastrointestin Liver Dis. 2006; 15 (4): 343-6.

Weinreb J, Kumara S, Phillips G, Pochaczevsky R. Portal vein measurements by real time sonography. AJR. 1982; 139: 497-9.

WHO. World Health Organization. The Control of Schistosomiasis. Geneva: WHO, 1985. (Technical Report Series, 728).

WHO. World Health Organization. The Control of Schistosomiasis. Geneva: WHO, 1993. (Technical Report Series, 830).

Widman A, de Oliveira IR, Speranzini MB, Cerri GG, Saad WA, Gama-Rodrigues J. Patent paraumbilical vein: hemodynamic importance in Mansoni's hepatosplenic portal hypertension (Study with ultrasonography Doppler). Arq Gastroenterol. 2001a:38(4):221-6.

Widman A, de Oliveira IR, Speranzini MB, Cerri GG, Saad WA, Gama-Rodrigues J. Hepatosplenic schistosomiasis portal hypertension: effect of esophagogastric devascularization with splenectomy on the diameter and mean flow velocity in the portal system (ultra-sonographic Doppler). Arq Gastroenterol. 2001 b; 38 (1): 19-23.

Widman A, de Oliveira IR, Speranzini MB. et al. Late morphologic and hemodynamic changes in the splenic territory of patients with mansoni's hepatosplenic schistosomiasis after distal splenorenal shunt. (UltrasonographyDoppler study). Arq. Gastroenterol. 2002; 39 (4): 217-21.

Widman A, de Oliveira IR, Speranzini MB, Cerri GG, Saad WA, Gama-Rodrigues J. Portal thrombosis: late postoperative prevalence in Mansoni's schistosomiasis. Hepatogastroenterol. 2003: 50 (53): 1463-6.

Zironi G, Gaiani S, Fenyves D, Rigamonti A, Bolondi L, Barbara L. Value of measurement of mean portal flow velocity by Doppler flowmetry in the diagnosis of portal hypertension. J Hepatology. 1992; 16: 298-303.

Zoli M, Marchesini G, Cordiani MR, Pisi P. et al. Echo-Doppler measurement of splanchnic blood flow in control and cirrhotic subjects. J Clin Ultrasound. 1986; 14: 429-35. 
APÊNDICES 


\section{Apêndice A - Modelo do Termo de Consentimento Livre e Esclarecido}

\section{Esclarecimento e autorização para inclusão em protocolo de pesquisa}

\section{Introdução:}

Você está sendo convidado a participar de uma pesquisa denominada: "Avaliação ultrassonográfica e dopplervelocimétrica da esquistossomose mansônica: estudo de campo em áreas de baixa, média e alta endemicidades"

Nosso objetivo é identificar a presença e o estágio em que se encontram possíveis alterações do fígado, baço e sistema portal causadas pela esquistossomose.

\section{Esclarecimentos:}

Será realizado exame de ultrassom abdominal com Doppler em cada participante. Este exame não oferece riscos e pode beneficiá-lo com o conhecimento do estágio evolutivo de sua doença.

Todos os dados obtidos serão utilizados exclusivamente com a finalidade de pesquisa. Os dados que identificam o paciente serão mantidos em sigilo. Nenhum paciente deixará de receber cuidados ou tratamento por ter se recusado a participar da pesquisa.

\section{Termo de consentimento pós-esclarecido:}

$\mathrm{Eu}$, declaro que após ter sido convenientemente esclarecido pelo pesquisador e ter entendido o que me foi explicado, consinto em participar do presente protocolo de pesquisa.

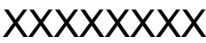
de de

Paciente ou responsável legal

Pesquisador:

Dra. Leticia Martins Azeredo

INRAD-HCFMUSP- Av. Dr. Enéas de Carvalho Aguiar, 255 - 3o.andar São Paulo, SP. 


\title{
Apêndice B
}

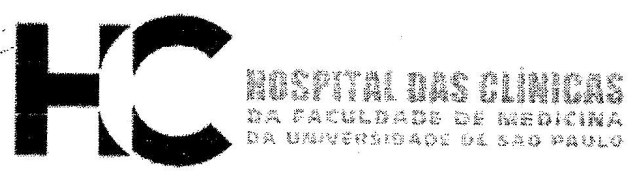

\section{APROVAÇÃO}

A Comissão de Ética para Análise de Projetos de Pesquisa - CAPPesq da Diretoria Clínica do Hospital das Clínicas e da Faculdade de Medicina da Universidade de São Paulo, em sessão de 25.05.05, APROVOU o Protocolo de Pesquisa $n^{\circ} 387 / 05$, intitulado: "Avaliação hemodinâmica pela ultra-sonografia Doppler na Esquistossomose mansônica: trabalho de campo em áreas de alta, média e baixa prevalências" apresentado pelo Departamento de RADIOLOGIA, inclusive o Termo de Consentimento Livre e Esclarecido.

Cabe ao pesquisador elaborar e apresentar à CAPPesq, os relatórios parciais e final sobre a pesquisa (Resolução do Conselho Nacional de Saúde n 196, de 10.10.1996, inciso IX. 2, letra "c")

Pesquisador(a) Responsável: Prof. Dr. Giovanni Guido Cerri Pesquisador (a) Executante: Dra. Letícia Martins Azeredo

CAPPesq, 25 de Maio de 2005.

\author{
Wlith cistlo
}

PROF. DR. EUCLIDES AYRES DE CASTILHO Presidente da Comissão de Ética para Análise de Projetos de Pesquisa 